\title{
Simulation of the Soil Water Balance of an Undeveloped Prairie in West-Central Florida
}

United States Geological Survey Water-Supply Paper 2472

Prepared in cooperation with th Southwest Florida Water Management District, and Sarasota County, Florida

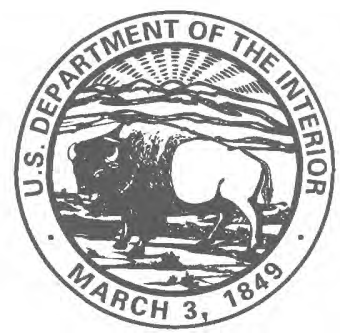


Instructions on ordering publications of the U.S. Geological Survey, along with prices of the last offerings, are given in the currentyear issues of the monthly catalog "New Publications of the U.S. Geological Survey." Prices of available U.S. Geological Survey publications released prior to the current year are listed in the most recent annual "Price and Availability List." Publications that may be listed in various U.S. Geological Survey catalogs (see back inside cover) but not listed in the most recent annual "Price and Availability List" may be no longer available.

Reports released through the NTIS may be obtained by writing to the National Technical Information Service, U.S. Department of Commerce, Springfield, VA 22161; please include NTIS report number with inquiry.

Order U.S. Geological Survey publications by mail or over the counter from the offices given below.

BY MAIL

\section{Books}

Professional Papers, Bulletins, Water-Supply Papers, Techniques of Water-Resources Investigations, Circulars, publications of general interest (such as leaflets, pamphlets, booklets), single copies of Earthquakes \& Volcanoes, Preliminary Determination of Epicenters, and some miscellaneous reports, including some of the foregoing series that have gone out of print at the Superintendent of Documents, are obtainable by mail from

U.S. Geological Survey, Branch of Information Services Box 25286,

Denver, CO 80225-0286

Subscriptions to periodicals (Earthquakes \& Volcanoes and Preliminary Determination of Epicenters) can be obtained ONLY from the

\section{Superintendent of Documents \\ Government Printing Office \\ Washington, DC 20402} Documents.)

(Check or money order must be payable to Superintendent of Maps

For maps, address mail orders to

U.S. Geological Survey, Branch of Information Services Box 25286, Denver, CO 80225-0286

Residents of Alaska may order maps from

U.S. Geological Survey, Earth Science Information Center 101 Twelfth Ave. - Box 12

Fairbanks, AK 99701

\section{OVER THE COUNTER}

\section{Books and Maps}

Books and maps of the U.S. Geological Survey are available over the counter at the following U.S. Geological Survey offices, all of which are authorized agents of the Superintendent of Documents:

- ANCHORAGE, Alaska-Rm. 101, 4230 University Dr.

- LAKEWOOD, Colorado-Federal Center, Bldg. 810

- MENLO PARK, California-Bldg. 3, Rm. 3128, 345 Middlefield Rd.

- RESTON, Virginia-USGS National Center, Rm. 1C402, 12201 Sunrise Valley Dr.

- SALT LAKE CITY, Utah-Federal Bldg., Rm. 8105, 125 South State St.

- SPOKANE, Washington-U.S. Post Office Bldg., Rm. 135, West 904 Riverside Ave.

- WASHINGTON, D.C.-Main Interior Bldg., Rm. 2650, 18th and C Sts., NW.

\section{Maps Only}

Maps may be purchased over the counter at the following U.S. Geological Survey offices:

- FAIRBANKS, Alaska-New Federal Bldg., 101 Twelfth Ave.

- ROLLA, Missouri-1400 Independence Rd.

- STENNIS SPACE CENTER, Mississippi-Bldg. 3101 


\section{Timulation of the Soil Water Balance of an Jndeveloped Prairie in West-Central Florida}

\section{3y W.R. BIDLAKE and P.F. BOETCHER}

Trepared in cooperation with the

inuthwest Florida Water Management District, and

Sarasota County, Florida 


\title{
U.S. DEPARTMENT OF THE INTERIOR BRUCE BABBITT, Secretary
}

\author{
U.S. GEOLOGICAL SURVEY \\ Gordon P. Eaton, Director
}

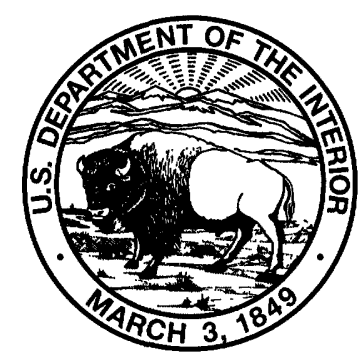

Any use of trade, product, or firm names in this publication is for descriptive purposes only and does not imply endorsement by the U.S. Government.

For sale by the

U.S. Geological Survey

Branch of Information Services

Box 25286

Denver, CO 80225-0286

\section{Library of Congress Cataloging in Publication Data}

Bidlake, W.R.

Simulation of the soil water balance of an undeveloped prairie in west-central Florida / by W.R. Bidlake and P.F. Boetcher.

p. cm. -- (United States Geological Survey water-supply paper : 2472) Includes bibliographical references.

1. Soil moisture--Florida--Measurement. 2. Soil moisture--Florida--Mathematical models. 3. Soil moisture--Florida--Computer simulation. 4. Water balance (Hydrology)--Florida. I. Boetcher, P.F. II. Title. III. Series: U.S. Geological Survey water-supply paper ; 2472.

S594.B465 1996

96-8189

551.48 '01' 13--dc20 


\section{CONTENTS}

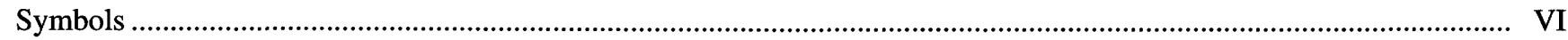

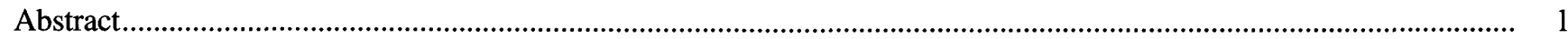

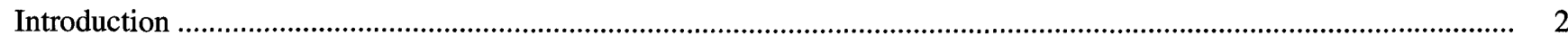

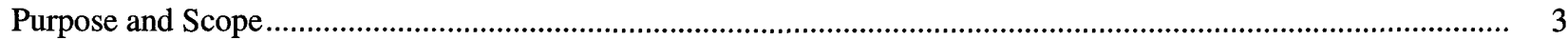

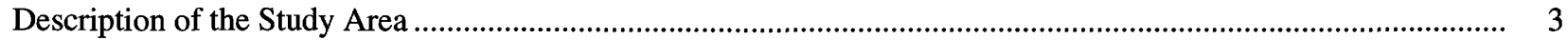

Vegetation and Soils ……………………………………………………………………………………. 5

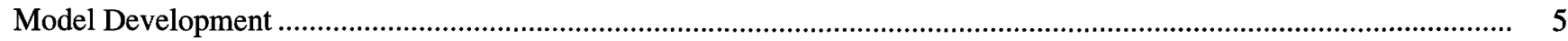

Governing and Auxiliary Equations for Flow and Plant Uptake of Soil Water ..................................................... 6

Numerical Implementation of Governing and Auxiliary Equations for Flow and Plant Uptake of Soil Water.......... $\quad 8$

Boundary and Initial Conditions and Data Requirements ..................................................................................... 10

Model Source Code and Input and Output Files ............................................................................................. 14

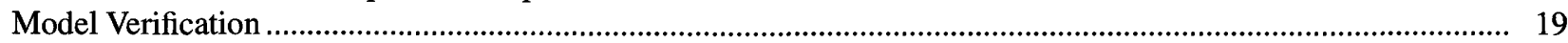

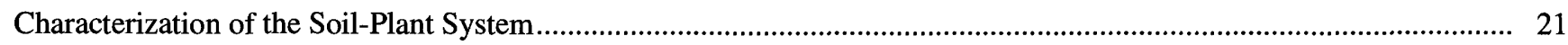

Measurement and Estimation of Soil Physical Properties............................................................................... 21

Measurement and Estimation of Site Vegetative Characteristics ......................................................................... 25

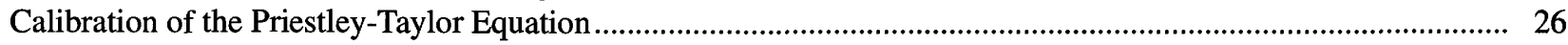

Calibration of the Soil Water-Balance Model.................................................................................................... 28

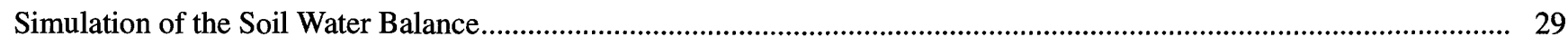

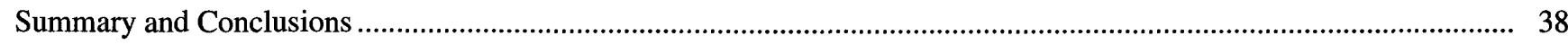

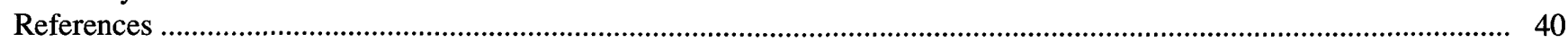

Appendixes:

Appendix 1. Flowchart for the Soil Water-Balance Model ………..................................................................... 44

Appendix 2. Source Code for the Soil Water-Balance Model .................................................................................... 45

\section{FIGURES}

1. Map showing location of study area and the study site on the T. Mabry Carlton, Jr.,

Memorial Reserve, Sarasota County

2-13. Graphs showing:

2. Simulated daily evaporation from the surface of a bare, homogeneous soil, with the water table

at a depth of 1.0 meter, as it varied with soil water-pressure potential at the soil surface

3. Simulated daily evaporation from the surface of a bare, homogeneous soil and daily evaporation computed using an approximate analytical expression, as they varied with depth to the water table ................... 21

4. Relation between degree of soil saturation and applied pressure during water extraction from samples collected from three soil-depth intervals

5. Profiles of relative root activity used for simulations of the soil water balance ..................................................... 25

6. Relation between hourly evapotranspiration computed by the eddy correlation technique and hourly evapotranspiration estimated using the Priestley-Taylor equation.

7. Relation between daily evapotranspiration computed by the eddy correlation technique and daily evapotranspiration estimated using the Priestley-Taylor equation.

8. Multiplier for the Priestley-Taylor equation on a daily basis as it varied with volumetric soil water content in the uppermost 0.15 meter of soil

9. Simulated daily evapotranspiration and evaporation from the soil surface at the study site and daily evapotranspiration computed using the energy-balance Bowen ratio technique for four simulation periods

10. Simulated and measured soil volumetric water content at the end of four simulation periods and effect of varying air-entry soil water-pressure potential on simulated soil water content 
11. Simulated and measured soil volumetric water content at the end of four simulation periods and effect of varying profiles of relative root activity on simulated soil water content

12. Simulated and measured soil volumetric water content at the end of four simulation periods and effect of varying the depth to the water table on simulated soil water content

13. Ratio of daily measured evapotranspiration to daily potential evapotranspiration, and ratio of daily, simulated, steady-state evaporation from the surface of a bare soil to potential evaporation from the soil surface as they varied with depth to the water table......

\section{TABLES}

1. Definitions of variables used in the computer coding of the soil water-balance model

2. Description and format of the file read by the computer program to input program control instructions, soil and plant parameter values, and initial soil water content

3. Example of the file read by the computer program to input soil and plant parameter values and initial soil water content

4. Description and format of the file read by the computer program to update day of year, time of day, and variables used to compute and update atmospheric boundary conditions

5. Example of the file read by the computer program to update day of year, time of day, and variables used to compute and update atmospheric boundary conditions

6. Description and format of the output file containing the profiles of volumetric soil water content and soil water-pressure potential

7. Example of the output file containing profiles of volumetric soil water content and soil water-pressure potential.

8. Description and format of the output file containing daily summaries of water fluxes that is written by the computer program

9. Example of the output file containing daily summaries of water fluxes that is written by the computer program.

10. Description of soil for discrete depth intervals.

11. Bulk density and saturated hydraulic conductivity by soil-depth interval

12. Mass fraction of sand, silt, and clay and estimated air-entry soil water-pressure potential by soil-depth interval

13. Simulation periods and beginning and ending depths to the water table

14. Average daily water fluxes and average daily potential evapotranspiration computed in conjunction with simulations of the soil water balance.

15. Average daily changes in soil water storage computed from simulations of the soil water balance and computed from measurements of volumetric soil water content 


\begin{tabular}{rll}
\hline Multiply & By & To obtain \\
\hline millimeter $(\mathrm{mm})$ & 0.03937 & inch \\
millimeter per day $(\mathrm{mm} / \mathrm{d})$ & 0.03937 & inch per day \\
centimeter $(\mathrm{cm})$ & 0.3937 & inch \\
meter $(\mathrm{m})$ & 3.281 & foot \\
joule $(\mathrm{J})$ & 0.2388 & calorie \\
Watt per square meter $\left(\mathrm{W} / \mathrm{m}^{2}\right)$ & 0.001433 & calorie per square \\
& & centimeter per minute \\
kilopascal $(\mathrm{kPa})$ & 0.2961 & inch of mercury \\
& 0.1450 & pound per square inch \\
& 10.00 & millibar \\
kilogram $(\mathrm{kg})$ & 2.205 & pound mass \\
\hline
\end{tabular}

Sea level: In this report, "sea level" refers to the National Geodetic Vertical Datum of 1929 (NGVD of 1929)—a geodetic datum derived from a general adjustment of the first-order level nets of the United States and Canada, formerly called Sea Level Datum of 1929.

To convert temperature given in degrees Celsius $\left({ }^{\circ} \mathrm{C}\right)$ or kelvins $(\mathrm{K})$ to degrees Fahrenheit $\left({ }^{\circ} \mathrm{F}\right)$, use the following equations:

$$
\begin{aligned}
& { }^{\circ} \mathrm{F}=1.8 \cdot{ }^{\circ} \mathrm{C}+32 \\
& { }^{\circ} \mathrm{F}=1.8 \cdot \mathrm{K}-459.67
\end{aligned}
$$

Other abbreviations used in this report:
American Standard Code for Information Interchange (ASCII)
hour (h)
million joules per kilogram $(\mathrm{MJ} / \mathrm{kg})$
million joules per square meter times day $\left(\mathrm{MJ} / \mathrm{m}^{2} \cdot \mathrm{d}\right)$
second (s) 


\begin{tabular}{|c|c|c|}
\hline$a$ & Well radius & $\mathrm{m}$ \\
\hline$b$ & Shape factor & dimensionless \\
\hline$C$ & Specific water capacity & $1 / \mathrm{m}$ \\
\hline$c$ & Shape factor of flow system & dimensionless \\
\hline$D$ & Maximum depth of roots & $\mathrm{m}$ \\
\hline$D_{v o}$ & $\begin{array}{l}\text { Binary diffusion coefficient for } \\
\text { water vapor in air }\end{array}$ & $\mathrm{m}^{2} / \mathrm{s}$ \\
\hline$\underline{D}_{v s}$ & Soil water-vapor diffusivity & $\mathrm{m}^{2} / \mathrm{s}$ \\
\hline $\bar{D}_{v s}$ & $\begin{array}{l}\text { Internodal soil water-vapor } \\
\text { diffusivity }\end{array}$ & $\mathrm{m}^{2} / \mathrm{s}$ \\
\hline
\end{tabular}

$\bar{d} \quad$ Midpoint diameter for particlesize class

$d_{g} \quad$ Geometric mean particle diameter

$E$ Evapotranspiration

$E_{p} \quad$ Potential evapotranspiration

$E_{s} \quad$ Evaporation from the soil surface

$E_{s m}$ Maximum steady evaporation

from the soil surface

$E_{s p} \quad$ Potential evaporation from the soil surface

$e_{s} \quad$ Saturation vapor pressure

$F \quad$ Water-balance error

$g \quad$ Gravitational acceleration

$G \quad$ Subsurface heat flux

$H \quad$ Ponding depth in a well

$h \quad$ Relative humidity of soil air

$h_{a} \quad$ Atmospheric relative humidity

$h_{s} \quad$ Relative humidity at the soil surface

I Shortwave irradiance measured below the plant canopy

$I_{0} \quad$ Shortwave irradiance measured above the plant canopy

$i \quad$ Node number

$i_{n} \quad$ Node at the bottom of the root zone

$j \quad$ Time-step index

$k_{l} \quad$ Hydraulic conductivity

$\bar{k}_{l} \quad$ Internodal hydraulic conductivity

$k_{s} \quad$ Saturated hydraulic conductivity

$L \quad$ Heat of vaporization for water

$M \quad$ Mass fraction

$M_{w} \quad$ Molar mass of water

$m \quad$ Exponent

$n \quad$ Deepest node in the soil domain or sample size

$P \quad$ Precipitation

$P_{a} \quad$ Applied pressure

$P_{e} \quad$ Bubbling pressure

$Q \quad$ Flow from a well $q_{l} \quad$ Vertical liquid flux

$q_{s} \quad$ Water infiltration at soil surface

$q_{v} \quad$ Vertical water-vapor flux

$q_{v s} \quad$ Evaporation from the soil surface

$R \quad$ Gas constant

$R_{n} \quad$ Net radiation

$R_{a} \quad$ Root activity

$R_{a}^{\prime} \quad$ Relative root activity

$S \quad$ Slope of the relation between saturation vapor pressure and temperature

$\mathrm{mm}$

$\mathrm{mm}$

$\mathrm{m} / \mathrm{s}$ or $\mathrm{mm} / \mathrm{d}$

$\mathrm{m} / \mathrm{s}$ or $\mathrm{mm} / \mathrm{d}$

$\mathrm{m} / \mathrm{s}$ or $\mathrm{mm} / \mathrm{d}$

$\mathrm{m} / \mathrm{s}$ or $\mathrm{mm} / \mathrm{d}$

$\mathrm{m} / \mathrm{s}$ or $\mathrm{mm} / \mathrm{d}$

$\mathrm{kPa}$

$\mathrm{m} / \mathrm{s}$

$\mathrm{m} / \mathrm{s}^{2}$

$\mathrm{W} / \mathrm{m}^{2}$

$\mathrm{m}$

dimensionless

dimensionless

dimensionless

$\mathrm{W} / \mathrm{m}^{2}$

$\mathrm{W} / \mathrm{m}^{2}$

dimensionless

dimensionless

dimensionless

$\mathrm{m} / \mathrm{s}$

$\mathrm{m} / \mathrm{s}$

$\mathrm{m} / \mathrm{s}$

$\mathrm{J} / \mathrm{kg}$

dimensionless

$\mathrm{kg} / \mathrm{mol}$

dimensionless

dimensionless

$\mathrm{m} / \mathrm{s}$ or $\mathrm{mm} / \mathrm{d}$

$\mathrm{kPa}$

$\mathrm{kPa}$

$\mathrm{m}^{3} / \mathrm{s}$ $s \quad$ Degree of saturation

$t \quad$ Time

$T_{k} \quad$ Temperature

$T$ Transpiration

$U$ Volumetric water sink term representing plant uptake of soil water

$V \quad$ Thickness of soil associated with a node

$W_{t} \quad$ Weighting factor

$z \quad$ Depth below the soil surface

$z_{1} \quad$ Depth to the water table

$\alpha \quad$ Multiplier for the Priestley-Taylor equation

$\alpha_{b} \alpha_{m}$ User-supplied values for the

Priestley-Taylor multiplier

$\gamma \quad$ Psychrometer coefficient

$\phi_{g} \quad$ Gas-filled soil porosity

$\Phi_{m} \quad$ Matric flux potential

$\theta \quad$ Volumetric soil water content

$\theta_{s} \quad$ Volumetric soil water content at saturation

$\kappa \quad$ Fraction of daily incoming shortwave radiation intercepted by the plant canopy

$\rho_{b} \quad$ Soil bulk density

$\rho_{s} \quad$ Soil particle density

$\rho_{w} \quad$ Density of water

$\psi_{p} \quad$ Soil water-pressure potential

$\psi_{p e} \quad$ Air-entry soil water-pressure potential

$\Delta \mathrm{Q} \quad$ Rate of decrease in the zero-head reservoir

$\Delta S \quad$ Simulated average daily change in soil water storage

$\Delta S_{m} \quad$ Measured average daily change in soil water storage

$\Delta t \quad$ Duration of a time step $\mathrm{m} / \mathrm{s}$ or $\mathrm{mm} / \mathrm{d}$

$\mathrm{m} / \mathrm{s}$ or $\mathrm{mm} / \mathrm{d}$

$\mathrm{m} / \mathrm{s}$ or $\mathrm{mm} / \mathrm{d}$

$\mathrm{m} / \mathrm{s}$ or $\mathrm{mm} / \mathrm{d}$

$\mathrm{J} / \mathrm{mol} \cdot \mathrm{K}$

$\mathrm{W} / \mathrm{m}^{2}$

$1 / \mathrm{m}^{2}$

dimensionless

$\mathrm{kPa} /{ }^{\circ} \mathrm{C}$

dimensionless

$\mathrm{s}$

kelvins (K)

$\mathrm{m} / \mathrm{s}$ or $\mathrm{mm} / \mathrm{d}$

$1 / \mathrm{s}$ or $\mathrm{m} / \mathrm{s}$

m

dimensionless

$\mathrm{m}$

$\mathrm{m}$

dimensionless

dimensionless

$\mathrm{kPa} /{ }^{\circ} \mathrm{C}$

dimensionless

$\mathrm{m}^{2} / \mathrm{s}$

dimensionless

dimensionless

dimensionless

$\mathrm{kg} / \mathrm{m}^{3}$

$\mathrm{kg} / \mathrm{m}^{3}$

$\mathrm{kg} / \mathrm{m}^{3}$

$\mathrm{m}$

m

$\mathrm{m} / \mathrm{s}$

$\mathrm{mm}$

$\mathrm{mm}$

$\mathrm{s}$ 


\title{
Simulation of the Soil Water Balance of an Undeveloped Prairie in West-Central Florida
}

\author{
By W.R. Bidlake and P.F. Boetcher
}

\section{Abstract}

Successful resolution of many waterresource management and environmental quality problems is possible through a better understanding of hydrologic processes that operate near the soil surface. A one-dimensional numerical model was developed to simulate the soil water balance of a densely vegetated prairie site on the T. Mabry Carlton, Jr., Memorial Reserve in the west-central Florida county of Sarasota. The model simulates the hydrologic processes of infiltration, soil water storage, deep percolation or recharge to the water table, evapotranspiration, and evaporation from the soil surface. The soil water-balance model was developed using the theory of water flow in unsaturated soil and empirical and heuristic arguments to account for evapotranspiration and plant uptake of soil water. Atmospheric boundary conditions, which include both constant flux and constant potential components, are computed using net radiation, subsurface heat flux, air temperature and vapor pressure, and precipitation. The lower boundary condition is a constant potential at the water table.

Field measurements and laboratory analysis of samples collected from the study site were used to determine or estimate the soil physical and plant properties used in the model. The soil profile was divided into three depth intervals on the basis of morphological characteristics. Saturated hydraulic conductivity, bulk density, air-entry soil water-pressure potential, soil watercharacteristic function, and particle-size distribution were determined or estimated for each depth interval. Fractional interception of incoming shortwave radiation by the plant canopy was sampled, and depth of the root zone was estimated by observation. Two hypothetical profiles of root activity were used for the simulations. The Priestley-Taylor equation was calibrated to predict evapotranspiration using measurements of evapotranspiration made by the eddy correlation technique on rainless days during a 16-month period. The Priestley-Taylor multipliers obtained from the calibrations, which were 0.72 and 0.73 for hourly and daily periods, respectively, were almost 30 percent less than the theoretical minimum multiplier of 1.0 that can be expected for a wet surface under conditions of minimal advection. This result was interpreted to indicate that evapotranspiration was substantially water limited on rainless days.

Transient and steady-state simulations of the soil water balance were performed. The transient simulations were performed for four periods of about 2 weeks in duration. Measured depth to the water table ranged from 0.58 to 1.52 meters among the simulation periods. Initial profiles of volumetric soil water content for the simulations were determined using gravimetric and neutron-scattering techniques. Simulated evapotranspiration differed from evapotranspiration measured by the energy-balance Bowen ratio technique by as much as 24 percent during the four transient simulation periods. The difference between simulated and estimated evapotranspiration was attributed to the inability of the model to account for the variation in the Priestley-Taylor multiplier that was observed in conjunction with energy-balance Bowen ratio measurements. 
Variation in the multiplier, however, did not appear to be related to variation in depth to the water table or to volumetric soil water content in the root zone.

Simulated and measured volumetric soil water content at the end of the transient simulation periods generally agreed to within 4 percent, although the two differed by as much as 9 percent in lower half of the second uppermost soil-depth interval and by as much as 7 percent in the uppermost soil-depth interval following intense precipitation events. Simulated and measured changes in soil water storage agreed to within 10 percent for three of the four simulation periods, and they differed by 50 percent for one simulation period. Simulated recharge to the saturated ground-water system ranged from -1.4 to 0 millimeter per day among the four simulation periods, indicating that the saturated groundwater system discharged water to the unsaturated zone during most of the simulations. Simulated recharge to the saturated ground-water system was sensitive to variations in either air-entry soil water-pressure potential or depth to the water table.

Steady-state simulations of the soil water balance were performed to aid in identification and examination of major controls of evapotranspiration. Steady-state evaporation from the soil surface was simulated for the study site assuming the soil surface was bare. The simulations indicated that evaporation would not become water limited unless depth to the water table exceeded a critical depth that ranged from 0.8 to 1.0 meter. Actual measurements of evapotranspiration for the densely vegetated site, however, indicated that evapotranspiration was water limited even when the water table was at the soil surface. The implication of these results is that a plant canopy might limit total evaporative loss from a soil with a shallow water table under some conditions, and it is suggested that this hypothesis could be tested by future study.

\section{INTRODUCTION}

Successful resolution of many water-resource management and environmental quality problems is possible through a better understanding of the hydrologic processes that operate near the soil surface and by developing better predictive capabilities for soil water-balance components. For example, groundwater-flow and -transport models are important tools in the management of saturated ground-water systems, and estimates of recharge are required for the operation and calibration of these models. Groundwater simulations can be sensitive to recharge from the overlying, predominantly unsaturated soil (Hutchinson, 1984). A better understanding of the hydrologic processes that operate in the soil above the water table and more reliable predictions of soil waterbalance components, such as recharge, could lead to more reliable simulation of ground-water systems.

A useful approach for studying one or more soil hydrologic process is to use a simulation model that accounts for the interdependence of soil hydrologic processes. As an example of this interdependence, rates of recharge are governed largely by hydrologic processes, such as evaporation, plant uptake of soil water, and infiltration, that operate near the soil surface. Many soil water-balance models have been developed and applied to wild-land and agricultural environments. Among the simple models are those in which the soil is conceptualized as one or more buckets (Bauer and Vaccaro, 1987). The buckets are filled by water that infiltrates the soil surface and they are emptied by evapotranspiration. Simulated recharge commences when the buckets are filled to capacity. Although the hydrologic processes are handled simplistically, these models appear to work reasonably well when the water table is deep enough that it does not influence processes that operate near the surface.

Complex, physically based, soil water-balance models also have been developed to simulate water balances of fully unsaturated (Rhia and Campbell, 1985) and variably saturated (Lappala and others, 1987) soil systems. Because these models are based on the theory of fluid flow in porous media, they typically require a minimum of empirical tuning parameters. Widespread application of physically based water-balance models is limited primarily by the amount and type of data needed. When the system to be simulated includes plants, parameters must be 
specified that represent physiological and morphological controls of plant uptake and loss of water. These controls generally vary among species and can vary with plant growth stage and drought history. Because data describing plant physiological and morphological characteristics generally are not available, the physically based models have been applied to baresoil systems or to sites dominated by a single species for which relevant plant characteristics are known or can be estimated.

One conceptual element shared by simple and complex soil water-balance models is the role of soil moisture status in limiting evaporation and transpiration. Evaporation from a soil surface decreases as the soil dries, and this interaction between soil water storage and evaporative loss can be an important aspect of unsaturated-zone hydrology (Hillel, 1982). The interaction is more complex when vegetated surfaces are involved because plant-mediated water fluxes depend partly on physiological and morphological responses of plants to drought. Simple water-balance models describe interactions between soil moisture status and evapotranspiration using empirical or heuristic arguments (Bauer and Vaccaro, 1987), and physically based models account for the interactions by modeling physiological and morphological responses of plants to varying environmental conditions (Rhia and Campbell, 1985).

This report is a product of an investigation designed to improve water management through better understanding of near-surface hydrologic processes. The investigation was a cooperative effort among the Southwest Florida Water Management District, Sarasota County, and the U.S. Geological Survey.

\section{Purpose and Scope}

This report presents part of the results from a 4-year study designed to examine the near-surface water balance of a site occupied by a prevalent type of native vegetation in west-central Florida. The overall objective of the study was to provide, by means of quantitative description, an example of a site water balance for west-central Florida and to improve the understanding of and predictive capabilities for hydrologic processes in the unsaturated zone. The specific objectives of the study were to describe the water balance for seasonal and annual time frames and to develop, test, and implement a computer model to simulate the water balance of the soil above the water table. An initial report (Bidlake and Boetcher, in press) described the water balance for seasonal and annual time frames. This final report addresses the objective of developing, testing, and implementing the computer model to simulate the soil water balance. The report describes the theoretical and empirical basis for the model, numerical implementation, input data requirements, and results from a model verification experiment. The report also describes implementation of the model to simulate the soil water balance of the field site. The description of implementation includes a description of the collection and analysis of site-specific field data needed to operate the model and comparison of simulated and measured evapotranspiration and profiles of soil water content.

\section{Description of the Study Area}

The study was made at the T. Mabry Carlton, Jr., Memorial Reserve (Carlton Reserve) in the westcentral Florida county of Sarasota (fig. 1). The Carlton Reserve lies on a sloping plain that ranges in altitude from 10 to $30 \mathrm{~m}$ above sea level. The plain is traversed by sloughs and by the Myakka River that drain to the Gulf of Mexico. The land is virtually flat, with slope gradients generally less than 1 percent.

The humid, subtropical climate of west-central Florida reflects its latitude and proximity to the Gulf of Mexico, the Caribbean Sea, the Atlantic Ocean, and the land mass of North America. The latitude of westcentral Florida, which ranges from about $26^{\circ} 30^{\prime}$ to $28^{\circ} 30^{\prime} \mathrm{N}$, establishes seasonal patterns of day length and effectively fixes the upper limit of clear-sky solar radiation that is received at the land surface. Day length ranges from about 11 hours in December to about 13 hours in June. Smajstrla and others (1988) averaged daily solar radiation by month for Tampa. The annual average of daily solar radiation is about $17 \mathrm{MJ} / \mathrm{m}^{2} \bullet \mathrm{d}$. The minimum monthly average of daily solar radiation, which occurs in December, is about $10 \mathrm{MJ} / \mathrm{m}^{2} \cdot \mathrm{d}$, and the maximum monthly average of daily solar radiation, which occurs in May, is about $22 \mathrm{MJ} / \mathrm{m}^{2} \cdot \mathrm{d}$.

The influence of warm, moist air from the Caribbean Sea and the Gulf of Mexico, combined with intense solar heating, typically results in warm, wet summers in west-central Florida. The wet season usually encompasses the months of June through 


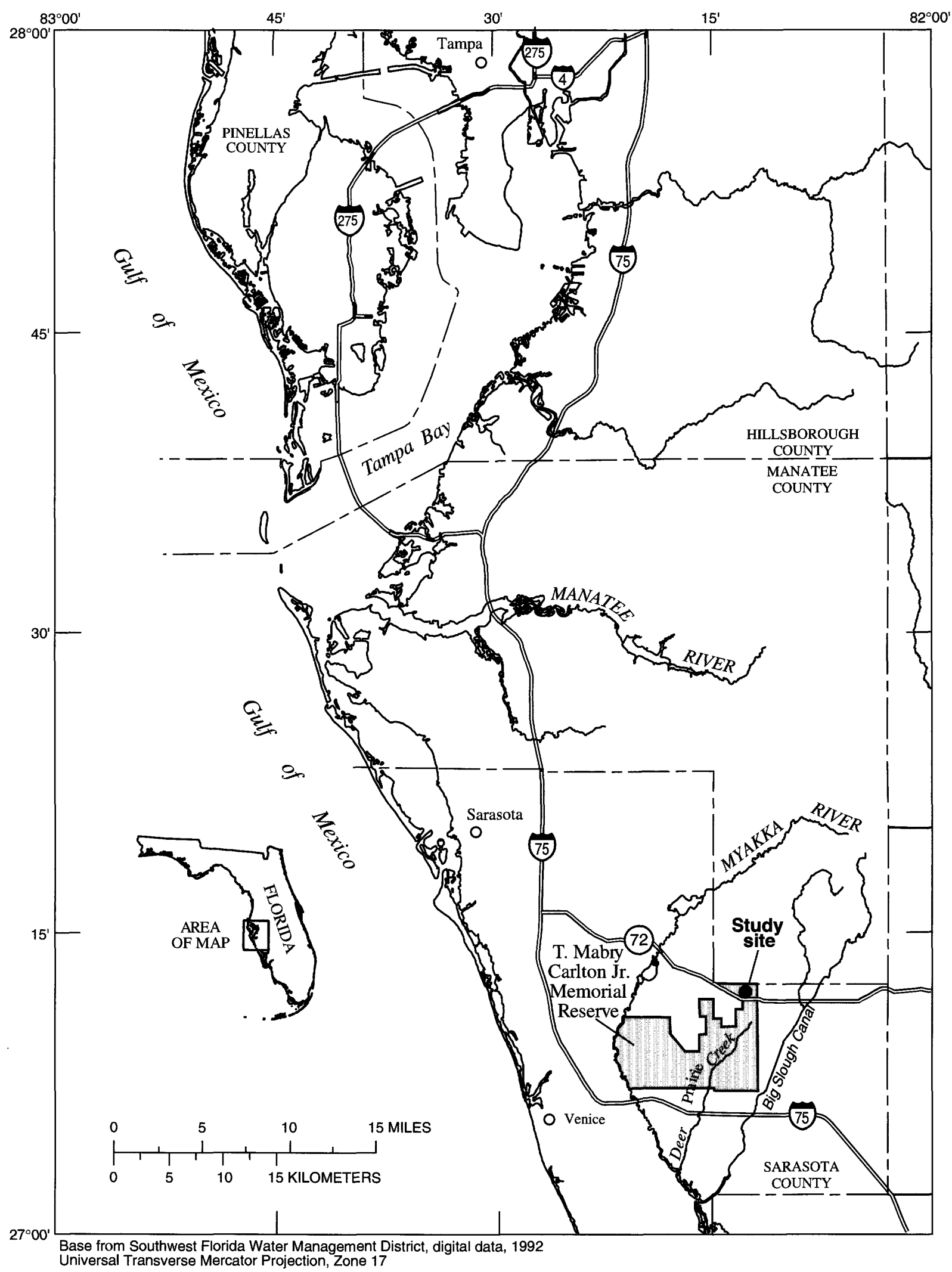

Figure 1. Location of study area and the study site on the T. Mabry Carlton, Jr., Memorial Reserve, Sarasota County. 
September, but sometimes includes October. Mean annual precipitation at Tampa for the period 1951-80 was $118 \mathrm{~cm}$ (National Oceanic and Atmospheric Administration, 1982); 57 percent of the precipitation fell during June through September when convective storms are common. July and August are the warmest months of the year. Mean daily temperature at Tampa for those months during the period $1951-80$ was $28^{\circ} \mathrm{C}$ (National Oceanic and Atmospheric Administration, 1982).

A distinct dry season occurs in west-central Florida during the months of November through May. Cool, dry conditions prevail from about November through March when cold fronts move in from the north and bring cool, dry air. Additionally, solar heating is less intense than during summer and the occurrence of warm temperatures and convective storms is much less common. The coolest month of the November through March period is January, when average air temperature at Tampa is $15^{\circ} \mathrm{C}$. The warmest month of this period is November, when average temperature is $19^{\circ} \mathrm{C}$. Less than 30 percent of the annual precipitation falls during November through March. Warm, dry conditions prevail during April and May as solar heating becomes intense and dry air is maintained over west-central Florida by an upper atmosphere high-pressure system in the eastern Atlantic Ocean. Average air temperature at Tampa reaches $25^{\circ} \mathrm{C}$ by May and monthly precipitation averages less than $9 \mathrm{~cm}$. Soils become progressively drier through winter because of the rainfall deficit. Effects of drought are most obvious during late spring. The warm, dry air and intense solar radiation combine to produce strong evaporative demand. If rainfall during the previous wet season and winter have been below normal, soil moisture deficits can become acute.

\section{Vegetation and Soils}

The study site was within a vegetation type that can be classified either as dry prairie (Jeffery Lincer, Sarasota County, written commun., 1990) or scrubby flatwood (Abrahamson and Hartnett, 1991). The dominant species was saw palmetto (Serinoa repens) and wax myrtle (Myrica cerifera). Total vegetative cover appeared to be greater than 90 percent, and saw palmetto coverage was about 60 percent. Average canopy height was about $0.7 \mathrm{~m}$. Other species represented at the site included the shrubs, dwarf blueberry (Vaccinium myrsinites), running oak (Quercus pumila), and gallberry (Ilex glabra), as well as the grasses, wiregrass (Aristida spp.) and beard grass (Andropogon spp.).

A recent soil classification map (Hyde and others, 1991) indicates that the soil at the study site is in either the EauGallie series (sandy, siliceous, hyperthermic Alfic Haplaquods) or the Myakka series (sandy, siliceous, hyperthermic Aeric Haplaquods).

The distinction between these two series is slight, and diagnostic information collected during this study was insufficient to classify the soils with certainty. Soils in both series are ground-water Spodisols that are common to the coastal plain of the southeastern United States (Hyde and others, 1991). Spodisols are characterized by extensive eluviation of organic matter, iron oxides, and clay from upper soil horizons to a soil horizon lower in the soil profile. Soils of the EauGallie and Myakka series are poorly drained, fine, sandy, mineral soils that occur on nearly level terrain. Seasonally, the water table ranges from the soil surface to depths of more than $1 \mathrm{~m}$. The mineral fraction is dominated by fine quartz sand. Silt mass fraction is less than 10 percent and clay mass fraction is less than 5 percent. The developed soil profile at the site extends to a depth of about $2.5 \mathrm{~m}$.

\section{MODEL DEVELOPMENT}

The approach used for model development was to construct a physically based, one-dimensional model capable of simulating water flow and evaporation for a soil without plants and then to use empirical and heuristic arguments to add capabilities for simulating evapotranspiration and plant uptake of soil water for a vegetated site. The model was developed with the capability to simulate water flow in soil above a shallow water table. Theory and numerical techniques given by Campbell (1985) for simulating water flow in unsaturated soil were adapted to simulate flow in soil above a water table. A sitespecific empirical function, developed from field observations, was incorporated in the model to predict evapotranspiration. Simple algorithms were used in the model to partition potential evapotranspiration to potential evaporation and potential transpiration and to distribute plant uptake of soil water throughout the depth of rooting. 
Development of the water-balance simulation model was accomplished, first, by defining the conceptual model and, second, by writing a computer program that could perform the computations prescribed by the conceptual model. The conceptual model was composed of the governing and auxiliary equations for flow, plant uptake, and evapotranspiration of soil water, of the numerical implementation of the governing and auxiliary equations, and of the boundary and initial conditions needed to solve the governing and auxiliary equations. The computer program was written: (1) to direct data inputs and outputs, (2) to perform the computations needed to apply initial and boundary conditions, and (3) to solve the governing and auxiliary equations.

\section{Governing and Auxiliary Equations for Flow and Plant Uptake of Soil Water}

A one-dimensional governing equation for the water balance of a nonswelling, isothermal, heterogenous soil can be written as (Campbell, 1985)

$$
\frac{\partial \theta}{\partial t}=\frac{\partial}{\partial z}\left(-q_{l}-q_{v}\right)-U(z)
$$

where

$\theta$ is volumetric soil water content, dimensionless;

$t$ is time, in seconds;

$z$ is depth below the soil surface, in meters;

$q_{l}$ is vertical liquid flux, in meters per second;

$q_{v}$ is vertical water-vapor flux, in meters per second; and

$U$ is a volumetric water sink term representing plant uptake of soil water, in per second.

Equation 1 is an expression of the law of conservation of mass as it applies to water in a soil profile.

Equation 1 can be solved for a single unknown variable, soil water-pressure potential ( $\psi_{p}$, in meters), by using auxiliary equations to express other unknown variables in terms of $\psi_{p}$. For example, $\theta$ can be expressed in terms of $\psi_{p}$ with the soil watercharacteristic function (Campbell, 1985)

$$
\theta=\theta_{s} \quad \text { for } \psi_{p} \geq \psi_{p e}
$$

and

$$
\theta=\theta_{s}\left(\psi_{p e} / \psi_{p}\right)^{1 / b} \quad \text { for } \psi_{p}<\psi_{p e}
$$

where

$\theta_{s}$ is volumetric soil water content at saturation; dimensionless;

$\Psi_{p e}$ is the air-entry soil water-pressure potential, in meters;

$b$ is an empirically determined shape factor, dimensionless; and other terms are as previously defined.

For development of the model used in this study, it was assumed that water content and soil waterpressure potential in unsaturated soil are uniquely related by equation 3 . Volumetric soil water content at saturation $\left(\theta_{s}\right)$ is computed using the equation: $\theta_{s}=1-\rho_{b} / \rho_{s}$, where $\rho_{b}$ is soil bulk density, in kilograms per cubic meter, and $\rho_{s}$ is density of soil particles, in kilograms per cubic meter.

The division between unsaturated and saturated flow regimes is defined by the air-entry soil waterpressure potential $\left(\psi_{p e}\right)$. When the soil water-pressure potential $\left(\psi_{p}\right)$ is equal to or greater than the air-entry value, the soil can be considered saturated. When pressure potential is less than the air-entry value, the soil is unsaturated. The air-entry soil waterpressure potential of hydrophilic soils is always negative and generally smaller in magnitude for a coarse-textured soil, such as a sand, than it is for a fine-textured soil, such as a loam or a clay loam.

The shape factor for the water-characteristic function $(b)$ varies with soil texture, and experimental values for $b$ reflect the soil pore-size distribution. Values of $b$ are typically less than 3 for coarse-textured soils, such as sand, and can be $\mathbf{5}$ or greater for fine-textured soils, such as loams and clay loams.

Liquid and Vapor Flux.- - Vertical liquid flux can be driven by gradients in soil water-pressure potential and gravitational potential. An equation for vertical liquid flux $\left(q_{1}\right)$ that contains both of the driving forces is (Jury and others, 1991)

$$
q_{1}=-k_{l}\left(\partial \psi_{p} / \partial z-1\right)
$$

where 
$k_{l}$ is hydraulic conductivity, in meters per second; and other terms are as previously defined.

Hydraulic conductivity of unsaturated soil can be computed using equations of the form given by Campbell (1974) as

$$
k_{l}=k_{s}, \quad \psi_{p} \geq \psi_{p e}
$$

and

$$
k_{l}=k_{s}\left(\psi_{p e} / \Psi_{p}\right)^{2+3 / b}, \psi_{p}<\psi_{p e}
$$

where

$k_{s}$ is saturated hydraulic conductivity, in meters

per second; and other terms are as previously defined.

Vapor flux can be an important form of water transport in some soils, particularly in dry near-surface volumes of drying soils. Fick's law for vertical watervapor flux $\left(q_{v}\right)$ in isothermal soil can be written as (Hillel, 1982)

$$
q_{v}=-D_{v s} 10^{3} e_{s} M_{w} /\left(\rho_{w} R T_{k}\right) \partial h / \partial z,
$$

where

$D_{v s}$ is diffusivity of soil water vapor, in square meters per second;

$e_{s}$ is saturation vapor pressure (equal to $4.24 \mathrm{kPa}$ at $30^{\circ} \mathrm{C}$ );

$M_{w}$ is the molar mass of water (equal to 0.018 $\mathrm{kg} / \mathrm{mol}$ );

$\rho_{w}$ is density of water (equal to $996 \mathrm{~kg} / \mathrm{m}^{3}$ at $30^{\circ} \mathrm{C}$ )

$R$ is the gas constant (equal to $8.314 \mathrm{~J} / \mathrm{mol} \cdot \mathrm{K}$ );

$T_{k}$ is temperature, in kelvins;

$h$ is relative humidity of the soil air, dimensionless; and

$z$ is as defined in equation 1.

The driving force for water-vapor diffusion in an isothermal soil is the gradient of relative humidity (eq. 7). However, to facilitate solution of the waterbalance equation in terms of soil water-pressure potential, relative humidity is written in terms of soil water-pressure potential using the equation (Campbell, 1985)

$$
h=\exp \left[M_{w} \psi_{p} g /\left(R T_{k}\right)\right]
$$

where

$g$ is gravitational acceleration, in meters per square second; and other terms are as previously defined.

Soil relative humidity $(h)$ is computed using equation 8 when soil water-pressure potential $\left(\psi_{p}\right)$ is less than 0 ; otherwise, relative humidity is set equal to 1. Diffusivity of soil water vapor varies most strongly with gas-filled soil porosity. An equation given by Campbell (1985) can be used to compute $D_{v s}$. The equation is

$$
D_{v s}=D_{v o} 0.9 \phi_{g}^{2.3} \text {, }
$$

where

$D_{v o}$ is the binary diffusion coefficient for water vapor in air; $2.57 \times 10^{-5} \mathrm{~m}^{2} / \mathrm{s}$ at $30^{\circ} \mathrm{C}$ and $100 \mathrm{kPa}$ atmospheric pressure (Campbell, 1977); and

$\phi_{g}$ is gas-filled soil porosity, dimensionless. Gas-filled porosity can be computed using the equation $\phi_{g}=1-\rho_{b} / \rho_{s}-\theta$, where terms have been previously defined. Gas-filled porosity and vapor flux are 0 in saturated soil.

Plant Uptake of Soil Water.-Plant uptake of soil water and transpiration are two processes that can have a large effect on the soil water balance of vegetated sites. Plant uptake is the process whereby water from soil enters tissues of plant roots. Transpiration is the evaporation into the atmosphere of water from tissues of aerial plant organs. In most terrestrial plants, all of the transpired water is initially absorbed by roots. Macroscopic patterns of water uptake by plants can markedly affect the distribution and redistribution of water within the soil profile. Plant uptake of soil water is modeled as an internal sink within the soil profile. Total plant uptake of soil water is assumed to equal transpiration, and a simple algorithm is used in the model to simulate spatial patterns of water uptake. Computation of transpiration is discussed in the section "Boundary and Initial Conditions and Data Requirements." An equation similar to one given by Moltz and Remson (1970) to compute plant uptake of soil water is 


$$
U(z)=\frac{T R_{a}(z) k_{1}(z) / C(z)}{\int_{O}^{D} R_{a}(z) k_{1}(z) / C(z) d z}
$$

where

$T$ is transpiration, in meters per second;

$R_{a}$ is root activity, in per square meter;

$C$ is specific water capacity, which is the derivative of the soil water-characteristic function in unsaturated soil (eq. 3) with respect to soil water-pressure potential $\left(\psi_{p}\right)$, in per meter;

$D$ is maximum depth of roots in the soil, in meters; and other terms are as previously defined.

Equation 10 distributes water uptake with depth in the root zone according to the product of root activity and the quantity of hydraulic conductivity divided by specific water capacity. Although derivation of the equation is somewhat heuristic (Moltz and Remson, 1970), the form does account for the observed phenomenon that water uptake takes place disproportionately from moist soil volumes (Taylor and Klepper, 1978).

Root activity is a quantitative expression of the hydraulic resistance of plant root systems and is determined principally by root density and hydraulic resistance of individual roots. If hydraulic resistance of individual roots is constant, root activity varies directly with root density. Root density profiles for many plants decrease with increasing depth in the soil, and exponential functions can be used to model root density profiles (Gerwitz and Page, 1974). Because of equation 10 , root activity can be normalized such that $\int_{0}^{D} R_{a}^{\prime}(z) d z=1$, where $R_{a}^{\prime}(z)$ is relative root activity at depth $\mathrm{z}$, dimensionless, and other terms are as defined previously. Plant water uptake can be computed with equation 10 using either root activity or relative root activity.

\section{Numerical Implementation of Governing and Auxiliary Equations for Flow and Plant Uptake of Soil Water}

The water-balance equation (eq. 1) is solved approximately using numerical techniques. To accomplish this, the domains of vertical distance and time are represented in discrete increments. For the vertical distance domain, the soil profile is represented as a network of nodes that extend from the soil surface to the water table. The nodes are numbered from $i=0$ at the soil surface to $i=n$, where $i$ is node number and $n$ is the deepest node in the soil. The variables of soil water-pressure potential, water content, and soil relative humidity are defined only at the nodes, and water storage and water uptake by plant roots take place at the nodes. Adjacent nodes are connected by internodal flow paths. The time domain of equation 1 is approximated using discrete time steps. Water flux between any two nodes and the rates of water storage and plant uptake of soil water at each node are steady during a time step. Time-dependent behavior of equation 1 is approximated using a sequence of time steps.

Liquid and Vapor Flux.-Steady liquid flux between nodes $i-1$ and $i$ can be computed by integrating equation 4. Campbell (1985) uses equations 3 and 4 to derive an analytically correct equation for liquid flux in homogenous, unsaturated soil. The simulation of liquid flux between saturated and unsaturated regions or in soil with varying physical properties is more difficult. An approximate procedure for computing liquid flux is used in the soil water-balance model. In this approximate procedure, liquid flux between nodes $i-1$ and $i$ is computed using the finite-difference form of equation 4 :

$$
\begin{gathered}
{\left[q_{l}\right]_{i-1}=\left[\bar{k}_{l}\right]_{i-1}-\left[\bar{k}_{l}\right]_{i-1}\left(\left[\psi_{p}\right]_{i}-\left[\psi_{p}\right]_{i-1}\right) /} \\
\left(z_{i}-z_{i-1}\right)
\end{gathered}
$$

where

$$
\begin{aligned}
& {\left[\bar{k}_{l}\right]_{i-1} \text { is internodal hydraulic conductivity, in meters }} \\
& \text { per second; and other terms are as } \\
& \text { previously defined. }
\end{aligned}
$$

Water flux between two nodes and internodal hydraulic conductivity are labeled with the number of the upper $(i-1)$ node to simplify notation. Internodal hydraulic conductivity is computed as a simple arithmetic mean, weighted arithmetic mean, or geometric mean of the hydraulic conductivities at two adjacent nodes. Internodal hydraulic conductivity for nodes $i-1$ and $i$ is computed as a weighted arithmetic mean using the equation 


$$
\left[k_{l}\right]_{i-1}=\left(1-W_{t}\right)\left[k_{l}\right]_{i-1}+W_{t}\left[k_{l}\right]_{i}
$$

where

$W_{t}$ is a weighting factor that ranges from 0 to 1 , dimensionless; and other terms are as previously defined.

Computation of internodal hydraulic conductivity as a simple arithmetic mean is accomplished by setting $W_{t}=0.5$. Internodal hydraulic conductivity for nodes $i-1$ and $i$ can be computed as a geometric mean using the equation

$$
\left[k_{l}\right]_{i-1}=\left(\left[k_{l}\right]_{i-1}\left[k_{l}\right]_{i}\right)^{1 / 2}
$$

The arithmetic and geometric schemes each offer certain advantages and disadvantages for simulating unsaturated flow, and the suitability of each scheme can vary depending on conditions of the simulations. The geometric scheme usually provides for the most accurate flow simulations; however, use of that scheme can lead to numerical instabilities, particularly for infiltration into dry, coarse soil. Lappala and others (1987) applied the arithmetic and geometric schemes to problems of simulating evaporation from bare soil above a water table and infiltration of water into soil. Evaporation simulated using the geometric scheme matched evaporation computed using an approximate analytical technique more closely than did evaporation simulated using the simple arithmetic scheme. For the infiltration problem, choice of either scheme made very little difference in the final simulation results.

Water-vapor flow between nodes $i-1$ and $i$ in soil is computed with the finite-difference form of equation 7:

$$
\begin{gathered}
{\left[q_{v}\right]_{i-1}=-\left[\bar{D}_{v s}\right]_{i-1} 10^{3} e_{s} M_{w} /\left(\rho_{w} R T_{k}\right)} \\
\left(h_{i}-h_{i-1}\right) /\left(z_{i}-z_{i-1}\right)
\end{gathered}
$$

where

$\left[\bar{D}_{v s}\right]_{i-1}$ is internodal soil-water-vapor diffusivity, in square meters per second; and other terms are as previously defined.
Internodal soil water-vapor diffusivity is computed by evaluating equation 9 using the mean volumetric soil water content for nodes $i-1$ and $i$.

Rate of Change in Water Storage.-The finitedifference form of the storage term in equation 1 is

$$
\left(\theta_{i}^{j+1}-\theta_{i}^{j}\right) V_{i} / \Delta t
$$

where

$j$ is a time-step index, dimensionless;

$V_{i}$ is thickness of soil associated with node $i$, in meters;

$\Delta t$ is duration of a time step, in seconds; and other terms are as previously defined.

The time step $j+1$ is the next future time step from the time step $j$. The thickness of soil associated with a node is important for determining water-storage capacity for the node and is computed from node spacing. For the surface node $(i=0)$, soil thickness is computed by the equation $V_{0}=z_{1} / 2$. For subsurface nodes, soil thickness is computed by the equation $V_{i}=\left(z_{i+1}-z_{i-1}\right) / 2$.

The sink term representing plant uptake of soil water for soil nodes within the root zone $\left(U_{i}\right)$ is computed with the equation

$$
U_{i}=\frac{T V_{i}\left[R_{a}\right]_{i}\left[k_{l}\right]_{i} / C_{i}}{\sum_{0}^{i=i_{n}} V_{i}\left[R_{a}\right]_{i}\left[k_{l}\right]_{i} / C_{i}},
$$

where

$U_{i}$ is in meters per second;

$i_{n}$ is the node at the bottom of the root zone, dimensionless; and other terms are as previously defined.

The water balance of each soil node can be written using the equations for liquid and vapor flux and the equations for the water storage and sink terms. The water balance of the soil surface node $(i=0)$ can be written as the finite-difference equation 


$$
\begin{gathered}
F_{0}=q_{s}-\left[q_{l}\right]_{0}-E_{s}-\left[q_{v}\right]_{0} \\
-\frac{\left(\theta_{0}^{j+1}-\theta_{0}^{j}\right) V_{0}}{\Delta t}-U_{0}
\end{gathered}
$$

where

$F_{0}$ is water-balance error for the soil surface node, in meters per second;

$q_{\mathrm{s}}$ is water infiltration at the soil surface, in meters per second;

$E_{s}$ is evaporation from the soil surface, in meters per second; and other terms are as previously defined.

Procedures used in the model for computing the boundary fluxes $q_{s}$ and $E_{s}$ are described in the section "Boundary and Initial Conditions and Data Requirements."

A water-balance equation can be written for the $i^{\text {th }}$ subsurface node as the finite-difference equation

$$
\begin{gathered}
F_{i}=\left[q_{l}\right]_{i-1}-\left[q_{l}\right]_{i}+\left[q_{v}\right]_{i-1}-\left[q_{v}\right]_{i} \\
-\frac{\left(\theta_{i}^{j+1}-\theta_{i}^{j}\right) V_{i}}{\Delta t}-U_{i},
\end{gathered}
$$

where all terms are as previously defined.

A water-balance equation can be written for each soil node to create a system of equations. The equations are nonlinear in soil water-pressure potential for unsaturated soil. A numerical procedure then can be used to solve the system of water-balance equations. The intent of the numerical procedure is to obtain $\psi_{p}$ for each node at the end of the time step so that the sum of absolute water-balance errors is below a specified tolerance. Estimates of $\psi_{p}$ at the end of the time step are used to evaluate water fluxes and the storage and sink terms in equations 15 and 16; therefore, the solution procedure is backward difference. The iterative Newton-Raphson procedure is used for this purpose. Application of the NewtonRaphson procedure is similar to that described by Campbell (1985), except the technique of Marquardt (1963) is added to reduce the occurrence and persis- tence of numerical instabilities during the numerical procedure.

Equations 15 and 16 are used to compute water balances for nodes in unsaturated and in saturated soil. In saturated soil $\left(\psi_{p} \geq \psi_{p e}\right)$, the mass rate of soil water storage is 0 . Vapor flux is 0 in saturated soil because vapor diffusivity $\left(D_{v s}\right)$ and the relative humidity gradient $(\partial h / \partial z)$ are both 0 . Because of the weak dependence of soil relative humidity on soil waterpressure potential (eq. 8), strong gradients in soil water-pressure potential are required before vapor flux becomes an important component of the water balance for any subsurface node. Strong gradients in soil water-pressure potential generally develop only in very dry soil; therefore, subsurface vapor flux generally is not important in unsaturated soil unless volumetric soil water content $(\theta)$ is less than about 10 percent of the saturated value $\left(\theta_{s}\right)$.

Water flow is simulated for soils in which physical properties vary with depth. The soil physical properties, such as saturated hydraulic conductivity, are defined for each node. In a layered soil, one or more physical properties change with depth to create an interface within the soil profile. Because the physical properties are defined for the nodes, the interface occurs between nodes.

\section{Boundary and Initial Conditions and Data Requirements}

A combination of constant flux and constant potential boundary conditions are specified for solution of the system of water-balance equations. The upper boundary condition is dictated by the physical processes of precipitation and evapotranspiration. The lower boundary condition is specified by the position of the water table.

Precipitation.-Precipitation, all of which is considered to be rainfall, is input to the soil surface node as a specified flux. The precipitation rate is assumed to be constant during a time step. If the precipitation rate does not exceed a specified maximum infiltration rate, the input flux is equal to the precipitation rate; otherwise, the input flux is equal to the specified maximum infiltration rate. Maximum infiltration rate is set equal to the saturated hydraulic conductivity of the surface soil node. Water in excess of that allowed to infiltrate the soil surface is numerically stored in a volumetric zero-head reservoir and is 
input to the soil surface when the precipitation rate falls below the specified maximum infiltration rate. Infiltration $\left(q_{\mathrm{S}}\right)$ is computed from the equation

$$
q_{s}=P+\Delta Q,
$$

where

$P$ is precipitation, in meters per second, and;

$\Delta Q$ is the rate of decrease in the volumetric zerohead reservoir, in meters per second.

Evapotranspiration.-Evapotranspiration is an important component of the water balance of terrestrial systems, and it is a difficult component to simulate accurately. Simulation of evapotranspiration is accomplished with simple, empirically based evapotranspiration equations. Because treatment of evapotranspiration is partly based on empiricism, it may require modifications before it is applicable to a given site. Description of the treatment of evapotranspiration in the model can begin with the following terms and definitions:

1. Evapotranspiration $(E)$ : The combined evaporation into the atmosphere of liquid water from soil surfaces and intercepted water on plant surfaces, plus transpiration by plants, in meters per second.

2. Evaporation from the soil surface $\left(E_{s}\right)$ : The component of $E$ accounted for by evaporation from wet or partially wet soil surfaces; dimensions are as previously defined.

3. Transpiration $(T)$ : Has been defined previously.

4. Potential evapotranspiration $\left(E_{p}\right)$ : Maximum evapotranspiration that can occur from an extensive area densely covered with actively growing, well-watered vegetation with the capacity to supply water to meet evaporative demand that is indistinguishable from said capacity for a fully wet surface, in meters per second.

5. Potential evaporation from the soil surface $\left(E_{s p}\right)$ : Maximum evaporation that can occur from an extensive, wet soil surface, in meters per second.

Evaporation can occur from a bare soil surface or from a soil surface beneath a plant canopy. In the model, $E_{S}$ is computed with the equation (Campbell, 1985)

$$
E_{s}=E_{s p}\left(h_{s}-h_{a}\right) /\left(1-h_{a}\right),
$$

where

$h_{a}$ is atmospheric relative humidity, dimensionless;

$h_{s}$ is relative humidity at the soil surface, dimensionless; and other terms are as previously defined.

Equation 18 predicts that $E_{s}$ is equal to $E_{s p}$ when $h_{s}$ is 1 and $h_{a}$ is less than 1, and it predicts that $E_{s}$ is less than $E_{s p}$ when $h_{s}$ drops below 1 . The result of equation 18 is undefined when atmospheric relative humidity is equal to 1 , and it is negative when atmospheric relative humidity is greater than soil relative humidity. Under these conditions, which usually occur only at dusk, at night, and at dawn, $E_{s}$ is set equal to 0 .

The value of $E_{s p}$ that is used in the model is derived from $E_{p}$ in a way that depends on whether the soil surface is bare or vegetated. When the system to be simulated is bare soil, $E_{s p}$ is equal to $E_{p}$, and the total evaporative flux is computed using equation 18 . When a plant canopy exists, $E_{p}$ is partitioned to $E_{s p}$ in proportion to the fraction of incoming shortwave radiation that passes through the plant canopy to reach the soil surface. The equation for $E_{s p}$ is: $E_{s p}=(1-\kappa) E_{p}$, where $\kappa$ is fraction of daily incoming shortwave radiation intercepted by the plant canopy, dimensionless.

Relative humidity at the soil surface $\left(h_{s}\right)$ varies with soil water-pressure potential at the surface according to equation 8 . Soil water-pressure potential at the soil surface varies according to the water balance at the surface and that water balance reflects $E_{s}$. The linkage between $E_{s}$ and the soil water balance can provide an important feedback control that limits $E_{s}$ from a dry soil. The soil surface must be very dry, however, before $E_{s}$ is limited by small soil relative humidity. Relative humidity of soil is fairly insensitive to soil water-pressure potential (eq. 8). For example, a reduction of soil relative humidity from 1.0 to 0.98 corresponds to a reduction in soil waterpressure potential from 0 to about $-280 \mathrm{~m}$. In most soils, pressure potentials on the order of $-280 \mathrm{~m}$ occur when volumetric soil water content is a few percent or less.

All of the computations for $E_{s}$ described above are carried out assuming that $E_{p}$ is known or can be computed; however, some uncertainty about the exact value of $E_{p}$ usually exists. Development of the concept of potential evapotranspiration arose from a desire on the part of researchers to predict $E$ when it is limited primarily by imposed meteorological factors 
rather than by characteristics of the evaporating surface. Characteristics of an evaporating surface, such as its aerodynamic roughness and albedo, are generally recognized as important determinants of $E$ under a given set of imposed meteorological conditions. As a result, estimates of $E$ developed using one of the many available potential evapotranspiration techniques that consider only meteorological variables (Jensen and others, 1990) should be considered to be only approximate unless independent experimental evidence indicates otherwise.

One technique for estimating $E_{p}$ for conditions of minimal advection, where advection refers to delivery of air from different upwind surfaces to the surface of interest, has been described by Priestley and Taylor (1972). The Priestley-Taylor equation is

$$
E_{p}=\frac{\alpha S\left(R_{n}-G\right)}{\rho_{w} L(S+\gamma)}
$$

where

$\alpha$ is a multiplier used to compute $E_{p}$ with the Priestley-Taylor equation, dimensionless;

$S$ is slope of the relation between saturation vapor pressure and temperature, in kilopascals per degree Celsius;

$R_{n}$ is net radiation measured above the plant canopy or bare soil surface, in watts per square meter;

$G$ is subsurface heat flux, in watts per square meter;

$L$ is heat of vaporization for water, in joules per kilogram;

$\gamma$ is the psychrometer coefficient, in kilopascals per degree Celsius; and

$\rho_{w}$ is as previously defined.

All of the variables in equation 19, with the exception of $\alpha$, can be determined in a straightforward manner for a given site using routine meteorological measurements, such as those described by Bidlake and Boetcher (in press). Priestley and Taylor (1972) argued theoretically, for conditions of minimal advection and water saturation at the surface, that $\alpha$ should range between 1.0 and the quantity $(S+\gamma) / S$. The quantity $(S+\gamma) / S$ is temperature dependent, and it varies from 1.85 at $10^{\circ} \mathrm{C}$ to 1.30 at $30^{\circ} \mathrm{C}$. Some experimental evidence indicates that $\alpha$ is approximately 1.26 for short, actively growing, wellwatered crops (Davies and Allen, 1973; Jury and Tanner, 1975) and open water (DeBruin and Keijman,
1979). The similarity between $\alpha$ reported for short, actively growing vegetation and $\alpha$ reported for open water indicates such vegetation can be indistinguishable from fully wet surfaces in terms of supplying water to meet evaporative demand. For this reason, $E_{p}$ is computed in the model using equation 19 , with $\alpha=\alpha_{m}$, where $\alpha_{m}$ is a user-supplied value for $\alpha$, and $E_{p}$ is partitioned directly to $E_{s p}$ as described above. The choice of a particular value for $\alpha_{m}$, such as 1.26 , might not be appropriate for computing $E_{p}$ under all conditions because, theoretically, $\alpha$ for a saturated surface can range between 1.0 and the quantity $(S+\gamma) / S$. Slope of the relation between saturation vapor pressure and temperature $(S)$ is computed using an equation given by Brutsaert (1982). Heat of vaporization $(L)$ is $2.43 \mathrm{MJ} / \mathrm{kg}$ at $30^{\circ} \mathrm{C}$, and this value is used in the model. The psychrometer coefficient $(\gamma)$ varies weakly with air temperature and atmospheric pressure. A value of $0.0665 \mathrm{kPa} /{ }^{\circ} \mathrm{C}$, which corresponds to a temperature of $30^{\circ} \mathrm{C}$ and a pressure of $100 \mathrm{kPa}$, is used in the model.

When the system to be simulated is vegetated, $E$ also is computed using the Priestley-Taylor equation, as is discussed below, and evaporation from the soil surface $\left(E_{s}\right)$ is computed using equation 18. Transpiration is computed from the equation $T=E-E_{s}$.

Discussion of the Priestley-Taylor equation (eq. 19) to this point in this report has focused on use of the equation for computing $E_{p}$, which is useful for establishing maximum $E$ when the evaporating surface either is saturated or behaves as a saturated surface. Few surfaces, other than open water, remain sufficiently moist so as to behave as saturated surfaces continuously, and $E$ in terrestrial environments often occurs under conditions where the capacity of plant and soil surfaces to supply water is limited to the extent that $E$ is less than $E_{p}$. Such conditions are referred to as water-limiting conditions in this report. Applicability of the Priestley-Taylor equation can be extended to predict $E$ under water-limiting conditions by allowing $\alpha$ in equation 19 to assume a value less than $\alpha_{m}$. If variations in $\alpha$ can be predicted for waterlimiting conditions, equation 19 can be used to compute $E$. Site-specific empirical relations between $\alpha$ and soil water content have been identified for baresurfaced soils (Barton, 1979) and for some vegetated surfaces (Davies and Allen, 1973; Flint and Childs, 1991). Empirical relations developed for a particular type of vegetation and soil cannot be expected to be generally applicable to different vegetation and soils, 
and the behavior of $\alpha$ must be established for each system to be simulated. The model, as it is currently (1997) coded, reads a user-supplied value for $\alpha$, designated here as $\alpha_{l}$, in order to compute $E$ with equation 19.

One of the motivations for constructing the water-balance simulation model was to identify, if possible, a site-specific relation between soil water content and $\alpha$ and then to simulate soil water content in the root zone so that the Priestley-Taylor equation could be used to predict $E$ under water-limiting conditions. This approach supposes that soil water content represents a significant control on $E$ and that the effects of varying soil water content on $E$ can be quantified for the particular system to be simulated. For vegetated surfaces, there are other environmental, physiological, and morphological controls on $\alpha$ that are more difficult to quantify than soil water content, including possibly the growth stage of canopy plants, atmospheric vapor-pressure deficit, leaf temperature, and flux of photosynthetically active radiation. Atmospheric vapor-pressure deficit is a measure that reflects the degree to which the atmosphere is saturated with water vapor. Photosynthetically active radiation is a portion of the electromagnetic spectrum that is particularly important for some biochemical processes of plants. Attempts to predict $\alpha$ based solely on soil water content might be considered simplistic; however, such efforts provide a starting point for examining controls on $E$ in water-limiting conditions.

The model does not simulate negative $E$. The Priestley-Taylor equation can yield negative values for $E$ at dusk, at night, and at dawn because net radiation minus subsurface heat flux $\left(R_{n}-G\right)$ is often negative at those times. Evapotranspiration, $T$, and $E_{s}$ are set equal to 0 in the model when $E$ computed with the Priestley-Taylor equation is negative.

Lower Boundary Condition.-When considering a system with a single regional water table, the lower boundary condition is a specified soil waterpressure potential $\left(\psi_{p}\right)$ equal to 0 at the water table. Water flow above the water table in isotropic soils is primarily vertical, whereas flow below the water table can have a strong horizontal component. Use of the water table as the lower boundary permits treatment of water flow in the simple one-dimensional form of equation 1 . Use of the water table as the lower boundary presents no problem if the position of the water table remains constant; however, this rarely occurs in unmanaged systems. Fluctuations in watertable depth reflect the dynamic balance of recharge and discharge for the saturated ground-water system. The position of the water table is fixed in the model for each simulation period; therefore, the maximum duration of a simulation period is limited to the period during which the fixed lower boundary condition for the simulations adequately approximates actual conditions in the field. If depth to the water table is great enough and changes in water-table depth occur slowly, variation in water-table position has little effect on hydrologic processes near the soil surface.

Data Requirements. - The data required to operate the model include data that describe the physical characteristics of the soil-plant system, data that describe initial soil water content, data that drive the model by updating boundary conditions, and procedural data that direct inputs to the model from files and outputs from the model to a monitor and to files. The soil flow system is defined using a network of vertically spaced nodes, and soil physical and plant properties are defined for each node. These properties are: (1) depth below the soil surface (z), in meters; (2) air-entry soil water-pressure potential $\left(\psi_{p e}\right)$, in meters; (3) soil bulk density $\left(\rho_{b}\right)$, in kilograms per cubic meter; (4) shape factor for the soil water-characteristic function $(b)$ used for equations 3 and 6, dimensionless; (5) saturated hydraulic conductivity $\left(k_{s}\right)$, in meters per second; and (6) root activity $\left(R_{a}\right)$, in per square meter, or relative root activity $\left(R_{a}^{\prime}\right)$, dimensionless. The user specifies the weighting scheme for internodal hydraulic conductivity to be either weighted arithmetic or geometric. If a weighted arithmetic scheme is selected, the weighting factor $\left(W_{t}\right)$ must be specified. The plant canopy is characterized by the fraction of daily incoming shortwave radiation intercepted by the plant canopy $(\kappa)$. The multipliers for the Priestley-Taylor equation $\alpha_{m}$ and $\alpha_{l}$ must be specified. When the system to be simulated includes vegetation ( $\kappa>0$ ), the multiplier $\alpha_{l}$ can be estimated from site-specific calibrations. If the system to be simulated is a bare soil $(\kappa=0), \alpha_{l}$ can be set equal to 1.0 .

An initial value for soil water content is specified for each node. The model computes initial soil water-pressure potential for each node by solving equation 3 for soil water-pressure potential. To obtain representative transient simulations, the correct initial soil water content must be supplied for each node. 
Upper boundary conditions, which are specified for each time step, are computed from the input variables: (1) average net radiation minus subsurface heat flux, in watts per square meter; (2) average air temperature, in degrees Celsius; (3) average atmospheric vapor pressure, in kilopascals; and (4) precipitation, in millimeters for the duration of the time step. Precipitation is entered in millimeters for convenience, and it is converted to meters of water by the program. All input variables, except precipitation, are averages for the duration of a time step. Time-step duration is computed from day of year and time of day, and those data are included with each time-step record. Depth to the water table, in meters, is input to compute the position of the lower boundary.

\section{Model Source Code and Input and Output Files}

The water-balance simulation model is coded as a computer program, the model source code, that can be compiled into a machine-language version on a computer equipped with the appropriate software. The machine-language version then can be executed on the computer to simulate the soil water balance. The source code was developed, compiled, and run on a personal computer with 640 kilobytes of memory and a numeric processor. The source code requires about 25 kilobytes of core memory. The proprietary software package used to edit and compile the source code and to execute the machinelanguage code is Turbo Pascal (version 5.5, Borland International). The source code has not been compiled or run using any other Pascal software package; however, experience of the authors indicates that this probably could be done after only minor modifications to the code.

The source code is composed of 24 functions and procedures and the main program segment. The main program segment, which is the last segment in the code, directs execution of the model, in part, by calling the functions and procedures for computa- tions. A generalized flowchart for the model source code is given in appendix 1 , and a complete listing of the code is given in appendix 2 . The purpose of each function and procedure is indicated directly above the function or procedure in the source-code listing.

The model source code includes numeric variables as scalars and in arrays. Data elements defined individually for each node or for each time step during a day are stored in single-column arrays. All other numeric variables are scalars. A complete listing of the numeric variables used in the model is given in table 1 .

Execution of the model on a computer requires two data input files. The first input file contains coded instructions for directing additional data inputs and outputs and for selecting computation options within the model (tables 2 and 3). The first file also serves as the source of data for defining the configuration of the soil-node network and for values of parameters for the soil-plant system. The second input file contains information needed to advance the water-balance solution in time. This information includes day of year and time of day, in a 24-hour format, as well as data needed to update atmospheric boundary conditions (tables 4 and 5). Both input files are free-format, space-delineated ASCII files and can be created and edited with any ASCII text editor.

Two types of output files can be created during the simulations. The first type of file contains simulated profiles of volumetric soil water content and soil water-pressure potential within the network of soil nodes. Description, format, and an example of the first type of file are given in tables 6 and 7. The second type of file is a daily summary of simulated evaporation from the soil surface, simulated transpiration, simulated evapotranspiration, potential evapotranspiration, precipitation inputs, and simulated water flux at the lower soil boundary. Description, format, and an example of the second type of output file are given in tables 8 and 9. 
Table 1. Definitions of variables used in the computer coding of the soil water-balance model

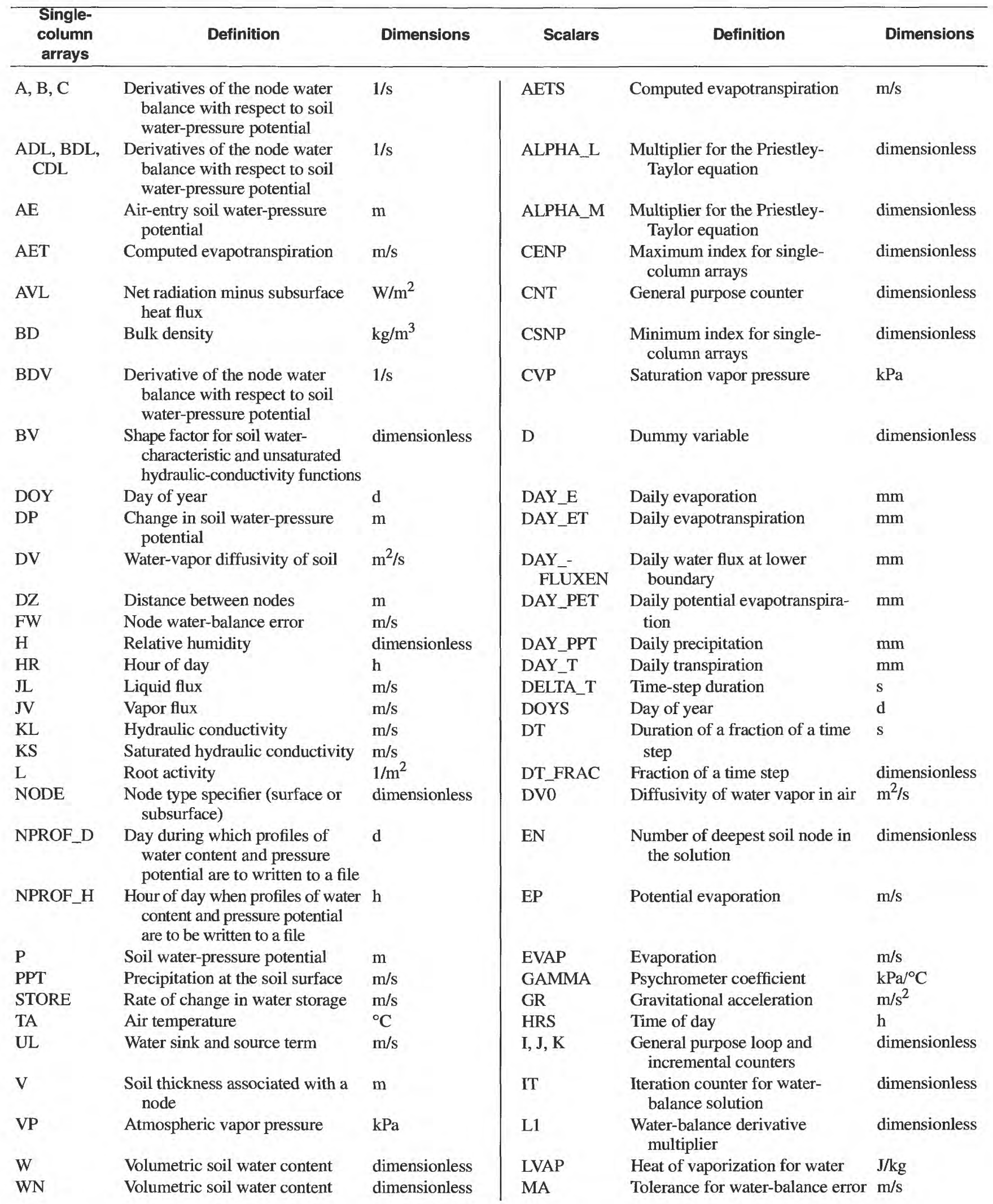


Table 1. Definitions of variables used in the computer coding of the soil water-balance model-Continued

\begin{tabular}{|c|c|c|c|c|c|}
\hline Scalars & Definition & Dimensions & Scalars & Definition & Dimensions \\
\hline $\begin{array}{l}\text { MASS } \\
\text { BALANCE }\end{array}$ & Water-balance error & $\mathrm{m} / \mathrm{s}$ & SPET_FRAC & $\begin{array}{l}\text { Fraction of daily incoming short- } \\
\text { wave radiation intercepted by } \\
\text { the plant canopy }\end{array}$ & dimensionless \\
\hline MAXINFIL & Maximum infiltration rate & $\mathrm{m} / \mathrm{s}$ & START_DOY & Starting year day of simulation & $\mathrm{d}$ \\
\hline MW & Molar mass of water & $\mathrm{kg} / \mathrm{mol}$ & START_HR & Starting hour of simulation & $\mathrm{h}$ \\
\hline NO & $\begin{array}{l}\text { Exponent for computing unsatur- } \\
\text { ated hydraulic conductivity }\end{array}$ & dimensionless & STOP_DOY & Final year day of simulation & d \\
\hline NPROF & $\begin{array}{l}\text { Counter indicating the number of } \\
\text { times profiles of soil water } \\
\text { content and pressure potential } \\
\text { are to be written to files }\end{array}$ & dimensionless & STOP_HR & Final hour of simulation & $\mathrm{h}$ \\
\hline OSEW & $\begin{array}{l}\text { Water-balance error from } \\
\text { previous iteration }\end{array}$ & $\mathrm{m} / \mathrm{s}$ & SUMRK & $\begin{array}{l}\text { Sum of the quantity equal to the } \\
\text { product of root activity and } \\
\text { hydraulic conductivity divided } \\
\text { by specific water capacity }\end{array}$ & $1 / \mathrm{s}$ \\
\hline PD & Density of soil particles & $\mathrm{kg} / \mathrm{m}^{3}$ & $\mathrm{~T}$ & Temperature & ${ }^{\circ} \mathrm{C}$ \\
\hline PETS & Potential evapotranspiration & $\mathrm{m} / \mathrm{s}$ & T0 & $\begin{array}{l}\text { Offset used to compute kelvins } \\
\text { from Celsius }\end{array}$ & $\mathrm{K}$ \\
\hline PLEVEL & $\begin{array}{l}\text { Flag indicating intensity of } \\
\text { displayed output }\end{array}$ & dimensionless & TAS & Air temperature & ${ }^{\circ} \mathrm{C}$ \\
\hline POND & $\begin{array}{l}\text { Precipitation held in numerical } \\
\text { storage }\end{array}$ & $\mathrm{mm}$ & TP & Potential transpiration & $\mathrm{m} / \mathrm{s}$ \\
\hline PPTS & $\begin{array}{l}\text { Precipitation infiltrating the soil } \\
\text { surface }\end{array}$ & $\mathrm{m} / \mathrm{s}$ & TR & Dimensionless temperature & dimensionless \\
\hline $\mathrm{R}$ & Gas constant & $\mathrm{J} / \mathrm{mol} \cdot \mathrm{K}$ & TRNS & Transpiration & $\mathrm{m} / \mathrm{s}$ \\
\hline$S$ & $\begin{array}{l}\text { Slope of the saturation vapor- } \\
\text { pressure*temperature curve }\end{array}$ & $\mathrm{kPa} /{ }^{\circ} \mathrm{C}$ & WD & Density of water & $\mathrm{kg} / \mathrm{m}^{3}$ \\
\hline SCC, SC & Time-step counters & dimensionless & WS & $\begin{array}{l}\text { Volumetric soil water content at } \\
\text { saturation }\end{array}$ & dimensionless \\
\hline SEW & Sum of water-balance errors & $\mathrm{m} / \mathrm{s}$ & WT & $\begin{array}{l}\text { Weighting factor for computing } \\
\text { internodal hydraulic conduc- } \\
\text { tivity }\end{array}$ & dimensionless \\
\hline SN & Node number at the soil surface & dimensionless & WTD & $\begin{array}{l}\text { Depth of the water table below } \\
\text { the soil surface }\end{array}$ & $\mathrm{m}$ \\
\hline
\end{tabular}

Table 2. Description and format of the file read by the computer program to input program control instructions, soil and plant parameter values, and initial soil water content

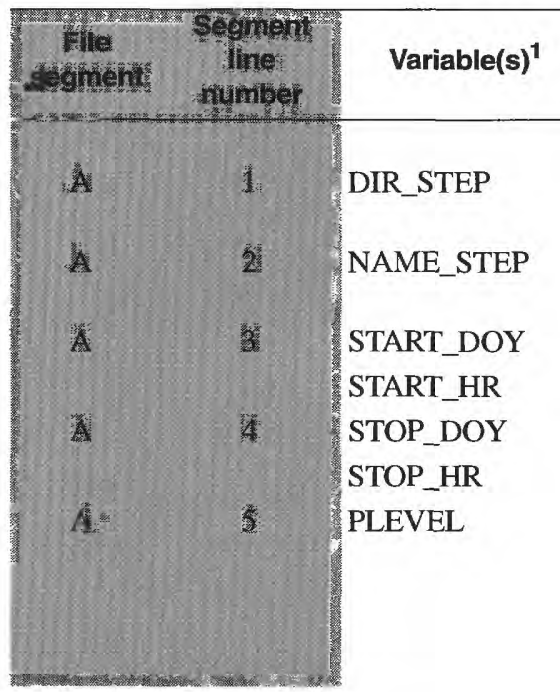

\section{Description}

Directory for file that is used to input day of year and time of day and to input data with which atmospheric boundary conditions are computed.

Name of file that is used to input day of year and time of day and to input data with which atmospheric boundary conditions are computed.

Day of year when a simulation period is begun.

Time of day when the simulation period is begun, in hours and minutes.

Day of year when the simulation period is concluded.

Time of day when the simulation period is concluded, in hours and minutes.

Intensity level for displaying intermediate results from the simulation on the computer monitor. The intensity levels are:

0 - No simulation results are displayed

1 - Daily summaries of evaporation, transpiration, evapotranspiration, potential evapotranspiration, and precipitation are displayed. 
Table 2. Description and format of the file read by the computer program to input program control instructions, soil and plant parameter values, and initial soil water content-Continued

\begin{tabular}{|c|c|c|c|}
\hline $\begin{array}{l}\text { Hile: } \\
\text { seğnientit }\end{array}$ & $\begin{array}{l}\text { Seginent } \\
\text { loge } \\
\text { numben }\end{array}$ & Variable(s) $^{1}$ & Description \\
\hline & & & $\begin{array}{l}\text { 2- Daily summaries indicated for PLEVEL }=1 \text { are displayed. In addition, the following } \\
\text { information is displayed for each time step: (1) profiles of soil humidity, volumetric } \\
\text { water content, and soil water-pressure potential; ( } 2 \text { evaporation, transpiration, } \\
\text { evapotranspiration, potential evapotranspiration, precipitation, and water-balance error } \\
\text { for the simulations. }\end{array}$ \\
\hline 策: & 1 & NPROF & $\begin{array}{l}\text { Number of times the profile of volumetric soil water content and soil water-pressure } \\
\text { potential is written to a file. }\end{array}$ \\
\hline \multirow[t]{2}{*}{ B } & 2 & $\begin{array}{l}\text { NPROF_D[*] } \\
\text { NPROF_H[*] }\end{array}$ & $\begin{array}{l}\text { If NPROF is greater than } 0 \text {, each remaining line in the B segment gives the day of year and } \\
\text { time of day when the profile is to be written to a file. Day of year is read into the column } \\
\text { array NPROF_D[*], and time of day is read into the column array NPROF_H[*]. }\end{array}$ \\
\hline & & & $\begin{array}{l}\text { NOTE: If the water-content and pressure-potential profiles are not to be written to files } \\
\text { (for example, NPROF }<=0 \text { ), segment } B \text { ends with line } 1 \text {. }\end{array}$ \\
\hline G & 1 & DFLUX & $\begin{array}{l}\text { Flag to control whether or not daily summaries of evaporation, transpiration, evapotranspi- } \\
\text { ration, potential evapotranspiration, and precipitation are written to a disk file. If } \\
\text { DFLUX }=1 \text {, the daily summaries are written to a file; otherwise, they are not written. }\end{array}$ \\
\hline C. & 2 & DIR_OUT & If DFLUX $=1$, the directory for the file in which the daily summaries are to be written. \\
\hline \multirow[t]{2}{*}{ c } & 触 & NAME_OUT & If DFLUX $=1$, the name of the file in which the daily summaries are to be written. \\
\hline & & & $\begin{array}{l}\text { NOTE: If daily summaries are not to be written (for example, DFLUX } \diamond 1 \text { ), segment C } \\
\text { ends with line } 1 \text {. }\end{array}$ \\
\hline B. & 1) & ARITH & $\begin{array}{l}\text { Flag used to indicate whether internodal hydraulic conductivity is to be computed using an } \\
\text { arithmetic or geometric averaging scheme. Values for ARITH and their meanings are: } \\
0 \text { - Arithmetic scheme is used. } \\
1 \text { - Geometric scheme is used. }\end{array}$ \\
\hline \multirow[t]{2}{*}{ D. } & 2. & WT & Weighting factor for arithmetic averaging scheme. \\
\hline & & & $\begin{array}{l}\text { NOTE: If the geometric averaging scheme is selected (for example, ARITH=1), } \\
\text { segment D ends with line } 1 \text {. }\end{array}$ \\
\hline 䗱: & 1: & WTD & Depth to the water table, in meters. \\
\hline E: & (2) & SPET_FRAC & $\begin{array}{l}\text { Fraction of daily incoming shortwave radiation intercepted by the plant canopy, dimension- } \\
\text { less. }\end{array}$ \\
\hline 些: & 3 & ALPHA_M & Multiplier for computing potential evapotranspiration with the Priestley-Taylor equation. \\
\hline 密" & 4 & ALPHA_L & Multiplier for computing actual evapotranspiration with the Priestley-Taylor equation. \\
\hline \multirow[t]{8}{*}{ 1) } & 13 & NODE[*] & $\begin{array}{l}\text { Node type. NODE is set equal to } 0 \text { for the surface soil node, and it is set equal to } 1 \text { for all } \\
\text { other soil nodes. }\end{array}$ \\
\hline & & $\mathrm{Z}[*]$ & Depth of a node below the soil surface, in meters. \\
\hline & & $\mathrm{AE}[*]$ & Air-entry soil water-pressure potential, in meters. \\
\hline & & $\mathrm{BD}[*]$ & Soil bulk density, in kilograms per cubic meter multiplied by $10^{-3}$ \\
\hline & & $\mathrm{BV}[*]$ & Shape factor for the soil water-characteristic function, dimensionless. \\
\hline & & $\mathrm{KS}[*]$ & Saturated hydraulic conductivity, in meters per second multiplied by $10^{5}$ \\
\hline & & $\mathrm{L}[*]$ & Root activity, in per square meter, or relative root activity, dimensionless. \\
\hline & & $\mathrm{W}[*]$ & Initial volumetric soil water content, dimensionless. \\
\hline
\end{tabular}

\footnotetext{
${ }^{1}$ Variables listed vertically under a segment and line number appear sequentially on a single line in the input file. The designation [ $\left.{ }^{*}\right]$ indicates that a variable is a single-column array.
} 
Table 3. Example of the file read by the computer program to input soil and plant parameter values and initial soil water content

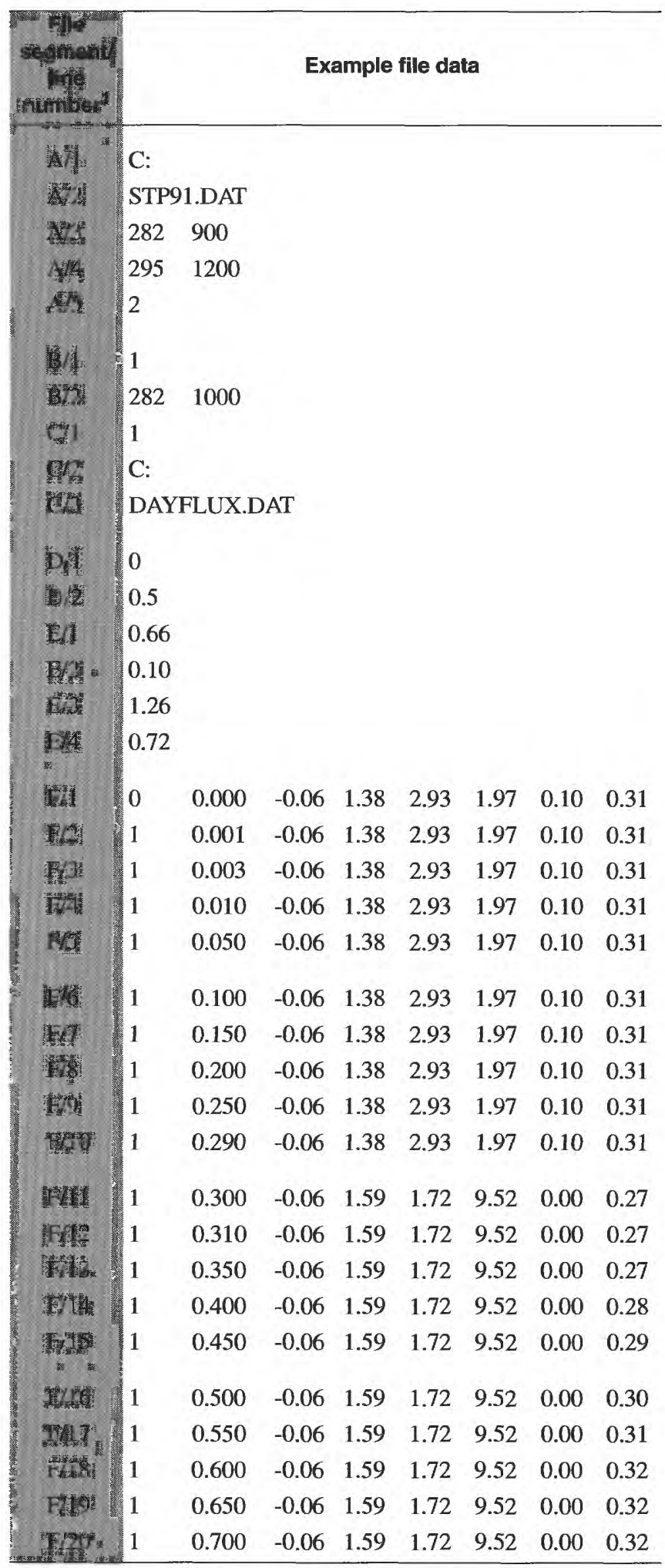

${ }^{1}$ File segment and line number are not part of the file and are shown only to facilitate comparison between tables 2 and 3.
Table 4. Description and format of the file read by the computer program to update day of year, time of day, and variables used to compute and update atmospheric boundary conditions

\begin{tabular}{|c|c|c|}
\hline Fithithe & Variable $^{1}$ & Description \\
\hline \multirow[t]{7}{*}{1} & DOY [*] & Day of year. \\
\hline & $\mathrm{HR}[*]$ & Hour of day. \\
\hline & AVL[*] & $\begin{array}{l}\text { Net radiation minus soil heat flux, in watts } \\
\text { per square meter. }\end{array}$ \\
\hline & $\mathrm{TA}[*]$ & Air temperature, in degrees Celsius. \\
\hline & $\mathrm{VP}[*]$ & Atmospheric vapor pressure, in kilopascals. \\
\hline & PPT $[*]$ & Precipitation, in millimeters. \\
\hline & & $\begin{array}{l}\text { NOTE: File line number } 1 \text { is repeated for } \\
\text { at least as many time steps as are } \\
\text { in the simulation period. }\end{array}$ \\
\hline
\end{tabular}

Table 5. Example of the file read by the computer program to update day of year, time of day, and variables used to compute and update atmospheric boundary conditions

\begin{tabular}{|c|c|c|c|c|c|c|}
\hline Filening & & & Examp & file dat & & \\
\hline b & 282 & 100 & -14.267 & 20.733 & 2.1967 & 0 \\
\hline . $2^{\prime \prime}$ & 282 & 200 & -15.633 & 20.467 & 2.1767 & 0 \\
\hline f & 282 & 300 & -11.7 & 19.733 & 2.1433 & 0 \\
\hline d) & 282 & 400 & -9.5333 & 19.333 & 2.1267 & 0 \\
\hline $5 i$ & 282 & 500 & -9.3667 & 19.4 & 2.14 & 0 \\
\hline 6 & 282 & 600 & -9.6333 & 19.7 & 2.1733 & 0 \\
\hline 1 & 282 & 700 & -6.2 & 19.867 & 2.1967 & 0 \\
\hline 10 & 282 & 800 & 72 & 21.067 & 2.3367 & 0 \\
\hline II) & 282 & 900 & 255.8 & 24.733 & 2.71 & 0 \\
\hline 12: & 282 & 1000 & 218.23 & 26.4 & 2.9033 & 0 \\
\hline$|3|$ & 282 & 1100 & 286.9 & 27.733 & 3.09 & 0 \\
\hline 14 & 282 & 1200 & 371.9 & 28.833 & 3.1833 & 0 \\
\hline 6 & 282 & 1300 & 342.07 & 29.5 & 3.2067 & 0 \\
\hline 16 & 282 & 1400 & 213.03 & 29.167 & 3.08 & 0 \\
\hline 17 & 282 & 1500 & 97.3 & 27.733 & 2.95 & 0 \\
\hline 18 & 282 & 1600 & 90.367 & 26.6 & 2.8833 & 0 \\
\hline (1) & 282 & 1700 & 57.5 & 25.933 & 2.8333 & 0 \\
\hline 29 & 282 & 1800 & 3.2 & 25.433 & 2.8067 & 0 \\
\hline 81 & 282 & 1900 & -8.2 & 24.533 & 2.7667 & 0 \\
\hline 22 & 282 & 2000 & -6.3 & 23.8 & 2.7233 & 0 \\
\hline 36 & 282 & 2100 & -5.0333 & 23.367 & 2.7067 & 0 \\
\hline 28 & 282 & 2200 & -8.4667 & 23.467 & 2.7233 & 0 \\
\hline 64 & 282 & 2300 & -9.0333 & 23.5 & 2.7167 & 0 \\
\hline
\end{tabular}

${ }^{1}$ The file line number is not part of the file and is shown only to facilitate comparison between tables 4 and 5 . 
Table 6. Description and format of the output file containing the profiles of volumetric soil water content and soil waterpressure potential

\begin{tabular}{|c|c|c|}
\hline $\begin{array}{l}\text { Fileding: } \\
\text { number }\end{array}$ & $\underset{1}{\text { Variable }}$ & Description \\
\hline \multirow[t]{4}{*}{ 萑 } & $\mathrm{Z}[*]$ & Depth below the soil surface, in meters. \\
\hline & $\mathrm{W}[*]$ & $\begin{array}{l}\text { Volumetric soil water content, dimension- } \\
\text { less. }\end{array}$ \\
\hline & $\mathbf{P}[*]$ & Soil water-pressure potential, in meters. \\
\hline & & $\begin{array}{l}\text { NOTE: Line } 1 \text { is repeated for as many nodes } \\
\text { as are defined for the soil system. }\end{array}$ \\
\hline
\end{tabular}

${ }^{1}$ The designation $\left[{ }^{*}\right]$ indicates that a variable is a single-column array.

Table 7. Example of the output file containing profiles of volumetric soil water content and soil water-pressure potential

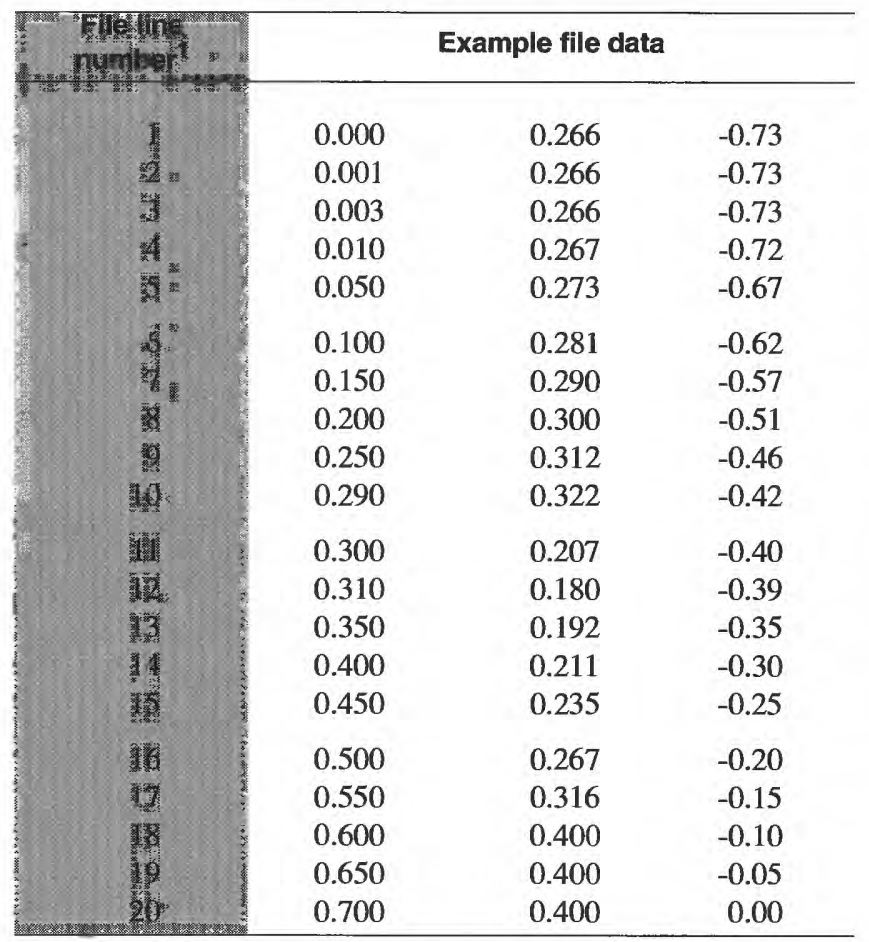

${ }^{1}$ The file line number is not part of the file and is shown only to facilitate comparison between tables 6 and 7 .

Table 8. Description and format of the output file containing daily summaries of water fluxes that is written by the computer program

\begin{tabular}{|c|c|c|}
\hline $\begin{array}{l}\text { Fue the } \\
\text { nurpuers }\end{array}$ & Variable & Description \\
\hline \multirow[t]{4}{*}{ I } & DOYS & Day of year. \\
\hline & DAY_E & $\begin{array}{l}\text { Daily evaporation from the soil, in } \\
\text { millimeters. }\end{array}$ \\
\hline & DAY_T & Daily transpiration, in millimeters. \\
\hline & DAY_ET & $\begin{array}{l}\text { Daily evapotranspiration, in } \\
\text { millimeters. }\end{array}$ \\
\hline
\end{tabular}

Table 8. Description and format of the output file containing daily summaries of water fluxes that is written by the computer program - Continued

\begin{tabular}{|c|c|c|}
\hline 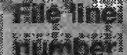 & Variable & Description \\
\hline & DAY_PET & $\begin{array}{l}\text { Daily potential evapotranspiration, } \\
\text { in millimeters }\end{array}$ \\
\hline & DAY_PPT & Daily precipitation, in millimeters \\
\hline & DAY_FLUXEN & $\begin{array}{l}\text { Daily flux of water at the lower } \\
\text { boundary, in millimeters. }\end{array}$ \\
\hline & & $\begin{array}{l}\text { NOTE: Line } 1 \text { is repeated for as } \\
\text { many days as are included } \\
\text { in the simulation period. }\end{array}$ \\
\hline
\end{tabular}

Table 9. Example of the output file containing daily summaries of water fluxes that is written by the computer program

\begin{tabular}{|c|c|c|c|c|c|c|c|}
\hline & & & Exan & le file & ata & & \\
\hline 1 & 282 & 0.28 & 1.30 & 1.58 & 2.76 & 0.00 & 9.14 \\
\hline 2 & 283 & 0.37 & 1.76 & 2.13 & 3.73 & 0.00 & -1.24 \\
\hline 3 & 284 & 0.37 & 1.73 & 2.10 & 3.67 & 0.00 & -2.03 \\
\hline 4 & 285 & 0.42 & 1.98 & 2.40 & 4.21 & 0.00 & -2.36 \\
\hline 3 & 286 & 0.46 & 2.18 & 2.64 & 4.61 & 0.00 & -2.60 \\
\hline (3) & 287 & 0.46 & 2.19 & 2.66 & 4.65 & 0.00 & -2.71 \\
\hline 7 & 288 & 0.23 & 1.09 & 1.32 & 2.32 & 2.17 & -0.66 \\
\hline$\$$ & 289 & 0.49 & 2.31 & 2.80 & 4.90 & 0.00 & -1.31 \\
\hline 9 & 290 & 0.48 & 2.27 & 2.75 & 4.81 & 0.00 & -2.70 \\
\hline 21 & 291 & 0.46 & 2.17 & 2.63 & 4.61 & 0.00 & -2.71 \\
\hline 18 & 292 & 0.45 & 2.13 & 2.59 & 4.53 & 0.00 & -2.60 \\
\hline 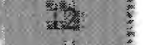 & 293 & 0.42 & 2.00 & 2.42 & 4.24 & 0.00 & -2.49 \\
\hline 13. & 294 & 0.17 & 0.79 & 0.96 & 1.68 & 0.00 & -1.33 \\
\hline 14. & 295 & 0.19 & 0.90 & 1.09 & 1.91 & 0.00 & -0.36 \\
\hline
\end{tabular}

${ }^{1}$ The file line number is not part of the file and is shown only to facilitate comparison between tables 8 and 9 .

\section{Model Verification}

Steady-state evaporation from the surface of a bare soil in the presence of a water table was chosen as a verification problem for the liquid water-flow part of the model. An approximate analytical solution of this problem was adapted from Jury and others (1991).

The system under consideration is a homogeneous soil with a water table at a fixed depth. If a large evaporative demand is imposed on the system and vapor flow in soil is neglected, maximum evaporation is determined by the ability of the unsaturated soil to supply water to the surface. If hydraulic conductivity $\left(k_{l}\right)$ is given by equation 6 , an approximating 
analytical expression for maximum steady evaporation from the soil surface $\left(E_{s m}\right)$ is

$$
E_{s m}=k_{s}\left[\frac{\pi \Psi_{p e}}{-z_{I} m \sin (\pi / m)}\right]^{m},
$$

where

$E_{s m}$ is in meters per second;

$z_{l}$ is depth to the water table, in meters;

$m$ is the exponent of equation $6(m=2+3 / b)$,

dimensionless; and other terms are as

previously defined.

Derivation of equation 20 involves setting soil waterpressure potential $\left(\psi_{p}\right)$ at the soil surface equal to $-\infty$ to facilitate analytical solution and to represent a soil that is subjected to a large evaporative demand.

Because of an approximation that is made in the derivation of equation 20 , it closely approximates $E_{s m}$ only when $E_{s m}$ is much less than $k_{s}$. This presents little problem for the range of $E_{s m}$ that is of interest because maximum evaporation in the field cannot be larger than potential evaporation from the soil surface $\left(E_{s p}\right)$, and $E_{s p}$ is almost always much less than $k_{s}$. Depth to the water table $\left(z_{l}\right)$ was varied between 0.75 and $2.5 \mathrm{~m}$, and equation 20 was used to compute $E_{s m}$ for each depth. The following values for soil physical properties were used in solution of equation 20 :

$$
\begin{aligned}
& k_{s}=1.42 \times 10^{-6} \mathrm{~m} / \mathrm{s} ; \\
& \Psi_{p e}=-0.31 \mathrm{~m} ; \text { and } \\
& m=3.0, \text { which is equivalent to } 2+3 / b \\
& \quad \text { for } b=3, \text { dimensionless. }
\end{aligned}
$$

The soil system described above was simulated using the soil water-balance model. The first step was to devise a network of soil nodes. The first node was at the soil surface, and the model was modified to specify it as a constant potential node. Maximum spacing between the four shallowest nodes was $0.008 \mathrm{~m}$, and depths of the remaining nodes were even multiples of $0.05 \mathrm{~m}$. Second, values for the soil physical properties and initial water content were assigned to each node. Values for $k_{s}, \psi_{p e}$, and $b$ that were used for the simulations were the same as described above for the analytical solution. Additionally, bulk density $\left(\rho_{b}\right)$ was set at $1,200 \mathrm{~kg} / \mathrm{m}^{3}$, although the exact value of this parameter was unimportant for simulating steadystate evaporation. Precipitation inputs, plant uptake of soil water, and vapor flow were not included in the simulations. Finally, two different types of simulations were made. In the first type, depth to the water table was held constant at $1 \mathrm{~m}, \psi_{p}$ at the soil surface was varied between -1.5 and $-500 \mathrm{~m}$, and simulations of the water balance were performed for each value of $\psi_{p}$ at the soil surface until the system reached steady state. The simulated flux of liquid water to the surface soil node from below was interpreted as being equivalent to $E_{S}$, and steady state was assumed when simulated $E_{s}$ changed by less than $0.01 \mathrm{~mm} / \mathrm{d}$ for 10 consecutive days. In the second type of simulations, $\psi_{p}$ at the soil surface node was held constant at $-500 \mathrm{~m}$, depth to the water table was varied from 0.75 to $2.5 \mathrm{~m}$, and simulations of the water balance were performed for each depth to the water table until the system reached steady state. The maximum steady flux of water to the soil surface node was interpreted as being equivalent to simulated $E_{s m}$ for each water-table depth. Simulated $E_{s m}$ then was compared with $E_{s m}$ computed using equation 20 to verify that the model is coded correctly. Comparison of simulated $E_{s m}$ and computed $E_{s m}$ was valid, despite the fact different values for $\psi_{p}$ at the soil surface were used to arrive at each of them. The reason for this validity is, as stated by Gardner (1958), $E_{S}$ becomes insensitive to $\psi_{p}$ at the surface when $\psi_{p}$ drops below about $-10 \mathrm{~m}$.

Simulated $E_{s}$ varied with the value of $\psi_{p}$ that was assigned to the soil surface node (fig. 2) and also according to the scheme used to compute internodal hydraulic conductivity $\left(\bar{k}_{l}\right)$. When $\bar{k}_{l}$ was computed using the geometric averaging scheme, simulated $E_{s}$ first increased with decreasing $\psi_{p}$ and then reached a stable value for $\psi_{p}$ equal to about $-10 \mathrm{~m}$ or less. When $\bar{k}_{l}$ was computed using the arithmetic averaging scheme, simulated $E_{S}$ did not reach a stable value, but continued to increase slightly with decreasing $\psi_{p}$. Simulated $E_{s}$ at each value of $\psi_{p}$ was smallest when the geometric averaging scheme was used. The reason for the differing result was that computed $\vec{k}_{l}$ in the dryer soil near the surface was substantially less when the geometric scheme was used.

The model conserved mass during the simulations. The mass balance was checked using the relation: flux in - flux out $=$ change in water storage . For example, when depth to the water table was $1.0 \mathrm{~m}$ and a steady-state condition was attained, the difference between simulated flux into the soil from the 


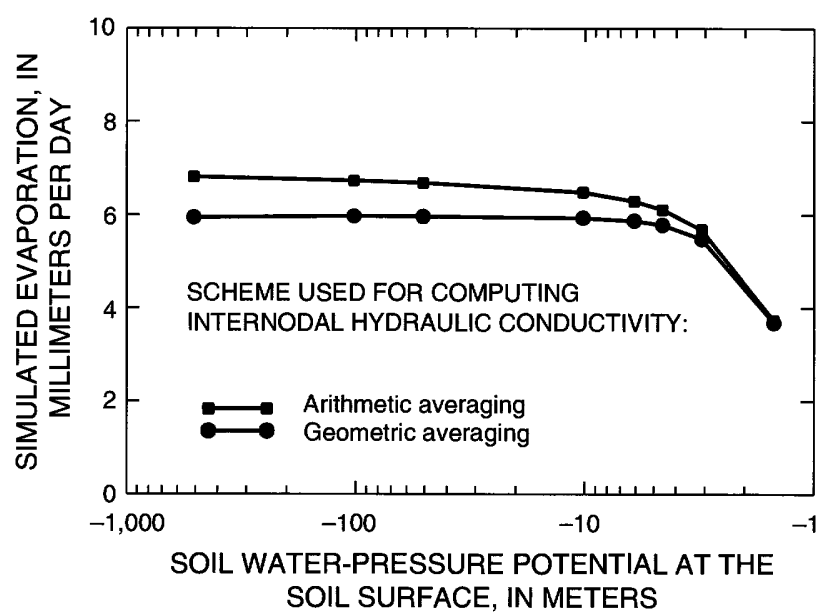

Figure 2. Simulated daily evaporation from the surface of a bare, homogeneous soil, with the water table at a depth of 1.0 meter, as it varied with soil water-pressure potential at the soil surface.

water table and simulated $E_{S}$ was less than $0.001 \mathrm{~mm} / \mathrm{d}$, while the change in soil water storage also was less than $0.001 \mathrm{~mm} / \mathrm{d}$. The check demonstrated the model did not create or destroy water during the simulations.

Simulated $E_{s m}$ and $E_{s m}$ computed using equation 20 agreed closely when depth to the water table was $1 \mathrm{~m}$ or more and the sign and magnitude of the difference between simulated $E_{s m}$ and computed $E_{s m}$ depended on the averaging scheme used to compute $\bar{k}_{l}$ (fig. 3). $E_{s m}$ simulated using the geometric averaging scheme for $\bar{k}_{l}$ was consistently less than $E_{s m}$ simulated using the arithmetic averaging scheme. At a water-table depth of $0.75 \mathrm{~m}$, simulated $E_{s m}$ was

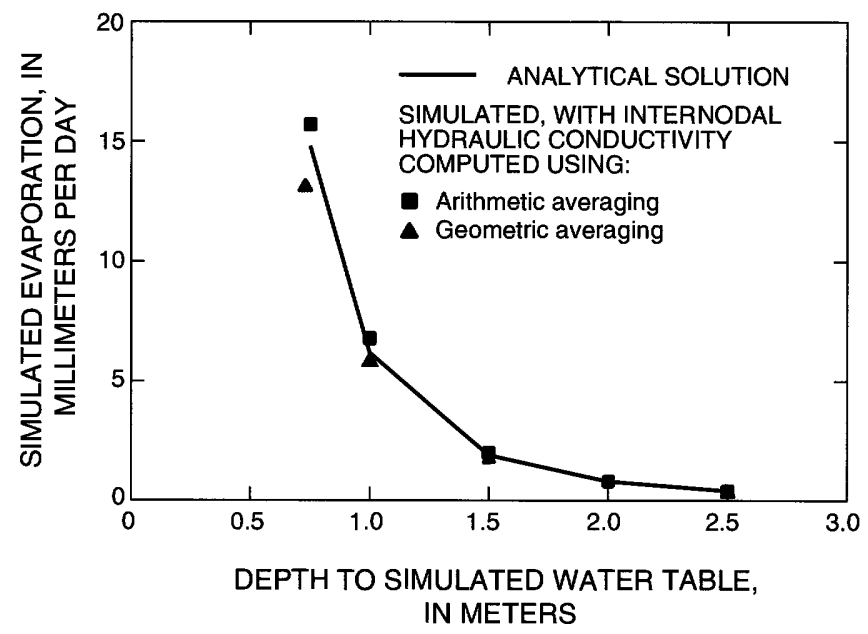

Figure 3. Simulated daily evaporation from the surface of a bare, homogeneous soil and daily evaporation computed using an approximate analytical expression, as they varied with depth to the water table.
7 percent greater than $E_{s m}$ computed using equation 20 when arithmetic averaging was used to compute $\bar{k}_{l}$. Simulated $E_{s m}$ was 13 percent less than computed $E_{s m}$ when geometric averaging was used to compute $\bar{k}_{l}$. The approximating analytical solution is less reliable for shallow water-table depths because computed $E_{s m}$ becomes larger with respect to $k_{s}$, which make less realistic an assumption used to derive equation 20 , and this could have been part of the reason for the greater disagreement. However, the disagreement between $E_{s m}$ simulated using the geometric and arithmetic schemes, which are arbitrary schemes, was substantial, indicating some of the difficulty in simulating unsaturated flow phenomena. Results of the verification exercise indicate that the governing and auxiliary equations for liquid water flow were coded correctly in the model source code.

\section{CHARACTERIZATION OF THE SOIL-PLANT SYSTEM}

Simulations of the soil water balance were performed using soil and plant properties established from field and laboratory studies. The studies were conducted either at the study site or by using samples collected from the site. Additionally, field measurements of evapotranspiration were used to calibrate the Priestley-Taylor equation for predicting evapotranspiration at the study site.

\section{Measurement and Estimation of Soil Physical Properties}

Soil physical properties used for simulations of the soil water balance were measured or estimated for the field site. Soil bulk density, saturated hydraulic conductivity, shape factor for the soil watercharacteristic function, and particle-size distribution were determined either in the field or by laboratory analysis of soil samples. Air-entry soil water-pressure potential was initially estimated using an empirical relation from the literature and relevant data about the soil at the site. Initial values for this last parameter were adjusted during calibration of the model for the study site.

Physical, chemical, and biological properties of field soils vary with depth. Examination of the soil profile in three different pits revealed soil-depth 
intervals in which properties, such as color, texture, structure, and appearance of roots, were relatively uniform. Variation of soil physical properties with depth was described according to these soil-depth intervals (table 10).

Table 10. Description of soil for discrete depth intervals

\begin{tabular}{cc}
\hline $\begin{array}{c}\text { Soil-depth } \\
\text { interval } \\
\text { (meters) }\end{array}$ & Description \\
\hline 0.0 to 0.30 & $\begin{array}{c}\text { Dark gray, fine sand; single grained; many fine } \\
\text { and coarse roots. }\end{array}$ \\
0.31 to 0.87 & $\begin{array}{c}\text { Light gray, fine sand; single grained; few coarse } \\
\text { roots upper third; no roots lower two-thirds. }\end{array}$ \\
0.88 to 1.36 & $\begin{array}{c}\text { Dark brown grading to light brown, loamy sand; } \\
\text { weak blocky structure; mottled appearance. }\end{array}$ \\
\hline
\end{tabular}

Soil Bulk Density.-Bulk density was determined from soil cores (length, $15.2 \mathrm{~cm}$; diameter, $4.8 \mathrm{~cm}$ ) extracted using a slide-hammer sampler. Soil from the cores was oven-dried at $105^{\circ} \mathrm{C}$ for 24 to 36 hours and then weighed to determine dry soil mass per unit volume $\left(\mathrm{kg} / \mathrm{m}^{3}\right)$. Cores were taken from the soil surface to a depth of $1.36 \mathrm{~m}$ at three randomly selected sites near the center of the study area. Bulk density was averaged by soil-depth interval (table 11).

Table 11. Bulk density and saturated hydraulic conductivity by soil-depth interval

[m, meter; $\mathrm{kg} / \mathrm{m}^{3}$, kilogram per cubic meter; $\mathrm{m} / \mathrm{s}$, meters per second; $k_{s}$, saturated hydraulic conductivity]

\begin{tabular}{ccc}
\hline $\begin{array}{c}\text { Soil-depth } \\
\text { interval } \\
(\mathbf{m})\end{array}$ & $\begin{array}{c}\text { Bulk density } \\
\left(\mathbf{k g} / \mathbf{m}^{\mathbf{3}}\right)\end{array}$ & $\begin{array}{c}\mathbf{1}^{\mathbf{1}} \boldsymbol{k}_{\mathbf{s}} \\
\left(\mathbf{\times 1 0 ^ { 5 }} \mathbf{~ m} / \mathbf{s}\right)\end{array}$ \\
\hline 0.0 to 0.30 & $1,380(130 ; 6)$ & $1.97(0.75 ; 6)$ \\
0.31 to 0.87 & $1,590(20 ; 9)$ & $9.52(1.10 ; 6)$ \\
0.88 to 1.36 & $1,730(30 ; 3)$ & $2.25(0.58 ; 6)$ \\
\hline
\end{tabular}

${ }^{1}$ Values reported are means; first number in the parentheses is standard deviation and second number is sample number.

Saturated Hydraulic Conductivity.-Saturated hydraulic conductivity $\left(k_{s}\right)$ of soil above the water table was estimated using measurements made with a Guelph permeameter. The Guelph permeameter can maintain a specified ponding depth in a small-diameter well and can be used to determine the rate of water delivery necessary to maintain that depth of water (Reynolds and others, 1983). Saturated hydraulic conductivity then can be estimated based on the rate of water delivery, ponding depth, and radius of the well
(Reynolds and Elrick, 1985; Elrick and Reynolds, 1992).

Field procedures that were used to collect data with the permeameter for computing $k_{s}$ were as follows: (1) a 4-cm diameter well was augured to a desired depth in unsaturated soil, (2) the permeameter was used to introduce water to the well and to maintain a constant ponding depth, and (3) the rate of water delivery to the well was monitored until it became steady and the steady value then was recorded for use in the computations. The steady rate of water delivery to each well hole was determined for ponding depths of 2.5 and $5.0 \mathrm{~cm}$. Field measurements were made at six randomly selected sites near the center of the study area. Measurements at each site were made in each of three wells that were augured to nominal depths of $0.15,0.45$, and $0.95 \mathrm{~m}$. Well depths were selected so that flow measurements could be made in each of the three soil-depth intervals.

Permeameter data were analyzed to estimate $k_{s}$ for each soil-depth interval using the procedures suggested by Elrick and Reynolds (1992). Theory of saturated and unsaturated flow in soil was used by Reynolds and Elrick (1985) to derive an equation for steady flow from a well above the water table. Flow from the well $(Q)$ is given approximately by the equation

$$
Q=k_{s} 2 \pi H^{2} / c+k_{s} \pi a^{2}+\Phi_{m} 2 \pi H / c,
$$

where

$Q$ is flow, in cubic meters per second;

$k_{s}$ is saturated hydraulic conductivity, in meters per second;

$H$ is ponding depth in the well, in meters;

$c$ is a factor accounting for the shape of the flow system, dimensionless;

$a$ is well radius, in meters; and

$\Phi_{m}$ is matric flux potential, in square meters per second.

The first term on the right side of equation 21 accounts for flow from the well that is driven by hydrostatic pressure gradients. The second term accounts for flow due to gravity. The third term accounts for flow caused by gradients in $\psi_{p}$ in the unsaturated part of the flow system. The shape factor $(c)$, which is dependent primarily on the ratio $H / a$, and to a lesser extent on soil texture, structure and water content, is intended to predict the shape of the nearly saturated soil volume around the well. Shape factors used in this study were 
read from a graph of $c$ as a function of $H / a$ that was included with instructions for the Guelph permeameter. Matric flux potential $\left(\Phi_{m}\right)$ is suggested by Gardner (1958) to aid in solving problems of water flow in unsaturated soil and is included in equation 21 as part of the term that accounts for flow in the unsaturated part of the flow system.

Estimates of $k_{s}$ obtained with the Guelph permeameter ranged within 1 order of magnitude among the three soil-depth intervals (table 11). Estimates of $k_{s}$ for the uppermost and lowermost soildepth intervals were almost the same. Estimated $k_{s}$ for the middle soil-depth interval was about 4 times as great as estimates of $k_{s}$ for the other two soil-depth intervals.

Estimates of $k_{s}$ that are obtained using the permeameter are only approximate. Two reasons for this are: first, the soil near the well does not become fully saturated with water during discharge from the well due to the presence of trapped air. As a result, $k_{s}$ estimated from permeameter data is generally less than hydraulic conductivity of fully saturated soil. Second, flow from the well is composed of an unknown mix of vertical and horizontal flow components, and the value of $k_{s}$ obtained for anisotropic soils will not represent vertical $k_{s}$ alone. Instead, $k_{s}$ estimated from the permeameter data will partly reflect vertical $k_{s}$ and it will partly reflect $k_{s}$ for other flow directions.

Distribution of the Soil Particle Size.-Information about the distribution of soil particle size is useful for describing soil texture and for estimating some soil physical properties. A single sample was collected from each of the three soil-depth intervals for particlesize analysis. The samples were analyzed to determine the mass fractions of sand, silt, and clay. The following particle diameter classes were used to differentiate between sand, silt, and clay:

\begin{tabular}{llll}
\hline clay & & $d$ & $<0.004 \mathrm{~mm}$ \\
silt & 0.004 & $<=d$ & $<0.062 \mathrm{~mm}$ \\
sand & 0.062 & $<=d$ & $<2.000 \mathrm{~mm}$ \\
\hline
\end{tabular}

where

$d$ is particle diameter, in millimeters.

The sand fraction was separated by dry sieving. The clay fraction was determined by the pipet technique (Gee and Bauder, 1986), and the silt fraction was computed from the total mineral mass of the sample minus the combined masses of sand and clay. Results of the particle-size analysis are given in table 12 .

Table 12. Mass fraction of sand, silt, and clay and estimated air-entry soil water-pressure potential by soil-depth interval [ $\Psi_{p e}$, air-entry soil water-pressure potential; $\mathrm{m}$, meter]

\begin{tabular}{ccccc}
\hline $\begin{array}{c}\text { Soil-depth } \\
\text { interval } \\
\text { (m) }\end{array}$ & $\begin{array}{c}\text { Sand } \\
\text { fraction }\end{array}$ & $\begin{array}{c}\text { Silt } \\
\text { fraction }\end{array}$ & $\begin{array}{c}\text { Clay } \\
\text { fraction }\end{array}$ & $\begin{array}{c}{ }^{1} \Psi_{\text {pe }} \\
\text { (m) }\end{array}$ \\
\hline 0.0 to 0.30 & 0.95 & 0.04 & $<0.01$ & -0.06 \\
0.31 to 0.87 & 0.96 & 0.04 & $<0.01$ & -0.06 \\
0.88 to 1.36 & 0.90 & 0.07 & 0.03 & -0.09 \\
\hline
\end{tabular}

${ }^{1}$ Air-entry soil water-pressure potential was estimated from bulk density and particle-size distribution using equation 5.12 of Campbell (1985).

\section{Air-Entry Soil Water-Pressure Potential.-} Estimates of air-entry soil water-pressure potential $\left(\psi_{p e}\right)$ were computed for each soil-depth interval using an empirical equation proposed by Campbell (1985, eq. 5.12). The equation is

$$
\psi_{p e}=-0.05\left(\rho_{b} / 1,300\right)^{0.67 b} /\left(d_{g}\right)^{0.5},
$$

where

$d_{g}$ is geometric mean particle diameter, in millimeters; and other terms are as previously defined.

Geometric mean particle diameter can be computed using the equation

$$
d_{g}=\exp \left[\Sigma M_{i} \ln \left(\bar{d}_{i}\right)\right]
$$

where the summation is carried out for the sand, silt, and clay particle-size classes ( $i=1,2$, or 3 );

$M_{i}$ is the mass fraction in the sand, silt, or clay particle-size class, dimensionless; and

$\bar{d}_{i}$ is the midpoint diameter for each particle-size class, in millimeters $\left(\bar{d}_{\text {sand }}=\right.$ $1.031, \bar{d}_{\text {silt }}=0.033$, and $\bar{d}_{\text {clay }}=0.002$ ).

Values of $\psi_{p e}$ for each soil-depth interval that were estimated using equation 22 are given in table 12.

Shape Factor for the Soil Water-Characteristic Function.-The shape factor ( $b$, eqs. 3 and 6 ) was estimated based on results of soil water-extraction experiments. The experiments were conducted using three intact soil cores of known volume $\left(6.8 \times 10^{-5} \mathrm{~m}^{3}\right)$ that were collected from each soil-depth interval. The 
samples were placed in a pressure cell that is generally called a Tempe cell (Klute, 1986). The Tempe cell consisted of a sample retainer, a porous ceramic plate, and a body that clamped the sample retainer to the ceramic plate and directed water that flowed from the sample when pressure was applied. During operation, the ceramic plate was saturated with water and a wetted sample was clamped to the plate. Compressed air then was used to apply pressure $\left(P_{a}\right)$, in kilopascals, to the sample to force some of the water out of the sample, through the ceramic plate, and out of the cell. Selected and progressively increasing values of $P_{a}$ in the range of 9.7 to $100 \mathrm{kPa}$ were applied. The degree of saturation $(s)$, which is defined as $s=\theta / \theta_{s}$, was computed for each value of $P_{a}$ by monitoring the mass of the cell. Analysis for $b$ then was performed using the soil water-retention equation for unsaturated soil

$$
s=\left(P_{e} / P_{a}\right)^{1 / b},
$$

where

$P_{e}$ is bubbling pressure of the soil sample, in kilopascals; and other terms are as previously defined.

Equation 23 is similar to the soil water-characteristic equation (eq. 3), except it is written in terms of the positive pressures $P_{e}$ and $P_{a}$. Equation 23 is useful for determining the parameter $b$ in equation 3 because, when the soil water is in thermodynamic equilibrium with applied pressure, the value of $\psi_{p}$ in the soil sample can be inferred from $P_{a}$ using the relation: $\psi_{p}=-\left(P_{a} 10^{3}\right) /\left(\rho_{w} g\right)$, where all terms have been defined previously. In a similar manner, the value of $\psi_{p e}$ for a soil sample is related to $P_{e}$ by the equation: $\psi_{p e}=-\left(P_{e} 10^{3}\right) /\left(\rho_{w} g\right)$. In the analysis performed for this study, $P_{e}$ for each soil-depth interval was computed from the value of $\psi_{p e}$ estimated using equation 22, $s$ and $P_{a}$ were obtained from the soil water-extraction experiments, and a nonlinear leastsquares procedure (Marquardt, 1963) was used to solve equation 23 for $b$.

Generally, $b$ reflects the width of the soil poresize distribution for mineral soils. The value of $b$ generally is smallest for sands, which have a relatively narrow range of pore sizes, and it is largest for clays, which have a relatively wide range of pore sizes. This general model was consistent with the shape factors and textural data for the two lowermost soil-depth intervals (fig. 4). Particle-size analysis indicated a larger clay content for the lowermost depth interval than for the second lowermost interval (table 12), and $b$ also was greatest for the lowermost depth interval. The shape factor for the uppermost depth interval did not follow the general model described above.

Particle-size analysis indicated similar percentages of sand, silt, and clay for the two uppermost depth intervals (table 12); however, $b$ for the uppermost
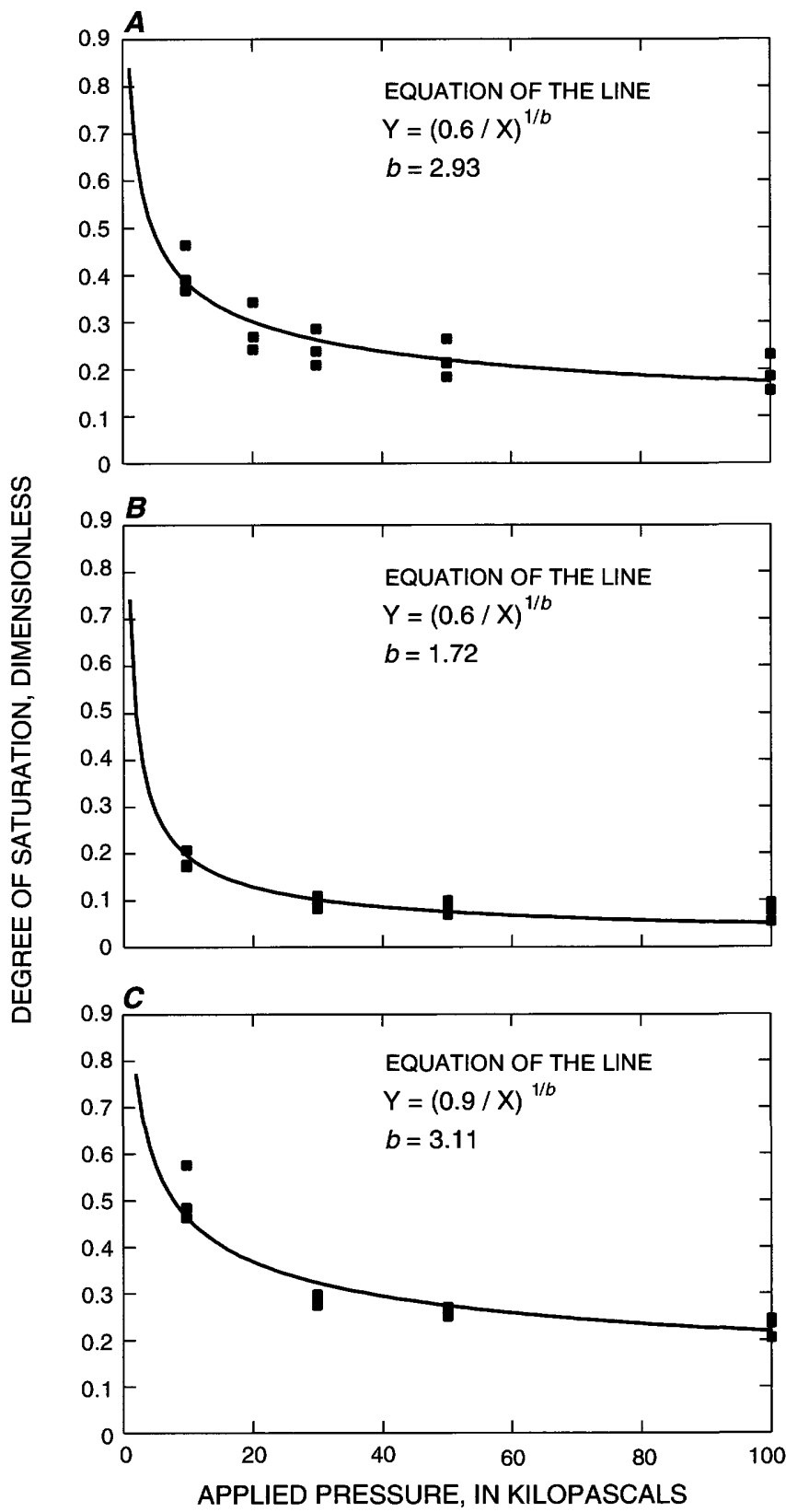

Figure 4. Relation between degree of soil saturation and applied pressure during water extraction from samples collected from three soil-depth intervals. The depth intervals were: $(A) 0.0$ to 0.30 meter, $(B) 0.31$ to 0.87 meter, and $(C) 0.88$ to 1.36 meters. 
depth interval was substantially greater than was $b$ for the second uppermost depth interval. One possible reason for the difference in $b$ between the two uppermost depth intervals was that the uppermost depth interval contained a large amount of roots and other organic matter, and that matter probably affected the water-retention characteristics of the soil. Very little root mass and organic matter were apparent in the second uppermost depth interval.

\section{Measurement and Estimation of Site Vegetative Characteristics}

The simplified treatment of vegetation in the soil water-balance model necessitated estimates of only two vegetative characteristics. These characteristics were vertical distribution of relative root activity $\left(R_{a}^{\prime}\right)$ and fraction of daily incoming shortwave radiation intercepted by the plant canopy. Vertical distribution of $R_{a}^{\prime}$ was estimated, first, by examining the soil and estimating depth of the root zone and, second, by assuming a profile of $R_{a}^{\prime}$ within the root zone. The soil profile in three soil pits was examined during spring and summer 1992. Roots were essentially confined to the uppermost soil-depth interval (table 10); therefore, the root zone was defined as that depth interval for the water-balance simulations.

Root activity data were not available for the plant species at the field site. As a first approximation, it was assumed that $R_{a}^{\prime}$ was constant with depth within the root zone, and simulations of the soil water balance were conducted using that $R_{a}^{\prime}$ profile (fig. 5). The sensitivity of the simulations to the profile of $R_{a}^{\prime}$ then was examined by comparing simulation results obtained using constant $R_{a}^{\prime}$ to simulation results obtained using a $R_{a}^{\prime}$ that decreased exponentially with depth in the root zone. The effect of varying the $R_{a}^{\prime}$ profiles on simulated soil water content is discussed in the section "Simulation of the Soil Water Balance."

Radiation Interception by the Plant Canopy.-The fraction of daily incoming shortwave radiation intercepted by the plant canopy ( $\kappa$ ) was computed from radiation measurements made using tube solarimeters. The tube solarimeters consisted of a long $(86-\mathrm{cm})$, narrow $(2.2-\mathrm{cm})$ sensing element inside a borosilicate glass tube. The element was constructed with alternating, equal-sized black and white areas on the upper surface in which a copper-constantan thermopile was imbedded. When irradiated, the

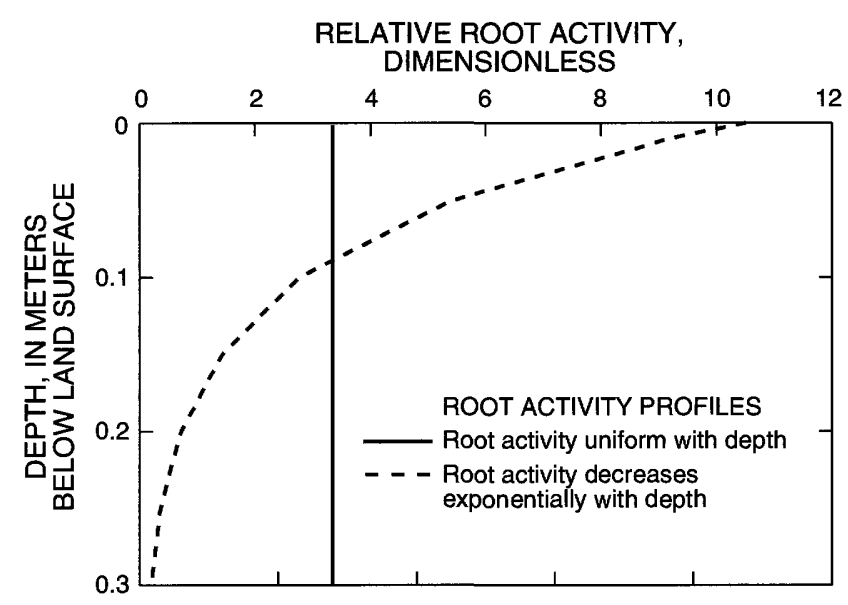

Figure 5. Profiles of relative root activity used for simulations of the soil water balance.

difference in temperature between the white and black areas produced a small voltage from the thermopile. Thermopile voltage then was related to incident radiation, in watts per square meter, by use of a calibration factor. The sensing element was built long and narrow so it could be used to obtain a spatially averaged value for irradiance beneath a plant canopy. Incoming shortwave radiation was measured using two solarimeters. One solarimeter was mounted above the canopy and the other was placed beneath the canopy. The fraction of shortwave radiation intercepted by the plant canopy was computed using the equation $\kappa=1-I / I_{0}$, where $I$ is shortwave irradiance measured beneath the canopy, in watts per square meter, and $I_{0}$ is shortwave irradiance measured above the canopy, in watts per square meter.

Three measurement stations were established to represent the range of canopy density at the field site. Irradiance measurements were made for periods of 24 hours or more at each station during 1992, and $\kappa$ was computed based on total daily irradiance. Measurements were made at each station once during each of the dry-season months of January, February, and April and then were repeated during the wet-season month of October. Values of $\kappa$ ranged from 0.88 to 96 during the dry season and from 0.85 to 0.93 during the wet season. Because the measurements were repeated at each station, analysis of meaningfully paired observations (Steele and Torrie, 1980, p. 102) was used to assess whether $\kappa$ varied between the dry and wet seasons. The analysis did not indicate a significant effect of season on $\kappa(P>0.05)$, and the dry- and wet-season results were pooled to yield a single mean (0.9). 


\section{Calibration of the Priestley-Taylor Equation}

Field studies were made to calibrate the Priestley-Taylor equation for simulating evapotranspiration $(E)$. The approach taken to do this was, first, to determine $E, R_{n}, G, S, L$, and $\gamma$ using field measurement techniques and, second, to use the field data to solve the Priestley-Taylor equation for $\alpha$ using leastsquares techniques. The value of $\alpha$ selected by this approach was supplied to the model as the userdefined parameter $\alpha_{l}$ during simulations to compute $E$ with the Priestley-Taylor equation (eq. 19). Hourly and daily $E$ were computed at the site using the technique of eddy correlation (Swinbank, 1951). Eddy correlation measurements were made about once a month from June 1991 to September 1992 for rainless periods of 24 hours or longer. Eddy correlation measurements were constrained to rainless periods because the eddy correlation instruments were damaged if they were wetted. Measurements needed to compute $R_{n}, G, S, L$, and $\gamma$ were made in conjunction with eddy correlation measurements. Additional detail concerning instrumentation, sampling, and computation techniques that were used to determine $E$, $R_{n}, G, S, L$, and $\gamma$ are given by Bidlake and Boetcher (in press).

Simple linear-regression analysis was used to regress the base term of the Priestley-Taylor equation, where the base term is $S\left(R_{n}-G\right) /\left[\rho_{w} L(S+\gamma)\right]$, on $E$ computed from eddy correlation measurements. The intercept of the regression equation was constrained to the origin, and $\alpha$ was the slope of the regression equation. Analyses were performed for hourly and daily time periods.

Analysis of hourly data collected during nighttime did not indicate a significant relation between the base term of the Priestley-Taylor equation and $E$ as computed from eddy correlation measurements. Eddy correlation measurements indicated that nighttime $E$ was small. Nighttime $E$, computed from eddy correlation measurements, averaged $-0.00021 \mathrm{~mm} / \mathrm{h}$, whereas hourly daytime $E$ averaged $0.23 \mathrm{~mm} / \mathrm{h}$. As a result, nighttime $E$ was neglected and the calibrations were based on daytime periods only. Regression through the origin indicated that $\alpha$ was $0.72(n=186)$ for daytime hourly periods and 0.73 $(n=16)$ for daytime daily periods.

Performance of the calibrated Priestley-Taylor equation for predicting $E$ under rainless conditions at the study site was evaluated using the same eddy correlation measurements that were used in the calibrations. Computed values of $\alpha$ were used with the Priestley-Taylor equation to predict $E$ for daily and hourly periods, and the result was regressed on $E$ computed from eddy correlation measurements. The intercept was not constrained to the origin. Predicted $E$ was strongly correlated with $E$ computed from eddy correlation for both hourly and daily periods (figs. 6 , 7) Only 6 percent of the variation about the mean of hourly $E$ computed from eddy correlation measure-

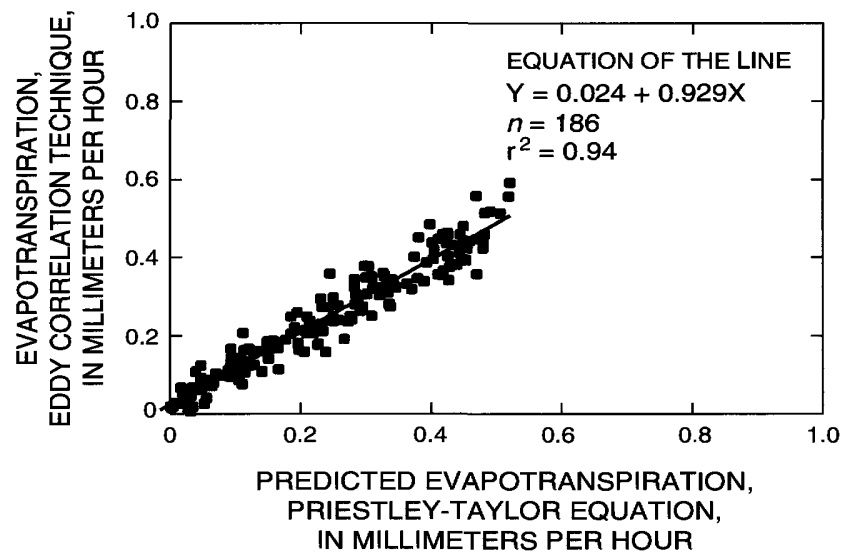

Figure 6. Relation between hourly evapotranspiration computed by the eddy correlation technique and hourly evapotranspiration estimated using the Priestley-Taylor equation.

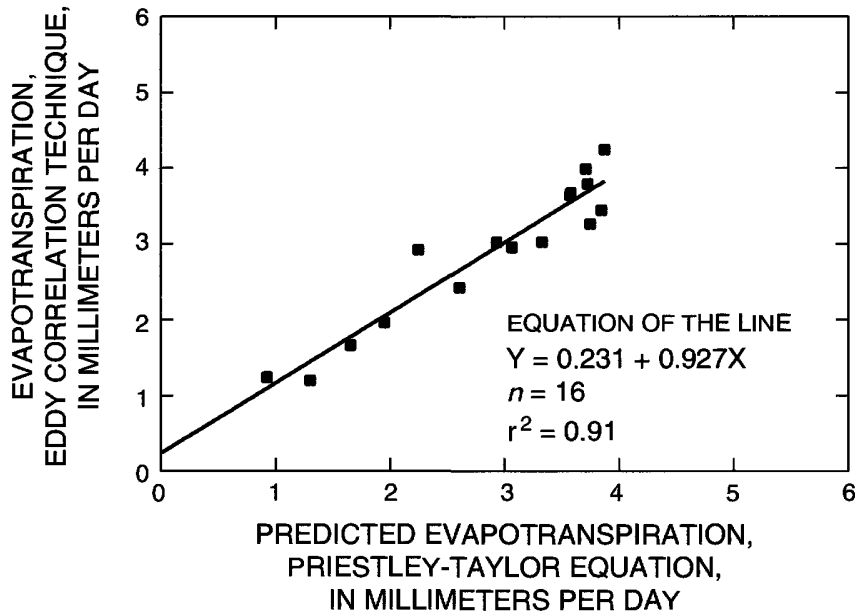

Figure 7. Relation between daily evapotranspiration computed by the eddy correlation technique and daily evapotranspiration estimated using the Priestley-Taylor equation. 
ments was unexplained by $E$ predicted using the Priestley-Taylor equation (fig. 6). Nine percent of the variation of daily $E$ was unexplained by the PriestleyTaylor equation (fig. 7). Scatter about the regression lines did not appear to vary in any systematic manner. However, predicted $E$ was biased, both for hourly and daily periods because the regression analysis to compute $\alpha$ during the calibrations was forced through the origin. The intercept of the relation for hourly data was significantly greater than $0(P<0.05)$ and the slope was significantly less than $1(P<0.05)$. For daily data, the intercept was significantly greater than $0(P<0.05)$, but the slope was not significantly different from 1 $(P>0.05)$. A regression intercept larger than 0 indicates that average measured $E$ was underpredicted by the calibrated Priestley-Taylor equation. A slope of less than 1 indicates that variation in measured $E$ from the mean was underpredicted by the calibrated Priestley-Taylor equation.

Hourly and daily values of $\alpha$ obtained from the least-squares calibration using eddy correlation data for rainless days were substantially less than 1.0, which is the theoretical lower limit for $\alpha$ given by Priestley and Taylor (1972) for wet surfaces under conditions of minimal advection. Possible explanations for this observation include: (1) soil and plant surfaces at the site were generally unable to supply water at a rate sufficient to meet evaporative demand and, therefore, $E$ was water limited; and (2) data used for the calibrations was substantially biased such that computed $\alpha$ was less than actual $\alpha$ by about 0.28 . This last explanation is unlikely because systematic errors in computed $E$ and the base term of the Priestley-Taylor equation needed to explain a bias in $\alpha$ of 0.28 are possible, but not likely.

An additional investigation was made to examine the explanation that $\alpha$ did not approach 1.0 because $E$ was water limited on rainless days. The approach taken was to contrast computed $\alpha$ for rainless days with $\alpha$ computed when plant and soil surfaces were wet to determine the effect of surface wetness on the computed $\alpha$. To accomplish this, hourly $E$ determined during and immediately after rain, when vegetation at the study site was wet, was regressed on the base term of the Priestley-Taylor equation. The regression was forced through the origin, and $\alpha$ was computed as the slope of the regression. The energy-balance Bowen ratio (EBBR) technique (Tanner, 1960) was used to make the measurements needed to compute $E$ during and within
1 hour after 10 separate storms that occurred during the period of August 13, 1991, through October 13, 1992 (Bidlake and Boetcher, in press). The value of $\alpha$ computed in this manner was $1.06(n=36)$, which was consistent with theoretical limits for $\alpha$ for wet surfaces that were suggested by Priestley and Taylor (1972). Based on these results, the probable reason that hourly and daily $\alpha$ obtained from the least-squares calibration were substantially less than 1.0 for rainless days was that $E$ was water limited on rainless days.

The value of 1.06 is a relatively small value for $\alpha$ for wet surfaces when it is compared to values of about 1.26, as discussed above, that have been reported for short, well-watered vegetation and open water. Probably, evaporative demand was diminished at the field site during and after rain because moisture entrained in the atmosphere as a result of the rainfall reduced the atmospheric vapor-pressure deficit. As a result, $\alpha$ computed from measurements during and after rain was relatively small. According to theory (Priestley and Taylor, 1972), $\alpha$ for a wet surface should approach 1.0 when the atmosphere near the surface approaches saturation and vapor-pressure deficit approaches 0 .

The premise of one hypothesis that has been used to explain water-limited $E$ is that some rooted plants develop physiological moisture stress when soil moisture becomes depleted, and they respond to this stress by reducing evaporative loss. Mechanisms for reducing water loss include increased stomatal resistance to vapor flow (Jarvis, 1976) and leaf shedding (Campbell, 1977). Although detailed investigation of physiological and morphological responses of the plants to soil moisture deficits was beyond the scope of this study, a simple analysis was made to determine if variations in $\alpha$ for rainless days were statistically related to variations in volumetric soil water content $(\theta)$ near the soil surface. A daily value for $\alpha$ was computed for rainless days by dividing daily values for $E$, computed using eddy correlation, by the daily values of the base term of the Priestley-Taylor equation. The analysis did not indicate a relation existed between $\alpha$ and $\theta$ in the uppermost $0.15 \mathrm{~m}$ of soil (fig. 8). Soil water content was smallest during late winter and spring 1992, and it was largest during the summers of 1991 and 1992. The two largest values of $\alpha$, which were larger than 1.0 , occurred during fall 1991 when soil water content was near the middle of the range of measured $\theta$. 


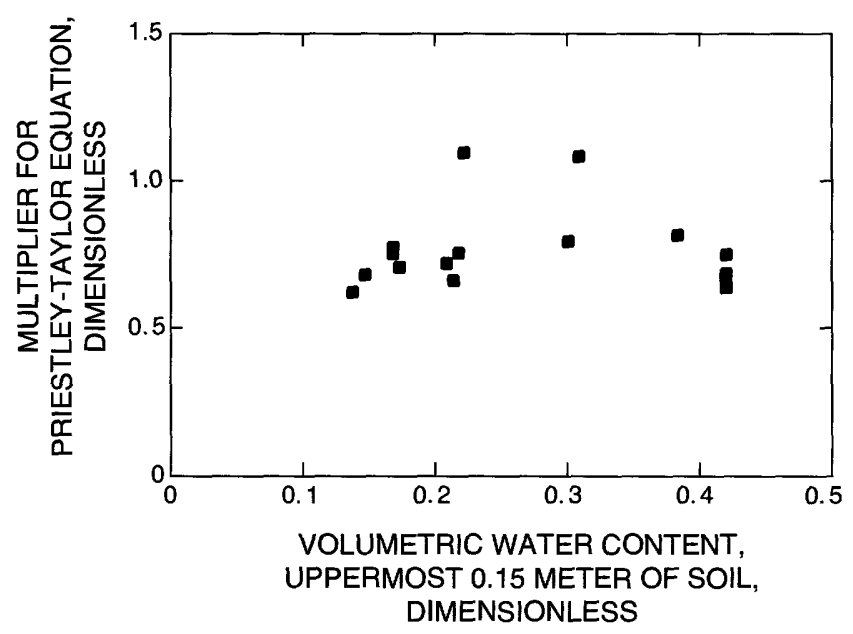

Figure 8. Multiplier for the Priestley-Taylor equation on a daily basis as it varied with volumetric soil water content in the uppermost 0.15 meter of soil.

\section{Calibration of the Soil Water-Balance Model}

Many of the soil and plant properties needed to simulate the soil water balance of the study site were only approximately known. Reasons for this were, first, some of the measurement and estimation techniques that were used yield only approximate results. For example, estimates of air-entry soil waterpressure potential $\left(\psi_{p e}\right)$ developed using equation 22 were probably only accurate to within an order of magnitude. Second, soil and plant properties typically exhibit considerable spatial variation, and large numbers of samples must be taken to provide representative property values. The limited numbers of measurement replications that were made in this study, usually three, were sufficient to confirm that soil and plant properties varied; however, the replications probably were not numerous enough to rigorously define representative values for all of the properties needed for the simulations. Because of uncertainty about the soil properties, a simple parameter optimization procedure was used to calibrate the model for the study site.

In this procedure, $\psi_{p e}$ computed for each soildepth interval with equation 22 was systematically varied using the Newton-Raphson technique (James and others, 1985) to obtain the best possible match between profiles of simulated and measured volumetric soil water content $(\theta)$. The approach taken was to set up the model using initial values for soil and plant properties and $\theta$ that were obtained from measurement. The soil water balance then was simulated for a period of about 2 weeks. After the simulation, the sum of squares error (SSE) for each depth interval was computed by summing the squared difference between final simulated and final measured $\theta$ for all nodes within the depth interval. The $\psi_{p e}$ for each soil-depth interval then was reduced by 0.001 , the simulations were repeated, and the change in SSE was computed for each depth interval. The change in SSE was divided by the change in $\psi_{p e}(-0.001)$ to yield a numerical derivative of SSE with respect to $\psi_{p e}$ for each depth interval. The initial values of SSE and $\psi_{p e}$ and the numerical derivative then were used to produce a new estimate of $\psi_{p e}$ for each depth interval using the Newton-Raphson technique. The new estimates of $\psi_{p e}$ then were used to compute new values of SSE for each depth interval, and the process described above was repeated. This iteration was continued until the SSE for each soil-depth interval became no smaller from one iteration to the next. The final $\psi_{p e}$ for each soil-depth interval was taken as the result of the calibration.

Profiles of initial and final $\theta$ were developed using field measurements. Gravimetric techniques were used to measure average $\theta$ in the uppermost $0.15 \mathrm{~m}$ of soil. The neutron-scattering technique (Gardner, 1986) was used to measure $\theta$ starting at a depth of $0.3 \mathrm{~m}$ and continuing in $0.15-\mathrm{m}$ increments to a depth of $1.6 \mathrm{~m}$. A continuous profile of $\theta$ was constructed by interpolating between the measured values. Descriptions of equipment, field procedures, and analyses of gravimetric and neutron-scattering data are given by Bidlake and Boetcher (in press).

The model was set up for the simulations using soil and plant properties described previously in this report. Maximum node spacing was $0.05 \mathrm{~m}$, and node spacing was reduced to $0.01 \mathrm{~m}$ or less near the soil surface and at boundaries between soil-depth intervals. Soil properties were assigned to each node; all nodes within a given soil-depth interval were assigned the same soil properties. The fraction of incoming solar radiation intercepted by the plant canopy $(\kappa)$ was 0.9 . Relative root activity $\left(R_{a}^{\prime}\right)$ was assumed to be constant with depth in the uppermost soil-depth interval, and it was 0 elsewhere. Internodal hydraulic conductivity was computed using the arithmetic averaging scheme with $W_{t}=0.5$. Initial $\theta$ for each node was determined from the profile of measured $\theta$.

Simulations used for the calibration were made for the period January 2 to January 15, 1992. Atmospheric 
boundary conditions were updated hourly based on measurements of net radiation, subsurface heat flux, air temperature, and atmospheric vapor pressure, which were measured at a height of $2.6 \mathrm{~m}$, and precipitation $(P)$ measured above the vegetation (Bidlake and Boetcher, in press). The multiplier $\alpha_{m}$, which is used for computing $E_{p}$ with the Priestley-Taylor equation, was 1.26. The lower boundary for the simulations was set at $1.5 \mathrm{~m}$, which was the average measured depth to the water table on the beginning and ending days of the simulation period. Depth to the water table was assumed to be equal to the measured depth below land surface to the water surface in a 3.4-m-deep well at the center of the study area. This water level was measured using a pressure transducer. The revised estimates of $\psi_{p e}$ that resulted from the calibration were, starting from the uppermost soil-depth interval, $-0.13,-0.10$, and $-0.26 \mathrm{~m}$.

\section{SIMULATION OF THE SOIL WATER BALANCE}

Two different types of numerical water-balance simulations were performed. The first type of simulations was carried out to examine capabilities of the model to simulate the water balance, to examine the sensitivity of simulations to some key input variables, and to examine variations in the water-balance components. These simulations were transient, and they were performed for a total of four simulation periods of about 2 weeks duration. Soil and plant properties used for the simulations initially were the original properties that were described in the section "Characterization of the Soil-Plant System." During the sensitivity analysis, some soil and plant properties were varied to examine effects of changes in those properties on simulation results. Node spacing and techniques for collecting data needed to compute atmospheric and lower boundary conditions and initial volumetric water content $(\theta)$ were the same as was described in the section "Calibration of the Soil WaterBalance Model." Depth to the water table was fixed for each simulation period at the average depth on the beginning and ending days of the simulation period. The range of depths determined from water-level measurements is given in table 13 . The relatively brief simulation periods were used because fluctuations in measured depth to the water table were larger during more extended periods, and this made the assumption of a constant unsaturated soil thickness untenable.

Table 13. Simulation periods and beginning and ending depths to the water table

\begin{tabular}{|c|c|c|}
\hline $\begin{array}{l}\text { Simulation } \\
\text { period }\end{array}$ & $\begin{array}{l}\text { Depth to the water } \\
\text { table at beginning } \\
\text { of the period }{ }^{1} \\
\text { (meters) }\end{array}$ & $\begin{array}{l}\text { Depth to the water } \\
\text { table at the end } \\
\text { of the period } \\
\text { (meters) }\end{array}$ \\
\hline $\begin{array}{l}\text { October } 9,1991, \text { to } \\
\text { October } 22,1991\end{array}$ & 0.58 & 0.74 \\
\hline $\begin{array}{c}\text { February } 11,1992, \text { to } \\
\text { February } 25,1992\end{array}$ & 1.51 & 1.43 \\
\hline $\begin{array}{l}\text { March 27, 1992, to } \\
\quad \text { April 9, } 1992\end{array}$ & 1.16 & 1.46 \\
\hline $\begin{array}{c}\text { May } 19,1992, \text { to } \\
\text { June } 2,1992\end{array}$ & 1.32 & 1.52 \\
\hline
\end{tabular}

or ending day of the simulation period.

The second type of simulations was steadystate simulations intended to aid in the identification and examination of major controls on evaporative water loss at the study site. These simulations, which were carried out using the same soil properties that were used in the first type of simulations, were performed for hypothetical bare-soil conditions at the study site. Initial $\theta$ for each node was assigned using the profile of $\theta$ that was measured on January 2, 1992, although any physically plausible $\theta$ profile could have been used. Hourly time steps were used in the simulations, and atmospheric and lower boundary conditions were held constant. Atmospheric relative humidity was fixed at 0.5 . Each simulation was continued until simulated evaporation from the soil surface $\left(E_{s}\right)$ became constant. The simulations were repeated for assumed depths to the water table that ranged from 0.1 to $1.6 \mathrm{~m}$ and for assumed potential evaporation from the soil surface $\left(E_{s p}\right)$ of either 3 or $8 \mathrm{~mm} / \mathrm{d}$. Simulated $E_{s}$ was normalized with respect to $E_{s p}$ and plotted against depth to the water table.

Transient Simulations of the Soil Water Balance.-Field measurements, which were used to estimate evapotranspiration $(E)$ and $\theta$, were available as direct evidence of the performance of the model in simulating the soil water balance. Daily estimates of $E$ were computed using the EBBR technique, and initial and final profiles of $\theta$ were obtained using gravimetric and neutron-scattering techniques as described previously.

Daily $E$ simulated with the Priestley-Taylor equation seemed to correlate with daily $E$ computed from EBBR measurements; however, simulated $E$ was 
generally less than measured $E$ for three of the four simulation periods (fig. 9). Daily simulated $E$ averaged 24,7 , and 9 percent less than daily $E$ computed from EBBR measurements for the simulation periods of October 9-22, 1991, February 11-25, 1992, and March 27-April 9, 1992, respectively. Simulated $E$ for the period May 19-June 2, 1992, averaged 5 percent greater than measured $E$. These differences can be explained, in part, by the range of variation in the multiplier for the Priestley-Taylor equation $(\alpha)$ that can be computed using EBBR measurements of $E$. Average daily $\alpha$ computed using EBBR measurements ranged from 0.69 to 0.94 among the four simulation periods, whereas $\alpha$ used in the simulations was fixed at 0.72 . Differences between simulated and measured $E$ can be attributed, in part, to an inability to adequately predict the variation in $\alpha$.
Measurement errors also could have contributed to the differences between simulated and measured $E$.

Sheltering of the soil surface by the nearly complete vegetative cover was reflected by the relatively small contribution of $E_{s}$ to total $E$ (table 14). Averaged among the four simulation periods, simulated $E_{s}$ comprised only about 15 percent of simulated evapotranspiration. Because potential evaporation from the soil surface $\left(E_{s p}\right)$ was only 10 percent of potential evapotranspiration $\left(E_{p}\right)$, the soil was capable of supplying water to the soil surface at a rate sufficient to meet the evaporative demand at the surface. As a result, the soil surface did not dry during any of the simulations, and simulated $E_{S}$ always occurred at the computed potential rate $\left(E_{s p}\right)$.

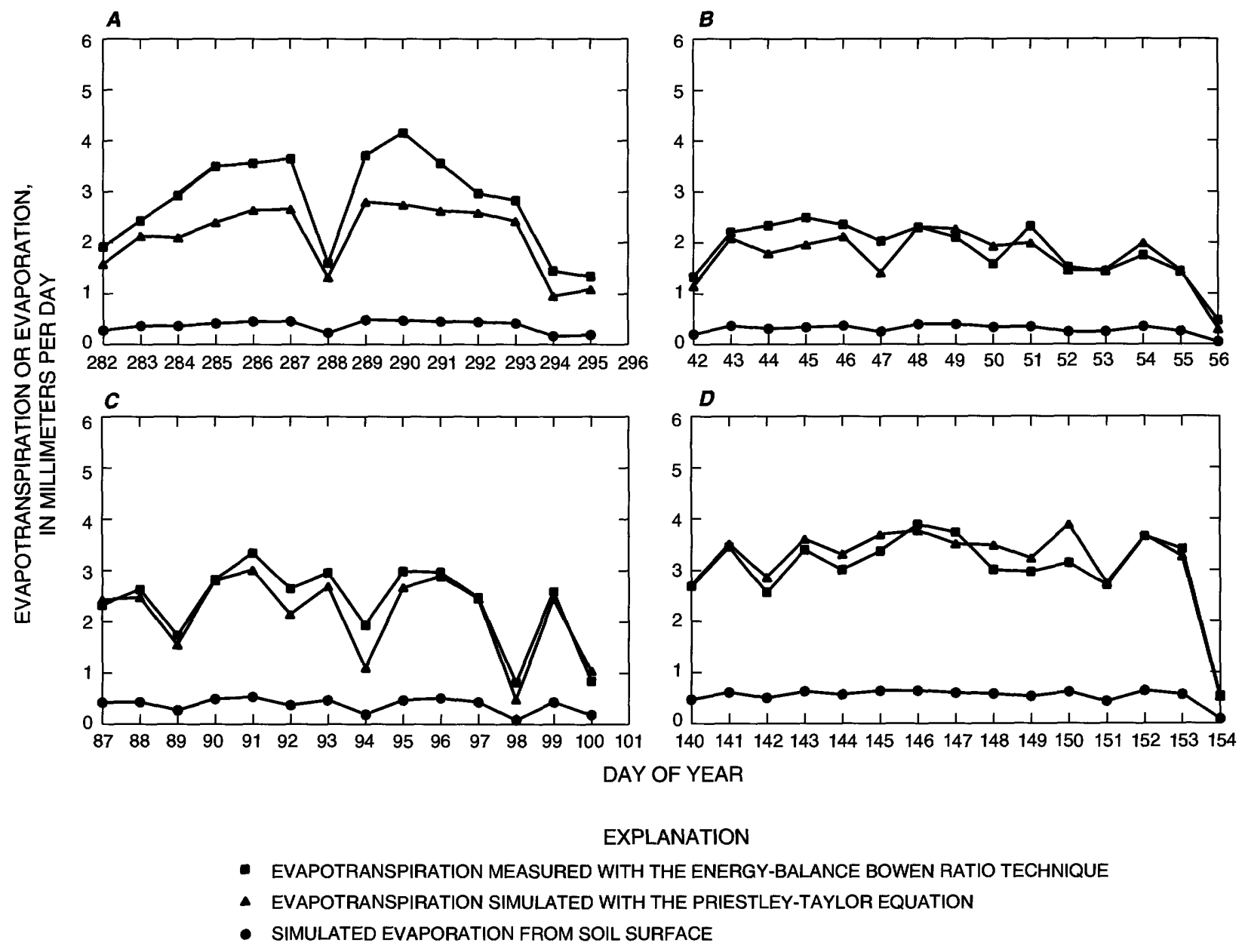

Figure 9. Simulated daily evapotranspiration and evaporation from the soil surface at the study site and daily evapotranspiration computed using the energy-balance Bowen ratio technique for four simulation periods. The simulation periods were: $(A)$, October 9-22, 1991; $(B)$, February 11-25, 1992; (C), March 27-April 9, 1992; and (D), May 19-June 2, 1992. 
Table 14. Average daily water fluxes and average daily potential evapotranspiration computed in conjunction with simulations of the soil water balance

$\left[E_{s}\right.$, evaporation from the soil surface; $T$, transpiration; $E$, evapotranspiration; $E_{p}$, potential evapotranspiration; $\left[q_{l}\right]_{n}$, flux of water to the water table; $P$, precipitation; values are in millimeters]

\begin{tabular}{ccccccc}
\hline $\begin{array}{c}\text { Simulation } \\
\text { period }\end{array}$ & $E_{s}$ & $T$ & $E$ & $E_{p}$ & {$\left[q_{f_{n}}\right.$} & $p$ \\
\hline $\begin{array}{c}\text { October 9, 1991, to } \\
\text { October 22, 1991 }\end{array}$ & 0.4 & 1.8 & 2.2 & 3.8 & -1.1 & 0.2 \\
$\begin{array}{c}\text { February 11, 1992, to } \\
\text { February 25, 1992 }\end{array}$ & 0.3 & 1.4 & 1.7 & 3.0 & -1.4 & 3.3 \\
$\begin{array}{c}\text { March 27, 1992, to } \\
\text { April 9, 1992 }\end{array}$ & 0.4 & 1.8 & 2.2 & 3.8 & -1.2 & 4.7 \\
$\begin{array}{c}\text { May 19, 1992, to } \\
\text { June 2, 1992 }\end{array}$ & 0.5 & 2.7 & 3.2 & 5.6 & 0.0 & 1.0 \\
\hline
\end{tabular}

Agreement between simulated $\theta$ obtained using the original soil and plant properties and measured $\theta$ varied among the four simulation periods, and it varied with depth in the soil. Differences between final simulated and final measured $\theta$ were generally less than 0.04 for the October 9-22, 1991, and May 19-June 2, 1992, simulations (fig. 10). An exception to this is that differences were as large as 0.09 in the lower half of the second lowermost soil-depth interval when the original soil and plant properties were used for the simulations. Agreement between final simulated $\theta$ obtained using the original soil and plant properties and final measured $\theta$ was weaker for the February 11-25, 1992, and March 27-April 9, 1992, simulations. First, final simulated $\theta$ in the uppermost soil-depth interval was

\section{VOLUMETRIC WATER CONTENT, DIMENSIONLESS}

OCTOBER 22, 1991
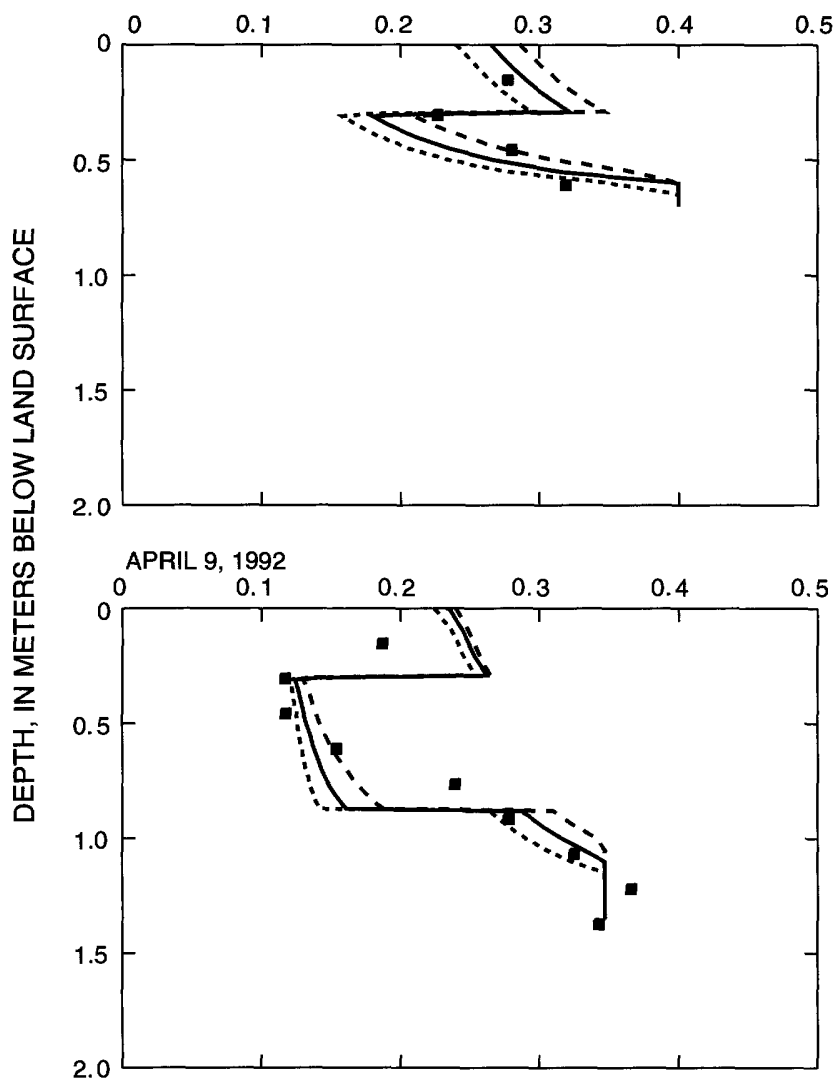

FEBRUARY 25, 1992
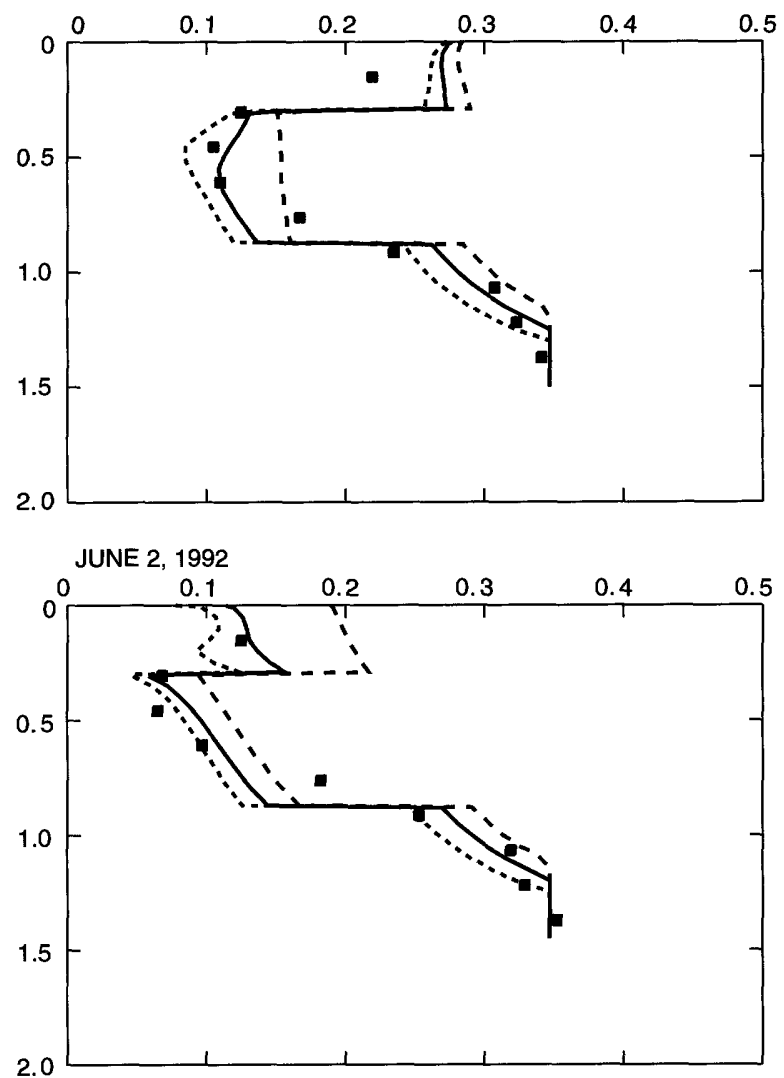

\section{EXPLANATION}

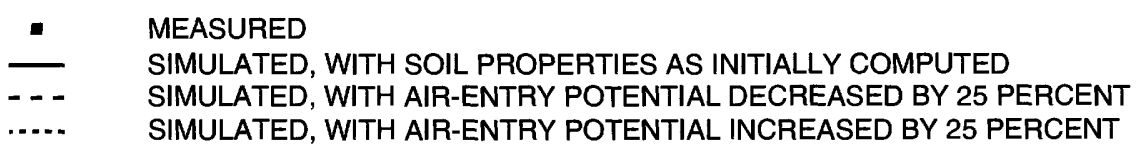

Figure 10. Simulated and measured soil volumetric water content at the end of four simulation periods and effect of varying air-entry soil water-pressure potential on simulated soil water content. 
0.05 to 0.07 greater than final measured $\theta$. Second, simulated $\theta$ in the lower half of the second lowermost soil-depth interval was less than measured $\theta$ by as much as 0.09 at the end of those two simulation periods.

Differences between simulated and measured $\theta$ at the end of the simulation periods probably were caused both by modeling and measurement deficiencies. Final simulated $\theta$ changed abruptly at boundaries between soil-depth intervals, whereas final measured $\theta$ changed more slowly with depth. The abrupt changes in simulated $\theta$ with depth were somewhat unrealistic and were due to the fact that, because of limited spatial resolution in sampling, soil physical properties used for the simulations were changed abruptly at the boundaries of the soildepth intervals. Soil hydraulic properties probably changed more gradually than was depicted for the simulations, and actual $\theta$ changed more gradually with depth. Another reason for the differences between simulated and measured $\theta$ was the operating characteristics of the gage used to apply the neutron-scattering technique. The neutron moisture gage does not provide a point measurement of $\theta$, but rather an integrated measurement for an approximately spherical volume of soil. The radius of the spherical volume ranges from about $0.2 \mathrm{~m}$ in moist soil to about $0.7 \mathrm{~m}$ in dry soil (Gardner, 1986). As a result, the neutron gage is not well suited for describing sharp changes in $\theta$. For this reason, $\theta$ probably varied more strongly with depth than was indicated by measurements made with the neutron moisture gage.

Relatively large differences between final simulated $\theta$ and final measured $\theta$ in the uppermost soil-depth interval, when they occurred, were preceded by intense precipitation events that occurred late in the simulation period. For example, approximately $60 \mathrm{~mm}$ of precipitation occurred during the final 48 hours of the February 11-25, 1992 , simulation period. Maximum hourly $P$ was $19.7 \mathrm{~mm}$. A similarly intense precipitation event occurred during the final 24 hours of the March 27April 9, 1992, simulation period. Simulated $\theta$ on both February 25 and April 9, 1992, was 0.05 to 0.07 greater than measured $\theta$ in the uppermost soil-depth interval (fig. 10). Conversely, $P$ was 0 during the final 3 days of the October 9-22 and May 19-June 2, 1992 , simulation periods, and final simulated $\theta$ in the uppermost soil-depth interval agreed with measured $\theta$ to within 0.02 .
Among possible explanations for this association between intense precipitation events late in a simulation period and substantially greater simulated $\theta$ than measured $\theta$ are: (1) the model does not adequately simulate infiltration, and (2) unobserved surface runoff or evaporation of intercepted precipitation from vegetation occurred and these water losses were not accounted for because the model does not simulate them. Concerning the first explanation, the model does not treat infiltration in a rigorous mechanistic manner for all precipitation rates. As was explained in the section "Model Development," the model limits maximum infiltration to a rate equal to the saturated hydraulic conductivity $\left(k_{s}\right)$ of the soil surface node, and it ponds excess water in a zero-head reservoir. The use of this simulation technique does not explain why simulated $\theta$ was greater than measured $\theta$. Maximum measured $P$ was approximately $0.6 \times 10^{-5} \mathrm{~m} / \mathrm{s}$, which was an order of magnitude smaller than $k_{s}$ at the soil surface node, and simulated ponding did not occur.

The model might not have adequately simulated the infiltration events for other reasons. For example, the arithmetic averaging scheme might not be the best scheme for computing internodal hydraulic conductivity $\left(\bar{k}_{l}\right)$ during infiltration events. If $\bar{k}_{l}$ computed using this scheme underestimates actual $k_{l}$ during infiltration, simulations could indicate anomalously large $\theta$ in upper portions of the soil profile. The model preserves the mass balance for the entire soil profile, however; and overestimates of $\theta$ in upper portions should be offset by underestimates of $\theta$ in lower portions of the profile. Although there were differences between final simulated and measured $\theta$ in the two lowermost soil-depth intervals for the February 11-25 and March 27-April 9, 1992, simulation periods, they were not dissimilar from corresponding differences for the October 9-22, 1991, and May 19-June 2, 1992, simulation periods. This evidence does not support a conclusion that the use of the arithmetic averaging scheme for computing $\bar{k}_{l}$ resulted in inadequate simulation of the physical process of infiltration.

It is unlikely that surface runoff caused the difference between final simulated and measured $\theta$ for the February 11-25 and March 27-April 9, 1992, simulation periods. The study site was not attended during the rain storms of February 25 and April 7, 1992. Observations by the authors during other intense storms were that surface runoff from the 
coarse-textured soils at the site did not occur unless the water table was at the land surface. If runoff had occurred, simulated $\theta$ in the uppermost soil-depth interval would have been greater than actual $\theta$ immediately after the infiltration events.

The model does not account for evaporation of intercepted precipitation from the vegetation. The result of this deficiency is that the model overestimates $q_{s}$ for vegetated sites. Part of the reason final simulated $\theta$ was greater than measured $\theta$ for the February 11-25 and March 27-April 9, 1992, simulation periods could have been that the model overestimated $q_{s}$.

Additional evaluation of model performance was done by comparing simulated changes in water storage within the soil profile with changes in soil water storage computed using measurements of $\theta$. Average daily simulated and measured changes in water storage were of the same sign for all four of the simulation periods, and they agreed to within 10 percent for three of the four simulation periods (table 15). The close agreement between simulated and measured changes in water storage for the March 27-April 9, 1992, simulation period was fortuitous because differences between simulated and measured storage changes in the uppermost soil-depth interval were partially offset by differences of the opposite sign in the second uppermost soil-depth interval. The relatively large difference between simulated and

Table 15. Average daily changes in soil water storage computed from simulations of the soil water balance and computed from measurements of volumetric soil water content

[ $\Delta S$, average daily change in soil water storage computed from simulations, in millimeters; $\Delta S_{m}$, average daily change in soil water storage computed from measurements, in millimeters; Percent difference is computed as $\left.100 \times\left(\Delta S-\Delta S_{m}\right) / \Delta S_{m}\right]$

\begin{tabular}{lccc}
\hline $\begin{array}{c}\text { Simulation } \\
\text { period }\end{array}$ & $\Delta \boldsymbol{S}$ & $\Delta \boldsymbol{S}_{\boldsymbol{m}}$ & $\begin{array}{c}\text { Percent } \\
\text { difference }\end{array}$ \\
\hline $\begin{array}{c}\text { October 9, 1991, to } \\
\text { October 22, 1991 }\end{array}$ & -1.0 & -1.1 & -10 \\
$\begin{array}{c}\text { February 11, 1992, to } \\
\text { February 25, 1992 }\end{array}$ & 3.0 & 2.0 & 50 \\
$\begin{array}{c}\text { March 27, 1992, to } \\
\text { April 9, 1992 }\end{array}$ & 3.7 & 3.4 & 9 \\
$\begin{array}{c}\text { May 19, 1992, to } \\
\text { June 2, 1992 }\end{array}$ & -2.2 & -2.3 & -4 \\
\hline
\end{tabular}

measured storage changes for the February 11-25, 1992, simulation period could have been caused either by inadequate treatment of infiltration or evaporation of intercepted water in the model or by an inability to adequately measure the $\theta$ profile as it exists shortly after a large infiltration event.

The simulated flux of water to the water table $\left(\left[q_{l}\right]_{n}\right)$ can be interpreted as simulated recharge to the saturated ground-water system. Ground water is being recharged when $\left[q_{l}\right]_{n}$ is positive, and ground water is discharging to the unsaturated zone when $\left[q_{l}\right]_{n}$ is negative. Simulated recharge, averaged over each of the four simulation periods, ranged from -1.4 to $0 \mathrm{~mm}$ per day (table 14), indicating that the saturated ground-water system discharged water to the unsaturated zone during most of the simulations. Some evidence exists that indicates that simulated recharge for the four simulation periods was not realistic. First, daily recharge on the first day of each simulation period ranged from -11.6 to $14.5 \mathrm{~mm}$, and this indicated the unsaturated zone was responding to a substantial stress that had been imposed shortly before the start of the simulations. An intense precipitation event just prior to a simulation period could have caused daily recharge to be as large as $14.5 \mathrm{~mm}$; however, probably no stress could have occurred that caused a transient daily discharge of $11.6 \mathrm{~mm}$ of ground water to the unsaturated zone.

Recorded fluctuations in depth to the water table provides additional evidence to indicate simulated recharge was not realistic. Changes in depth to the water table generally reflect changes in the difference between recharge to and discharge from the saturated ground-water system. Depth to the water table increases when discharge is greater than recharge, and depth to the water table decreases when recharge is greater than discharge. Depth to the water table increased during three of the simulation periods, and it decreased during one of the simulation periods (table 13). Unless there existed another source of water for recharge other than the unsaturated zone, depth to the water table should have increased or remained constant during the simulation periods if simulated recharge was correct. The estimates of recharge could have been in error as a result of errant estimates of soil and plant properties or boundary conditions or as a result of using governing or auxiliary equations that were not appropriate for the soil-plant system that was studied. 
Sensitivity Analysis.- - Selected soil physical and plant properties and boundary conditions were varied one at a time, and the simulations were repeated to examine the effects of uncertainty in those variables on simulated profiles of $\theta$ and recharge. The effect on simulated $\theta$ profiles of a 25 -percent change in air-entry soil water-pressure potential $\left(\psi_{p e}\right)$ was substantial, particularly for the May 19-June 2, 1992, simulation period (fig. 10). Simulated $\theta$ increased when $\psi_{p e}$ was decreased by 25 percent, and simulated $\theta$ decreased when $\psi_{p e}$ was increased by 25 percent. When $\psi_{p e}$ was decreased, it became a larger negative number, and when $\psi_{p e}$ was increased, it became a smaller negative number. Profiles of simulated $\theta$ and measured $\theta$ matched more closely when the original values for $\psi_{p e}$ obtained from the calibrations were used than when the values were increased or decreased by 25 percent. Simulated recharge also changed when
$\Psi_{p e}$ values were altered. The effect of a 25 -percent increase in $\psi_{p e}$ was to increase simulated recharge by an average of $1.4 \mathrm{~mm} / \mathrm{d}$. The effect of a 25 -percent decrease in $\psi_{p e}$ was to decrease simulated recharge by an average of $1.8 \mathrm{~mm} / \mathrm{d}$. The large changes in simulated recharge that accompanied the 25-percent changes in $\psi_{p e}$ indicate the importance of reliable $\psi_{p e}$ estimates for simulating the soil water balance when the water table is near the surface. Uncertainty about $\Psi_{p e}$ could make simulation-derived estimates of recharge for the study area unreliable when the water table is within $1.5 \mathrm{~m}$ of the soil surface.

The profile of relative root activity $\left(R_{a}^{\prime}\right)$ was altered so that $R_{a}^{\prime}$ decreased exponentially with depth in the root zone, which was assumed to encompass the uppermost soil-depth interval. Effects of varying the $R_{a}^{\prime}$ profile on the simulated profiles of $\theta$ were small (fig. 11). The most substantial effect occurred in the

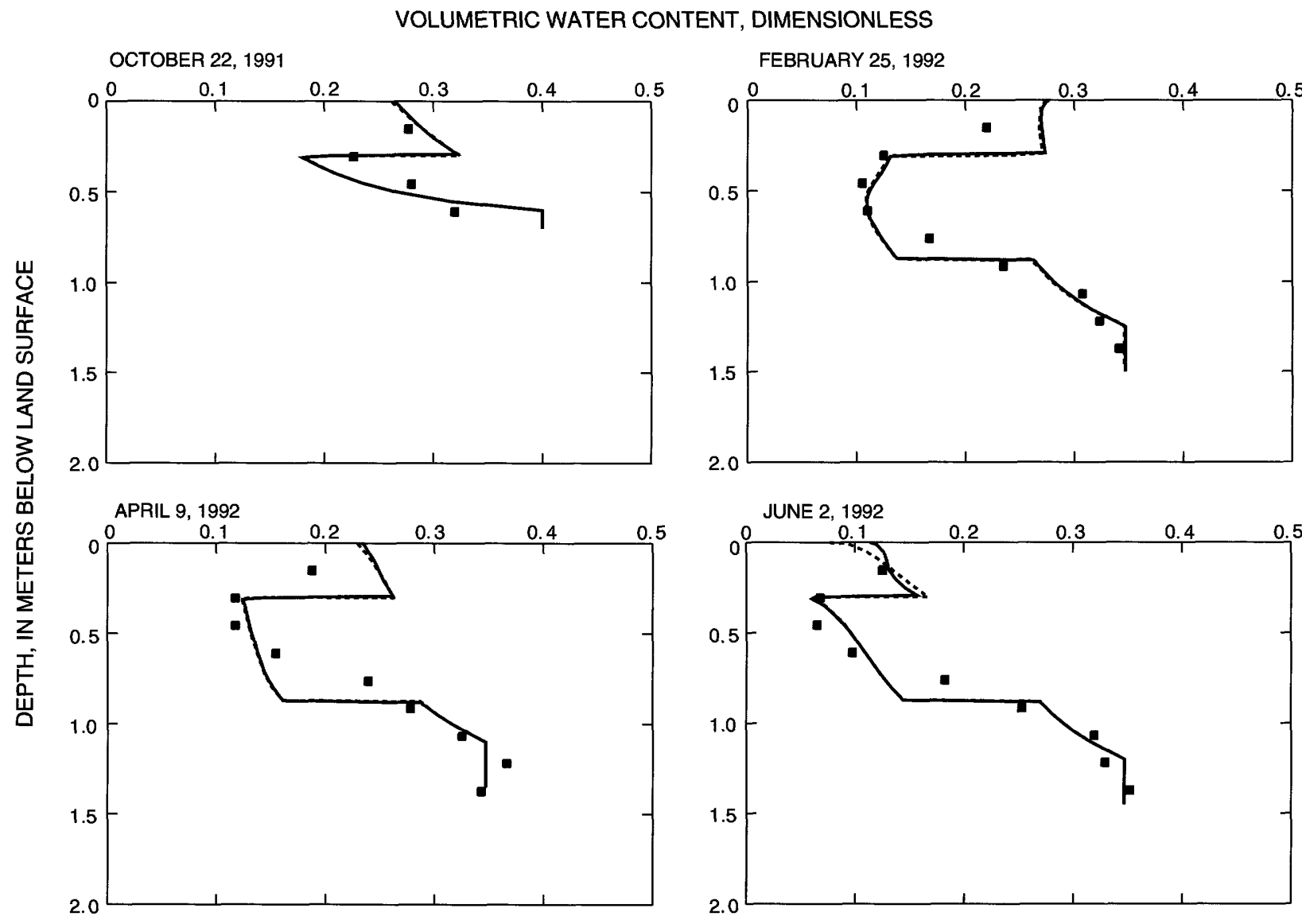

EXPLANATION

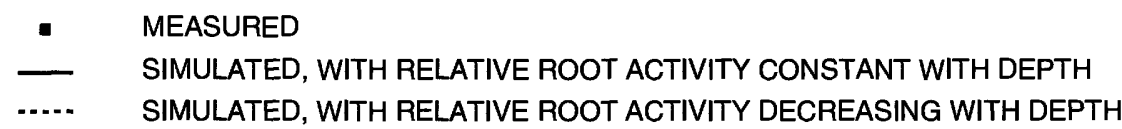

Figure 11. Simulated and measured soil volumetric water content at the end of four simulation periods and effect of varying profiles of relative root activity on simulated soil water content. 
simulated profiles for June 2, 1992. Simulations performed assuming a profile of exponentially decreasing $R_{a}^{\prime}$ with depth exhibited smaller $\theta$ near the surface and larger $\theta$ near the bottom of the root zone than did simulations that were performed assuming uniform $R_{a}^{\prime}$ with depth. The differences in simulated $\theta$ profiles within the root zone associated with the different $R_{a}^{\prime}$ profiles were caused by differing patterns of simulated water extraction. Differences in simulated $\theta$ profiles did not extend below the root zone. The change of $R_{a}^{\prime}$ profile had little effect on simulated recharge. Daily recharge simulated when the exponential $R_{a}^{\prime}$ profile was used differed by less than $0.1 \mathrm{~mm}$ from recharge simulated when the uniform $R_{a}^{\prime}$ profile was used. The weak effects of substantial changes in $R_{a}^{\prime}$ profiles indicate, in the presence of a shallow water table, knowledge of actual root activity profiles was not particularly important for simulating the water balance.

Another source of uncertainty for the simulations was selection of the appropriate lower boundary condition. The water table represents the point of atmospheric pressure in the interface between the unsaturated zone and the saturated ground-water system, and using the water table as the lower boundary for simulations of the soil water balance is appropriate and convenient. However, depth of the water table varied during all four simulation periods. The use of a single depth for each simulation period, which was equal to the average of the measured depths on the beginning and ending days for the period, might not have provided a realistic lower boundary condition. To examine possible effects of varying the depth to the water table, simulations were repeated using average daily depth on the beginning and ending days of each simulation period (table 13).

The effect of increasing depth to the water table generally was to decrease simulated $\theta$ at all soil depths as compared to $\theta$ simulated using the average of water-table depths on the beginning and ending days of the simulation periods (fig. 12). Conversely, the effect of decreasing depth to the water table generally was to increase simulated $\theta$. These effects were most pronounced for the October 9-22, 1991, simulation period. Changes in depth to the water table also affected simulated recharge. Simulated daily recharge increased by an average of $0.9 \mathrm{~mm}$ when the largest depths to the water table were used, and it decreased by an average of $1.0 \mathrm{~mm}$ when the smallest depths to the water table were used. These results indicate that both simulated $\theta$ and simulated recharge were sensitive to the depth to the water table for the depths used in the simulations.

Steady-State Simulation.-Useful insights into major controls of water-balance components can be gained by examining steady-state conditions. For example, Gardner (1958) and Gardner and Fireman (1958) developed and applied analytical solutions to the flow equation for unsaturated soil (eq. 1) for computing steady evaporation from a homogeneous, bare soil $\left(E_{s}\right)$ with a shallow water table. In a similar manner, the numerical model that was developed in this study was used to simulate $E_{s}$ for the layered soil at the study site assuming that the soil surface was bare.

The simulations indicated that $E_{s}$ was equal to $E_{s p}$ when depth to the water table did not exceed a critical depth that depended on the value of $E_{s p}$ used (fig. 13). When depth to the water table was greater than the critical depth, simulated $E_{s}$ became less than $E_{s p}$ and $E_{s}$ continued to decrease as depth to the water table increased. These results are qualitatively the same as results reported by Gardner and Fireman (1958), and they demonstrate the following important concept in the physics of evaporation from bare soil.

As long as the soil surface remains wet, $E_{s}$ is controlled by evaporative demand. The quantity $E_{s p}$ is essentially an expression of evaporative demand. The soil surface remains wet as long as the soil can transmit water to the surface fast enough to replace water lost by evaporation. The ability of the soil to transmit water to the surface at rates sufficient to replace evaporative loss depends somewhat on $E_{s p}$ and soil hydraulic conductivity, and it depends strongly on depth to the water table when the latter is greater than the critical depth. When depth to the water table is greater than the critical depth, the soil surface begins to dry, and $E_{s}$ decreases as it becomes water limited. In the bare-soil system, depth to the water table strongly controls availability of water to meet the evaporative demand specified by $E_{s p}$. It is recognized that $E_{s p}$ is not determined solely by external atmospheric factors, but instead it is partly determined by the albedo and aerodynamic roughness of the surface. For this reason, the actual $E_{s p}$ that would have been observed if the study site had been bare soil is unknown. However, the wide range of $E_{s p}$ used for the steady-state simulations probably encompassed the range of values $E_{s p}$ would have assumed if the site had been bare soil. 

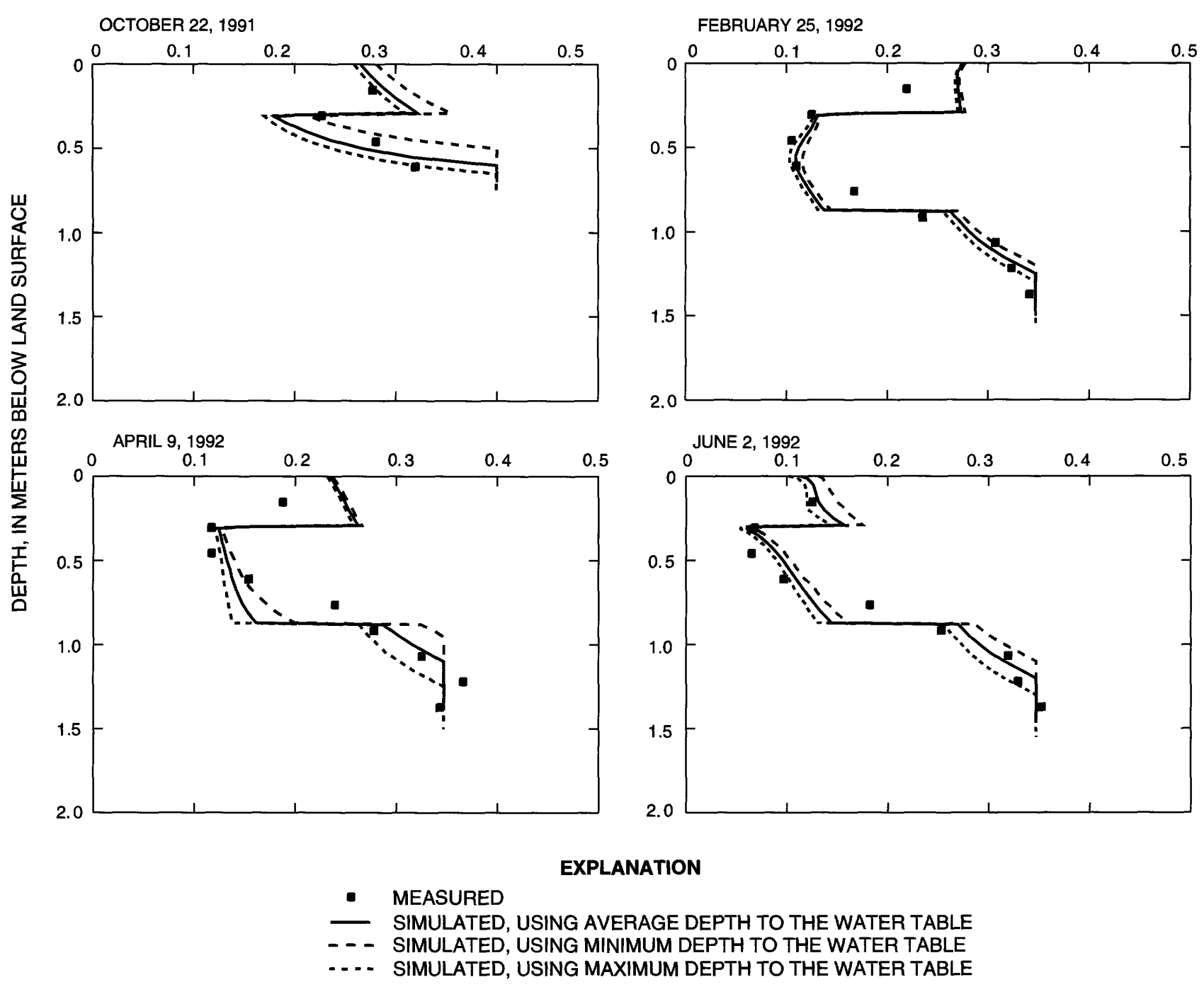

Figure 12. Simulated and measured soil volumetric water content at the end of four simulation periods and effect of varying the depth to the water table on simulated soil water content.

Results from the simulations of $E_{s}$ for hypothetical bare-soil conditions at the study site can be used to help explain the role of the actual vegetation that existed at the site in controlling evaporative loss. Results presented in the section "Calibration of the Priestley-Taylor Equation" indicated that evapotranspiration $(E)$ on rainless days was generally water limited because measured $E$ was generally much less than even the most conservative estimate of potential evapotranspiration $\left(E_{p}\right)$ that could be computed with the Priestley-Taylor equation (i.e., $\alpha_{m}=1.0$ ). The steady-state simulations of $E_{s}$ under hypothetical baresoil conditions indicated $E_{s}$ would not have become water limited until depth to the water table was greater than 0.8 or $1.0 \mathrm{~m}$, depending on the value of $E_{s p}$ that was used for the simulations; however, when vegetation was present, daily $E$ apparently was water limited even when the water table was at the soil surface (fig. 13).

The plant canopy at the study site probably was responsible for $E$ being water limited on rainless days when the water table was close to the soil surface. Part of the reason for this likely was that only a fraction of the canopy consisted of living, transpiring plants. A substantial part of the standing biomass at any time during the study consisted of senescent plant stems and leaves, and dead plant materials. Transpiration $(T)$ is a physiologically mediated activity of plants. The senesced plant leaves probably transpired little, and the dead 


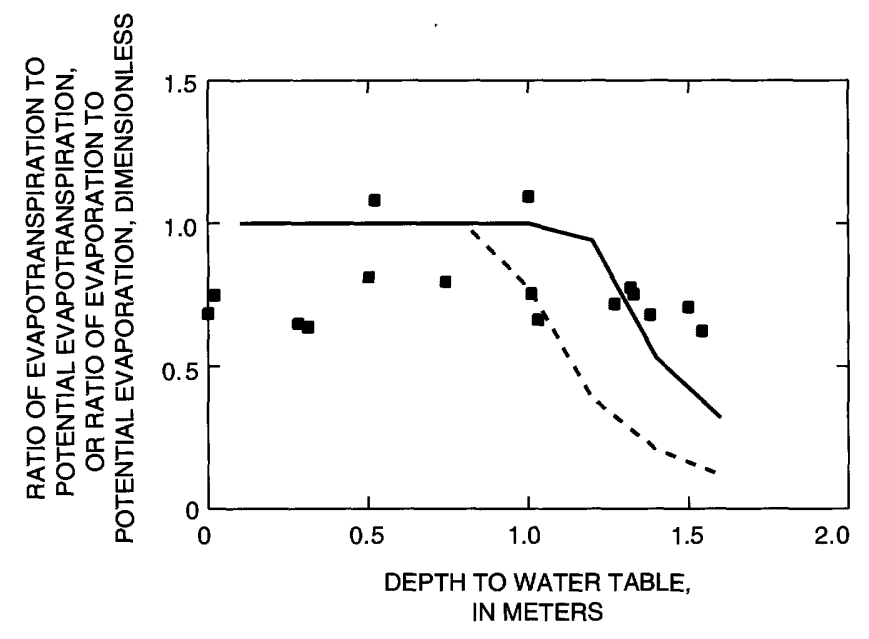

EXPLANATION

- RATIO OF MEASURED EVAPOTRANSPIRATION TO POTENTIAL EVAPOTRANSPIRATION, WHERE POTENTIAL EVAPOTRANSPIRATION IS COMPUTED USING THE PRIESTLEY-TAYLOR EQUATION WITH $\alpha=1.0$

- RATIO OF SIMULATED EVAPORATION FROM BARE SOIL TO POTENTIAL EVAPORATION, WHERE POTENTIAL EVAPORATION IS ASSUMED TO BE 3 MILLIMETERS PER DAY

- - - RATIO OF SIMULATED EVAPORATION FROM BARE SOIL TO POTENTIAL EVAPORATION, WHERE POTENTIAL EVAPORATION IS ASSUMED TO BE 8 MILLIMETERS PER DAY

Figure 13. Ratio of daily measured evapotranspiration to daily potential evapotranspiration, and ratio of daily, simulated, steady-state evaporation from the surface of a bare soil to potential evaporation from the soil surface as they varied with depth to the water table.

plant materials did not transpire at all. These senesced and dead plant materials probably contributed little to $E$. Instead, they could have acted to reduce $E_{S}$ to below what it would have been for a bare soil by performing a mulching function for the moist soil surface.

A material that lies on a moist surface and reduces evaporation can be considered to be a mulch. A mulch on a moist surface acts to absorb, reflect, or re-emit energy received from the atmosphere that would otherwise impinge on the surface and accelerate evaporation. A mulch can consist of a layer of dry soil, plant matter, or anthropogenically produced materials, such as plastics. It is probably reasonable to extend the definition of mulching materials to include senescent leaves and stems if they act to reduce total evaporative loss.

Another possible cause for $E$ being water limited when the water table was close to the soil surface was flooding in the root zone. Living plant roots require oxygen, and the usual source of oxygen for terrestrial plant roots is the gas-filled pore space in the soil. Roots are deprived of oxygen when the soil becomes flooded. It is known that root uptake of soil water is physiologically mediated and that uptake is impaired in flooded soil (Ting, 1982). Most terrestrial plants must replace losses of water by $T$ with water that is taken up by roots. If root uptake is impaired by flooded soil, a transpiring plant can exhibit symptoms of physiological moisture stress (Hillel, 1982). One plant response to moisture stress is to reduce transpiration water losses by closing stomates. If plants at the study site responded to flooding by closing stomates, this could partly explain why $E$ was water limited when the water table was close to the soil surface. It would have been possible to test this hypothesis by testing for effects of stomatal closure for individual plants at the study site. The detailed physiological measurements needed to do this were beyond the scope of this study, however, and the hypothesis of stomatal closure in response to flooding at the study site remains untested.

The implication of these results is that a plant canopy might act to limit total evaporative loss from a soil with a shallow water table under some conditions. It is possible that the effect of wild-land vegetation at the study site was to reduce $E$ to less than what $E_{s}$ would have been if bare-soil conditions had existed. Whether this actually occurs could be determined by a future investigation in which concurrent measurements of $E$ and $E_{s}$ are made for vegetated and bare-soil sites, respectively. The results do indicate that $E$ for the densely vegetated study site was often water limited on rainless days when depth to the water table was such that $E_{s}$ for bare-soil conditions would not have been water limited. Because of likely errors in the simulations caused by errant estimates of soil physical properties and because of uncertainty concerning $E_{s p}$ for a bare soil, it is not possible to determine a precise value for the critical depth to the water table for which $E_{S}$ would have become water limited. Certainly, $E_{s}$ would not have been water limited when the water table was at the soil surface. 
physiological measurements needed to do this were beyond the scope of this study, however, and the hypothesis of stomatal closure in response to flooding at the study site remains untested.

The implication of these results is that a plant canopy might act to limit total evaporative loss from a soil with a shallow water table under some conditions. It is possible that the effect of wild-land vegetation at the study site was to reduce $E$ to less than what $E_{S}$ would have been if bare-soil conditions had existed. Whether this actually occurs could be determined by a future investigation in which concurrent measurements of $E$ and $E_{S}$ are made for vegetated and bare-soil sites, respectively. The results do indicate that $E$ for the heavily vegetated study site was often water limited on rainless days when depth to the water table was such that $E_{s}$ for bare-soil conditions would not have been water limited. Because of likely errors in the simulations caused by errant estimates of soil physical properties and because of uncertainty concerning $E_{s p}$ for a bare soil, it is not possible to determine a precise value for the critical depth to the water table for which $E_{s}$ would have become water limited. Certainly, $E_{s}$ would not have been water limited when the water table was at the soil surface.

\section{SUMMARY AND CONCLUSIONS}

A numerical model was developed to simulate the soil water balance of a prairie site in west-central Florida. The model simulates the hydrologic processes of infiltration, soil water storage, deep percolation or recharge to the water table, evapotranspiration $(E)$, and evaporation from the soil surface $\left(E_{s}\right)$. The soil water-balance model was developed using the theory of water flow in unsaturated and saturated soil and using empirical and heuristic arguments to account for $E$ and plant uptake of soil water. Soil water flow is simulated by approximate solution of a time-dependent, one-dimensional governing equation through the use of numerical techniques and auxiliary equations. As the model is currently written, $E$ from vegetated surfaces, such as the study site, is simulated using the Priestley-Taylor equation, which must be calibrated for each site. Evapotranspiration is partitioned to $E_{S}$, and to transpiration $(T)$ based on the relative humidity at the soil surface and on the fraction of incoming shortwave radiation intercepted by the plant canopy. No provision is made in the model to account for evaporation of intercepted precipitation. Plant uptake of soil water is simulated by assuming that total uptake is equal to $T$ and by distributing total uptake with depth in the rooting zone according to a simple, heuristically derived algorithm.

The water-balance simulation model is coded as a computer program, the model source code, that can be compiled into a machine-language version on a computer equipped with the appropriate software. The machine-language version then can be executed on the computer to simulate the soil water balance. The model source code is written in the high-level Pascal language and was developed, compiled, and run on a personal computer with 640 kilobytes of memory and a numeric processor. The source code requires about 25 kilobytes of core memory.

Documentation of the model is included in this report. Documentation given includes: (1) description of the governing and auxiliary equations; (2) description of the numerical implementation of the governing and auxiliary equations; (3) description of boundary and initial conditions and of data needed to operate the model; and (4) description of the model source code and of the content and format of the input and output files, as well as examples of those files. Documentation also includes a generalized flowchart for the source code (app. 1) and a listing of the model source code (app. 2). Finally, a complete listing of program variables, including definitions, is given in table 1.

Steady-state $E_{S}$ from a bare soil in the presence of a water table was used as a verification problem for the water-flow part of the model. Steady-state $E_{s}$ for a soil with a given set of physical properties was computed as a function of depth to the water table, using an approximate analytical technique, and $E_{s}$ for the same soil was simulated using the numerical model. Agreement between simulated $E_{s}$ and $E_{s}$ that was computed by the analytical technique generally was close, except when the water table was less than $1 \mathrm{~m}$ below the surface. Variations in simulated $E_{s}$ were dependent on the averaging scheme used in the model to compute internodal hydraulic conductivity. Computed $E_{S}$ was greater than simulated $E_{s}$ when a geometric averaging scheme was used and computed $E_{S}$ was less than simulated $E_{S}$ when an arithmetic averaging scheme was used. Despite the sensitivity of 
simulated $E_{s}$ to the averaging scheme for internodal hydraulic conductivity, the verification exercise demonstrated that the part of the numerical model involving soil water flow and $E_{s}$ is probably coded correctly in the source code.

Field and laboratory investigations were made to measure or estimate soil physical properties and vegetative properties needed to perform simulations of the soil water balance. The soil was divided into three depth intervals and physical properties were estimated for each depth interval. Soil bulk density, determined using a soil corer, ranged from $1,380 \mathrm{~kg} / \mathrm{m}^{3}$ in the uppermost soil-depth interval to $1,730 \mathrm{~kg} / \mathrm{m}^{3}$ in the deepest soil-depth interval. Saturated hydraulic conductivity, estimated using a Guelph permeameter, ranged from $1.97 \times 10^{-5}$ to $9.52 \times 10^{-5} \mathrm{~m} / \mathrm{s}$. Initial estimates of air-entry soil water-pressure potential $\left(\psi_{p e}\right)$, which were made based on soil particle-size distribution, bulk density, and an empirical relation from the literature, ranged from -0.09 to $-0.06 \mathrm{~m}$. These initial estimates were adjusted for the study site using a simple model calibration procedure. Soilwater extraction data obtained with Tempe pressure cells were used in conjunction with estimates of $\psi_{p e}$ to define the soil water-characteristic function for each soil-depth interval.

The only vegetative properties explicitly required for the simulations were fractional interception of incoming shortwave radiation by the plant canopy ( $\kappa)$ and the profile of root activity $\left(R_{a}\right)$ or the profile of relative root activity $\left(R_{a}^{\prime}\right)$. The property $\kappa$ was sampled using tube solarimeters that integrated radiation penetration to the soil surface over a length of about $1 \mathrm{~m}$. Sampled $\kappa$ did not vary between the wet and dry seasons at the study site and averaged 90 percent of incoming shortwave radiation on a daily basis. Depth of the root zone was estimated based on observations in the field, and two hypothetical profiles of $R_{a}^{\prime}$ within the root zone were used for the simulations. In the first hypothetical profile, $R_{a}^{\prime}$ remained constant with depth and in the second hypothetical profile, $R_{a}^{\prime}$ decreased exponentially with depth.

The Priestley-Taylor equation was calibrated using measurements of $E$ to predict actual $E$ for the study site. Measurements of $E$, which were made using the eddy correlation technique, and measurements of net radiation, subsurface heat flux, and air temperature were used for the calibration. Measurements used for the calibrations were made about once a month for 24 hours or more from June 1991 through
September 1992. Results from the calibration indicated that the multiplier for the Priestley-Taylor equation $(\alpha)$ was 0.72 and 0.73 for hourly and 24-hour periods. These multipliers were nearly 30 percent less than the theoretical minimum $\alpha$ for a wet surface, and this indicated that $E$ at the study site was substantially moisture limited. Daily $\alpha$ did not vary systematically with volumetric soil water content in the root zone or with depth of the water table below the soil surface.

Both transient and steady-state water-balance simulations were performed using the numerical model described in this report. The transient simulations were performed to examine capabilities of the model to simulate the water balance, the sensitivity of simulations to some key input variables, and to examine variations in the water-balance components at the study site. These simulations were carried out for periods of about 2 weeks in duration. Daily simulated $E$ was less than $E$ measured using the energy-balance Bowen ratio technique for three of the four simulation periods. Simulated $E$ differed from $E$ measured using the energy-balance Bowen ratio technique by as much as 24 percent. The disagreement between simulated and measured $E$ was due largely to an inability of the model to account for variation in the Priestley-Taylor multiplier $\alpha$.

Performance of the model was further assessed by comparing simulated and measured profiles of volumetric soil water content $(\theta)$ at the end of each simulation period and by examining simulated soil water fluxes. Simulated and measured profiles of $\theta$ matched closely, except in the lower half of the second uppermost soil-depth interval and in the uppermost soil-depth interval following intense precipitation events. Simulated $\boldsymbol{\theta}$ in the lower half of the second uppermost soil-depth interval was less than measured $\theta$ by as much as 0.09 , and simulated $\theta$ in the uppermost soil-depth interval following intense precipitation events was greater than measured $\theta$ by as much as 0.07 . The change in soil water storage during each simulation period was computed both from simulations and measurements of $\theta$. Simulated and measured changes in soil water storage differed by 10 percent or less for three of the four simulation periods, and they differed by 50 percent for one simulation period.

Simulated recharge to the saturated groundwater system ranged from -1.4 to $0 \mathrm{~mm} / \mathrm{d}$ among the four simulation periods, indicating that the saturated ground-water system discharged water to the unsatur- 
ated zone during most of the simulations. Simulated recharge might have been unrealistic if errant estimates of soil and plant properties or boundary conditions were used in the simulations or if the governing or auxiliary equations on which the model was based were not appropriate for the soil-plant system that was studied.

Selected soil physical and plant properties and boundary conditions were varied and the simulations were repeated to examine the effects of uncertainty in those variables on simulated $\theta$ and simulated recharge. Simulated $\theta$ and simulated recharge were sensitive to the air-entry soil water-pressure potential $\left(\psi_{p e}\right)$ and depth to the water table, and they were insensitive to the distribution of $R_{a}^{\prime}$. Because of the sensitivity of simulated $\theta$ and simulated recharge to $\psi_{p e}$, the reliability of the model to predict recharge to shallow water tables is questionable unless that parameter can be determined accurately. In addition, the approach used in the model to establish the lower boundary condition fixes the water table at a single depth for the duration of a simulation period. A more realistic approach would be to allow the water-table depth to be varied during simulations, and this might improve the reliability of simulated recharge when actual depth to the water table varies during a simulation.

Steady-state simulations of $E_{s}$ under hypothetical bare-soil conditions at the study site indicated $E_{S}$ would not become water limited until depth to the water table was greater than a critical depth of 0.8 or $1.0 \mathrm{~m}$, depending on the value of potential evaporation from the soil surface that was used for the simulations. Actual measurements of $E$ for the densely vegetated site, however, indicated that $E$ was water limited even when the water table was at the soil surface. The implication of these results is that a plant canopy might limit total evaporative loss from a soil with a shallow water table under some conditions. Possible mechanisms for this regulation include mulching of the wet soil surface by senescent and dead plant materials and stomatal closure by plants in response to root-zone flooding.

\section{REFERENCES}

Abrahamson, W.G., and Hartnett, D.C., 1991, Pine flatwoods and dry prairies, in Myers, R.L., and Ewel, J.J., eds., Ecosystems of Florida: Orlando, University of Central Florida Press, p. 103-149.

Barton, I.J., 1979, A parameterization of the evaporation from nonsaturated surfaces: Journal of Applied Meteorology, v. 18, p. 43-47.

Bauer, H.H., and Vacarro, J.J., 1987, Documentation of a deep percolation model for estimating ground-water recharge: U.S. Geological Survey Open-File Report 86-536, $180 \mathrm{p}$.

Bidlake, W.R., and Boetcher, P.F., in press, Near-surface water balance of an undeveloped upland site in westcentral Florida: U.S. Geological Survey Water-Supply Paper 2452.

Brutsaert, W., 1982, Evaporation into the atmosphere: Theory, history, and applications: Boston, Reidel, $299 \mathrm{p}$.

Campbell, G.S., 1974, A simple method for determining unsaturated hydraulic conductivity from moisture retention data: Soil Science, v. 117, p. 311-314.

_-1977, An introduction to environmental biophysics: New York, Springer-Verlag, $159 \mathrm{p}$.

1985, Soil physics with BASIC. Transport models for soil-plant systems: New York, Elsevier, 150 p.

Davies, J.A., and Allen, C.D., 1973, Equilibrium, potential, and actual evaporation from cropped surfaces in southern Ontario: Journal of Applied Meteorology, v. 12 , p. 649-657.

DeBruin, H.A.R., and Keijman, J.Q., 1979, The PriestleyTaylor evaporation model applied to a large shallow lake in the Netherlands: Journal of Applied Meteorology, v. 18, p. 898-903.

Elrick, D.E., and Reynolds, W.D., 1992, Methods for analyzing constant-head well permeameter data: Soil Science Society of America Journal, v. 56, p. 320-323.

Flint, A.L., and Childs, S.W., 1991, Use of the PriestleyTaylor evaporation equation for soil water limited conditions in a small forest clearcut: Agricultural and Forest Meteorology, v. 56, p. 247-260.

Gardner, W.H., 1986, Water content, in Klute, A., ed., Methods of soil analysis, physical and mineralogical methods ( $2 \mathrm{~d}$ ed.): Madison, Wis., American Society of Agronomy, monograph 9, part 1, p. 493-544.

Gardner, W.R., 1958, Some steady-state solutions of the unsaturated moisture flow equation with application to evaporation from a water table: Soil Science, v. 85, no. 4 , p. 228-232. 
Gardner, W.R., and Fireman, M., 1958, Laboratory studies of evaporation from soil columns in the presence of a water table: Soil Science, v. 85, no. 5, p. 244-249.

Gee, G.W., and Bauder, J.W., 1986, Particle-size analysis, in Klute, A., ed., Methods of soil analysis, physical and mineralogical methods, (2d ed.): Madison, Wis., American Society of Agronomy, monograph 9, part 1, p. $383-411$.

Gerwitz, A., and Page, E.R., 1974, An empirical mathematical model to describe plant root systems: Journal of Applied Ecology, v. 11, p. 773-782.

Hillel, D., 1982, Introduction to soil physics: Orlando, Fla., Academic Press, 364 p.

Hutchinson, C.B., 1984, Hydrogeology of well-field areas near Tampa, Florida, phase 2-Development of a quasi-three-dimensional finite difference model for simulation of steady-state ground-water flow: U.S. Geological Survey Water-Resources Investigations Report 84-4002, 174 p.

Hyde, A.G., Hurt, G.W., and Wettstein, C.A., 1991, Soil survey of Sarasota County, Florida: Washington, D.C., U.S. Government Printing Office, 147 p., 31 sheets.

James, M.L., Smith, G.M., and Wolford, J.C., 1985, Applied numerical methods for digital computation: New York, Harper and Row Publishers, 753 p.

Jarvis, P.G., 1976, The interpretation of variations in leaf water potential and stomatal conductance found in canopies in the field: Phil. Trans. R. Soc. London, Ser. B, 273, p. 593-610.

Jensen, M.E., Burman, R.D., and Allen, R.G., 1990, Evapotranspiration and irrigation water requirements: New York, American Society of Civil Engineers, $332 \mathrm{p}$.

Jury, W.A., Gardner, W.R., and Gardner, W.H., 1991, Soil physics: New York, John Wiley and Sons, 328 p.

Jury, W.A., and Tanner, C.B., 1975, Advection modification of the Priestley-Taylor evapotranspiration formula: Agronomy Journal, v. 67, p. 840-842.

Klute, A., 1986, Water retention: Laboratory methods, in Klute, A., ed., Methods of soil analysis, physical and mineralogical methods ( $2 \mathrm{~d}$ ed.): Madison, Wis., American Society of Agronomy, monograph 9, part 1, p. 635-662.

Lappala, E.G., Healy, R.W., and Weeks, E.P., 1987, Documentation of computer program VS2D to solve the equations of fluid flow in variably saturated porous media: U.S. Geological Survey Water-Resources Investigations Report 83-4099, 184 p.

Marquardt, D.W., 1963, An algorithm for least squares estimation of nonlinear parameters: SIAM Journal of Applied Mathematics, v. 11, p. 431-444.

Moltz, F.J., and Remson, I., 1970, Extraction term models of soil moisture use by transpiring plants: Water Resources Research, v. 6, no. 5, p. 1346-1356.

National Oceanic and Atmospheric Administration, 1982, Monthly normals of temperature, precipitation, and heating and cooling degree days, 1951-1980, Florida: Asheville, N.C., National Climatic Data Center, Climatography of the United States, no. $81,15 \mathrm{p}$.

Priestley, C.H.B., and Taylor, R.J., 1972, On the assessment of surface heat flux and evaporation using large-scale parameters: Monthly Weather Review, v. 100, no. 2, p. 81-92.

Reynolds, W.D., and Elrick, D.E., 1985, In situ measurement of field-saturated hydraulic conductivity, sorptivity, and the $\alpha$ parameter using the Guelph permeameter: Soil Science, v. 140, p. 292-302.

Reynolds, W.D., Elrick, D.E., and Topp, G.C., 1983, A reexamination of the constant head well permeameter method for measuring saturated hydraulic conductivity above the water table: Soil Science, v. 136, p. 250-268.

Rhia, S.J., and Campbell, G.S., 1985, Estimating water fluxes in Douglas-fir plantations: Canadian Journal of Forest Research, v. 15, p. 701-707.

Smajstrla, A.G., Schmidt, G.M., Zazueta, F.S., and Clark, G.A., 1988, Characteristics of solar radiation in Florida: Soil and Crop Science Society of Florida Proceedings, v. 48, p. 103-108.

Steele, R.G.D., and Torrie, J.H., 1980, Principles and procedures of statistics-A biometrical approach: New York, McGraw-Hill, 633 p.

Swinbank, W.C., 1951, The measurement of vertical transfer of heat and water vapor by eddies in the lower atmosphere: Journal of Meteorology, v. 8, p. 135-145.

Tanner, C.B., 1960, Energy balance approach to evapotranspiration from crops: Soil Science Society of America Proceedings, v. 24, p. 1-9.

Taylor, H.M., and Klepper, B., 1978, The role of rooting characteristics in the supply of water to plants: Advances in Agronomy, v. 30, p. 99-128.

Ting, I.P., 1982, Plant physiology: Menlo Park, California, Addison-Wesley Publishing, 642 p. 
APPENDIXES 


\section{APPENDIX 1. Flowchart for the Soil Water-Balance Model}
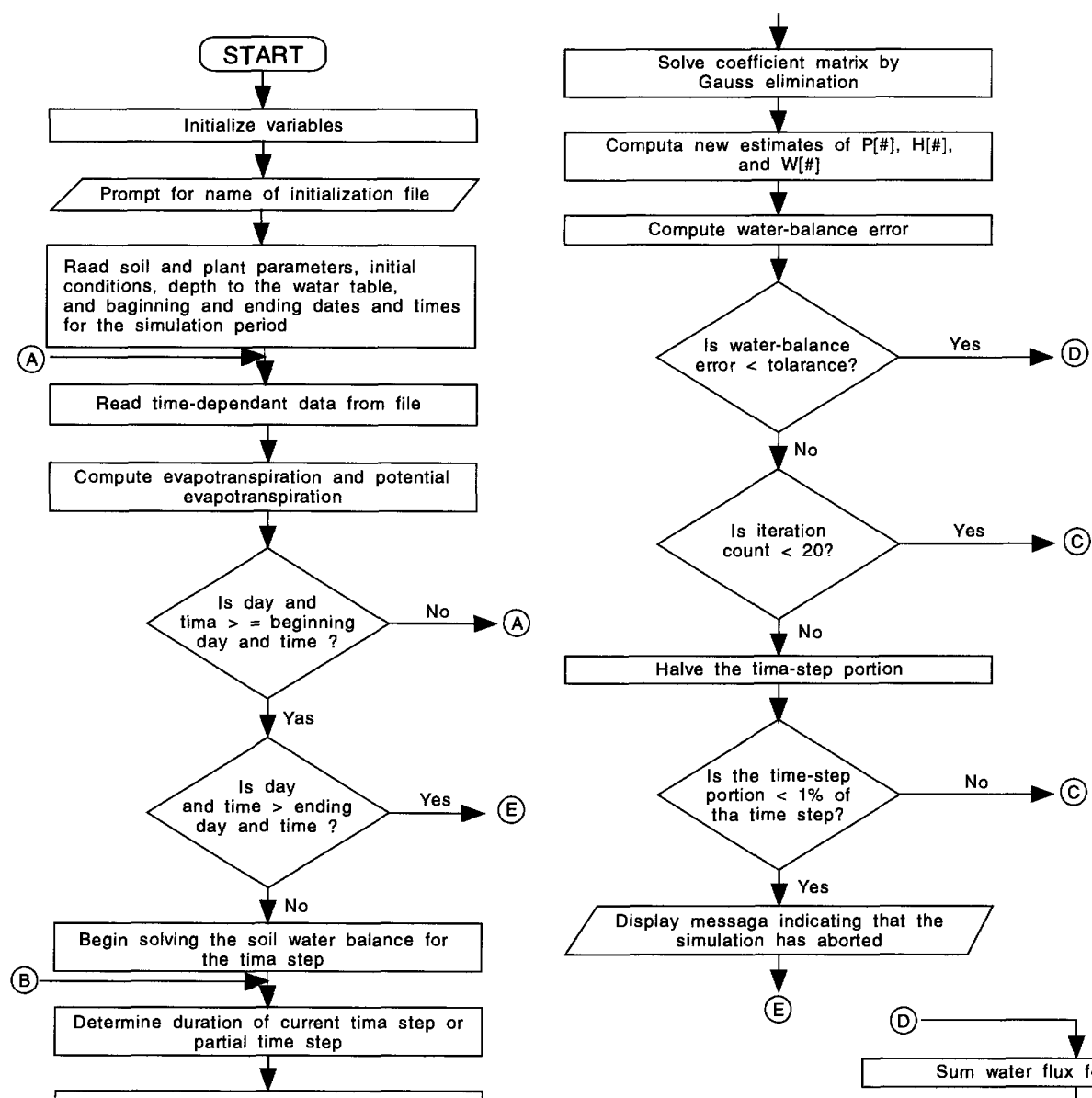

(E)
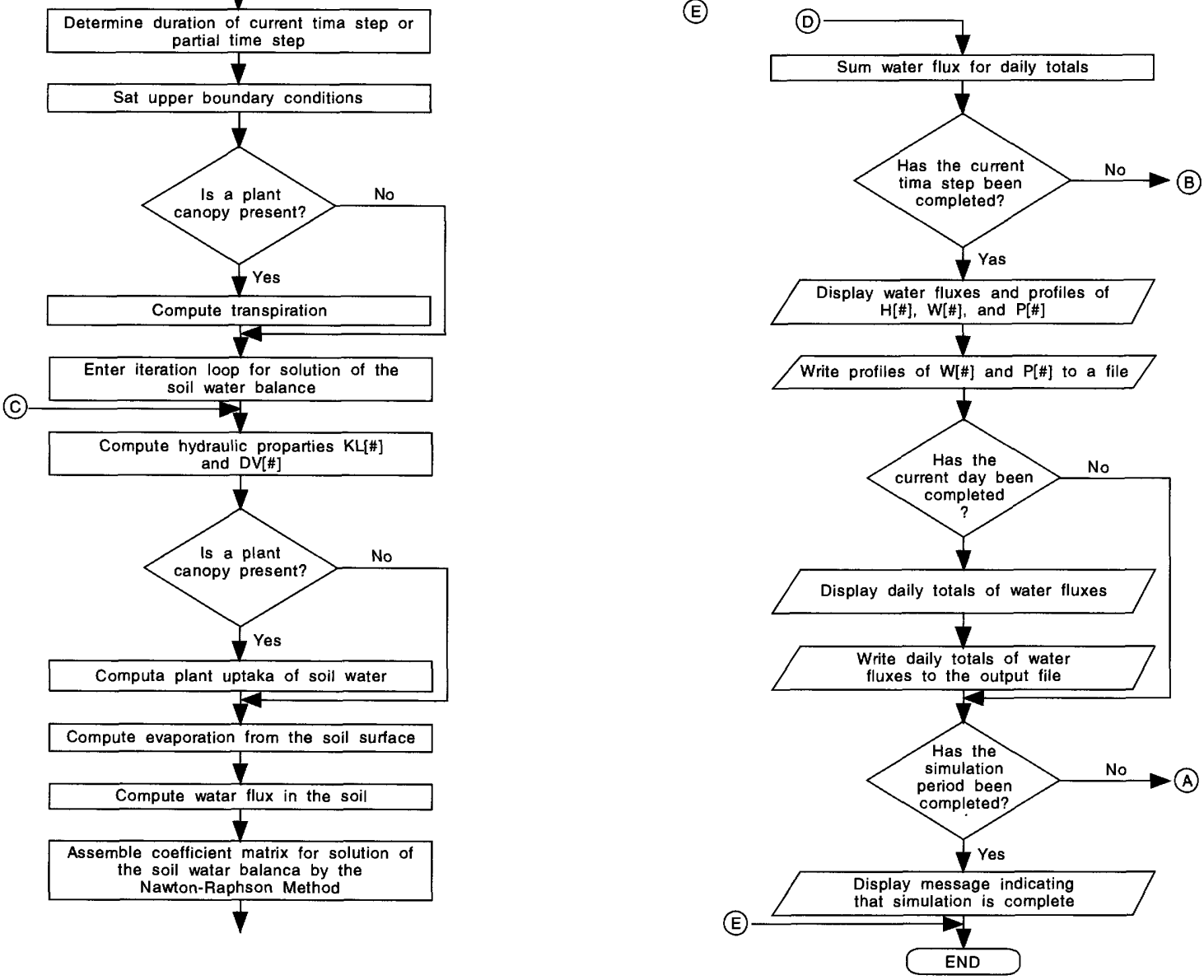


\section{APPENDIX 2. Source Code for the Soil Water-Balance Model}

$\{\$ \mathrm{R}+\}$

PROGRAM FL506HD;

$\{2 / 25 / 95\}$

USES CRT;

\section{CONST}

CSNP $=-1 ;$ CENP $=100$;

MDT_FRAC $=0.01$;

$\mathrm{R}=8.3143$;

$\mathrm{GR}=9.8$;

$\mathrm{MW}=0.018$;

$\mathrm{T} 0=273.15$;

$\mathrm{PD}=2650$;

\{ Temperature-dependent variables are evaluated at $30^{\circ} \mathrm{C}$ Pressure-dependent variables are evaluated at $100 \mathrm{kPa}$ \} $\mathrm{T}=30$;

$\mathrm{WD}=996$;

LVAP $=2.43 E+06$

GAMMA $=0.0665$;

$\mathrm{CVP}=4.24$;

$\mathrm{DV} 0=2.57 \mathrm{E}-05$;

$\mathrm{MA}=1 \mathrm{E}-09$;

TYPE

REAL=DOUBLE;

TLAY=ARRAY[CSNP..CENP] OF REAL;

TS=STRING[60];

$\{--($ Taise a real number to a power $\}$

\{ Raise a real number to a power \}

FUNCTION POW(X,Y:REAL):REAL;

VAR SIGN:INTEGER;

BEGIN

POW:=EXP(Y*LN(ABS(X)));

END;

$\{$ -

\{ Decimal time of day \}

FUNCTION FDECHR(HRMIN:REAL):REAL;

BEGIN

FDECHR:=TRUNC(HRMIN/100)+FRAC(HRMIN/100)/0.6;

END;

$\{$ -

\{ Elapsed time, in hours

FUNCTION FTIMER(DOY,HRMIN,START_DAY,START_HR:REAL):REAL;

BEGIN

FTIMER:=24.0*(DOY-START_DAY)+FDECHR(HRMIN)-FDECHR(START_HR);

END; 


\section{APPENDIX 2. Source Code for the Soil Water-Balance Model-Continued}

\{ Test equality of reals \}

FUNCTION FREQ(ARG1,ARG2:REAL):BOOLEAN;

BEGIN

IF (ABS(ARG1-ARG2)>1E-12) THEN FREQ:=FALSE

ELSE FREQ:=TRUE;

END;

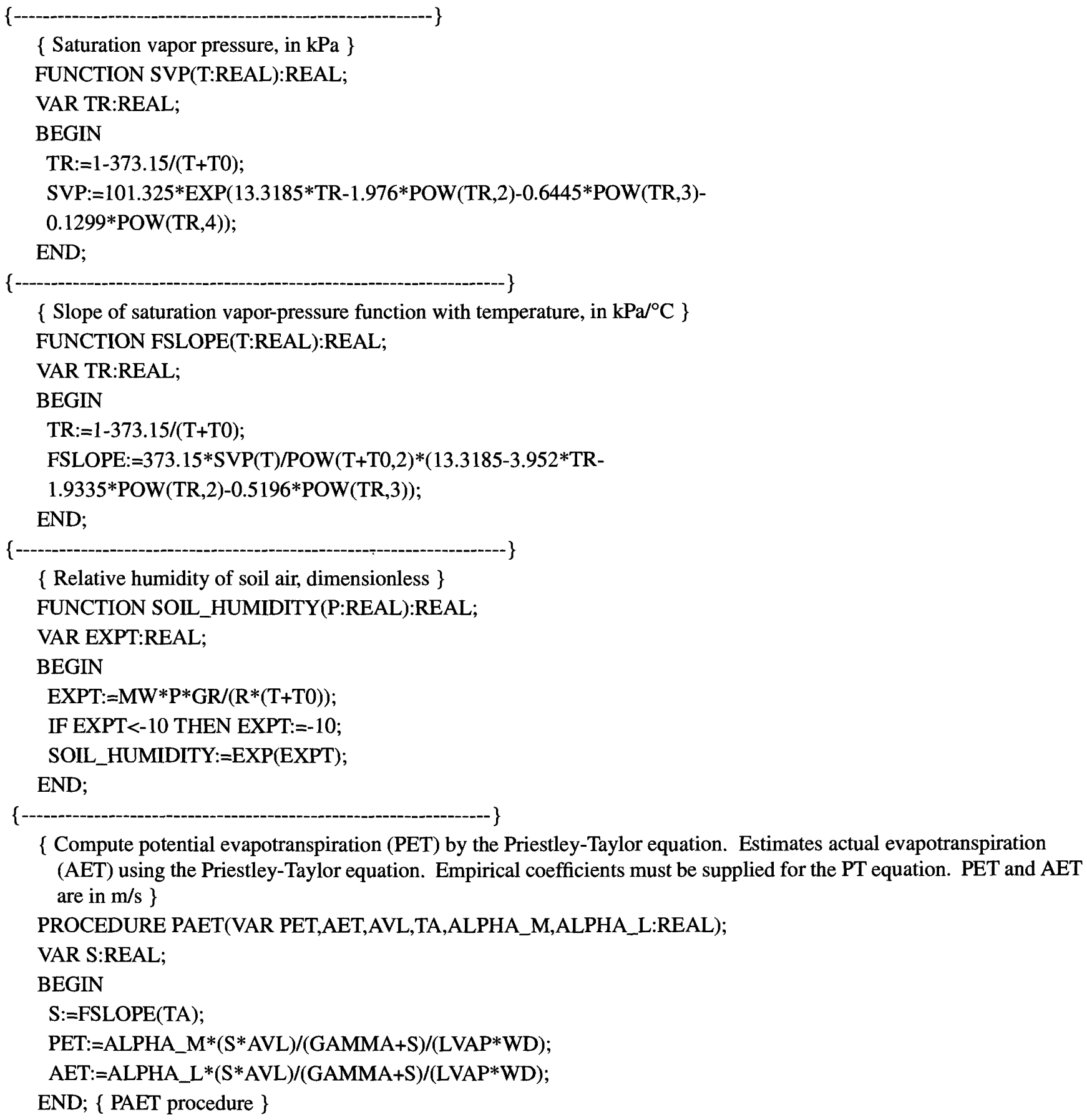

\{ Compute potential evapotranspiration (PET) by the Priestley-Taylor equation. Estimates actual evapotranspiration (AET) using the Priestley-Taylor equation. Empirical coefficients must be supplied for the PT equation. PET and AET are in $\mathrm{m} / \mathrm{s}$ \}

PROCEDURE PAET(VAR PET,AET,AVL,TA,ALPHA_M,ALPHA_L:REAL);

VAR S:REAL;

BEGIN

$\mathrm{S}:=$ FSLOPE(TA);

PET:=ALPHA_M*(S*AVL)/(GAMMA+S $) /($ LVAP*WD);

AET:=ALPHA_L*(S*AVL)/(GAMMA+S $) /(L V A P * W D) ;$

END; $\{$ PAET procedure $\}$ 


\section{APPENDIX 2. Source Code for the Soil Water-Balance Model--Continued}

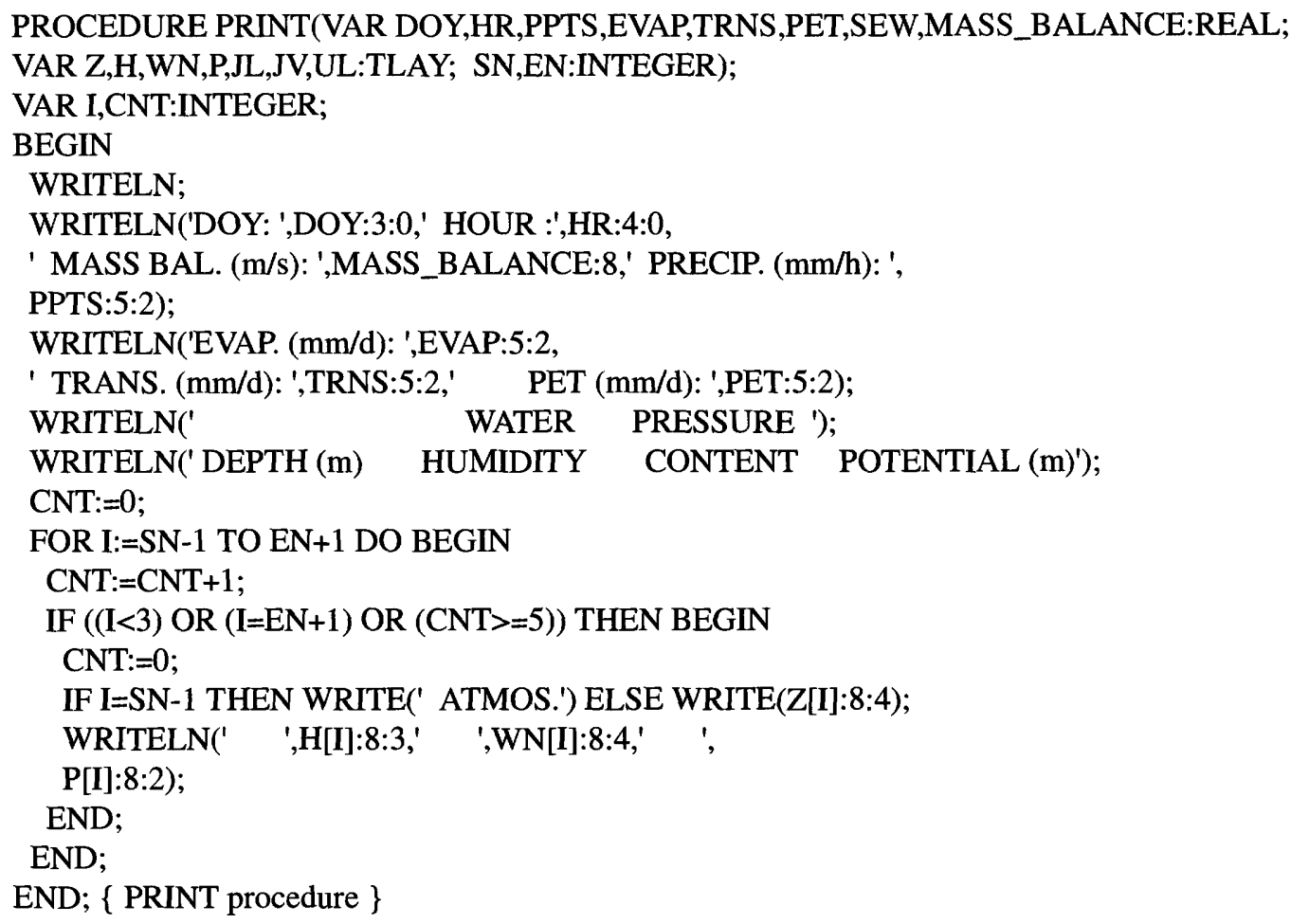




\section{APPENDIX 2. Source Code for the Soil Water-Balance Model--Continued}

\{ Compute water-content-dependent and pressure-potential-dependent hydraulic parameters \}

PROCEDURE HYD_PARAM(VAR P,WN,KL,DV,AE,BV,KS,BD:TLAY; VAR SN,

EN:INTEGER);

VAR WS,N0:REAL;

I:INTEGER;

BEGIN

FOR I:=SN TO EN+1 DO BEGIN

NO: $=2+3 / \mathrm{BV}[\mathrm{I}]$;

IF P[I]>=AE[I] THEN KL[I]:=KS[I]

ELSE

$\mathrm{KL}[\mathrm{I}]:=\mathrm{KS}[\mathrm{I}] * \mathrm{POW}(\mathrm{AE}[\mathrm{I}] / \mathrm{P}[\mathrm{I}], \mathrm{N} 0)$;

$\mathrm{DV}[\mathrm{I}]:=0.9 * \mathrm{DV} 0 * \mathrm{POW}((2-\mathrm{BD}[\mathrm{I}+1] / \mathrm{PD}-\mathrm{WN}[\mathrm{I}+1]-\mathrm{BD}[\mathrm{I}] / \mathrm{PD}-\mathrm{WN}[\mathrm{I}]) / 2,2.3)$;

END;

END; $\{$ HYD_PARAM procedure $\}$

\{ Assemble coefficient matrix for water-balance solution \}

PROCEDURE WATER(VAR F,ADL,BDL,CDL,P,WN,W,H,KL,DV,AE,BV,BD,NODE,

DZ,V,JL,JV,UL:TLAY; VAR EP,TP,SEW,DT,L1,WT:REAL; SN,EN:INTEGER;

ARITH:BOOLEAN);

VAR STORE:TLAY;

BDV,WS,N0:REAL;

I:INTEGER;

BEGIN

SEW: $=0$;

IF H[SN-1]<H[SN] THEN JV[SN-1]:=-EP*(H[SN]-H[SN-1])/(1-H[SN-1])

ELSE JV[SN-1]:=0;

FOR I:=SN TO EN DO BEGIN

WS:=1-(BD[I]/PD);

N0: $=2+3 / \mathrm{BV}[\mathrm{I}]$;

CASE TRUNC(NODE[I]) OF

\{ Surface node \}

$0:$ BEGIN

$\mathrm{ADL}[\mathrm{I}]:=0$;

\{ If ARITH=TRUE, then internodal hydraulic conductivity is computed using an arithmetic averaging scheme $\}$

IF ARITH THEN BEGIN

$\mathrm{JL}[\mathrm{I}]:=-(\mathrm{WT} * \mathrm{KL}[\mathrm{I}]+(1-\mathrm{WT}) * \mathrm{KL}[\mathrm{I}+1]) *((\mathrm{P}[\mathrm{I}+1]-\mathrm{P}[\mathrm{I}]) / \mathrm{DZ}[\mathrm{I}]-1)$;

IF $\mathrm{P}[\mathrm{I}]>=\mathrm{AE}[\mathrm{I}]$ THEN BDL[I]:=-(WT*KL[I]+(1-WT)*KL[I+1])/DZ[I]

ELSE

$\mathrm{BDL}[\mathrm{I}]:=\mathrm{V}[\mathrm{I}] * \mathrm{WN}[\mathrm{I}] /(\mathrm{BV}[\mathrm{I}] * \mathrm{P}[\mathrm{II}] * \mathrm{DT})-\mathrm{WT} * \mathrm{~N} 0 *$

$\mathrm{KL}[\mathrm{I}] / \mathrm{P}[\mathrm{I}] *((\mathrm{P}[\mathrm{I}+1]-\mathrm{P}[\mathrm{I}]) / \mathrm{DZ}[\mathrm{I}]-1)-\mathrm{WT} * \mathrm{KL}[\mathrm{I}] / \mathrm{DZ}[\mathrm{I}]-$

$(1-\mathrm{WT})^{*} \mathrm{KL}[\mathrm{I}+1] / \mathrm{DZ}[\mathrm{I}]$

IF P[I+1]>=AE[I+1] THEN CDL[I]:=(WT*KL[I]+(1-WT)*KL[I+1])/DZ[I]

ELSE

$\mathrm{CDL}[\mathrm{I}]:=\mathrm{WT} * \mathrm{KL}[\mathrm{I}] / \mathrm{DZ}[\mathrm{I}]-(1-\mathrm{WT}) *(2+3 / \mathrm{BV}[\mathrm{I}+1]) * \mathrm{KL}[\mathrm{I}+1] / \mathrm{P}[\mathrm{I}+1]$

$*((\mathrm{P}[\mathrm{I}+1]-\mathrm{P}[\mathrm{I}]) / \mathrm{DZ}[\mathrm{I}]-1)+(1-\mathrm{WT}) * \mathrm{KL}[\mathrm{I}+1] / \mathrm{DZ}[\mathrm{I}]$;

END

\{ If ARITH=FALSE, then internodal hydraulic conductivity is computed using a geometric averaging scheme \} 


\section{APPENDIX 2. Source Code for the Soil Water-Balance Model--Continued}

ELSE BEGIN

$\mathrm{JL}[\mathrm{I}]:=-\mathrm{SQRT}(\mathrm{KL}[\mathrm{I}] * \mathrm{KL}[\mathrm{I}+1]) *((\mathrm{P}[\mathrm{I}+1]-\mathrm{P}[\mathrm{I}]) / \mathrm{DZ}[\mathrm{I}]-1)$;

IF P[I]>=AE[I] THEN BDL[I]:=-SQRT(KL[I]*KL[I+1])/DZ[I]

ELSE

$\mathrm{BDL}[\mathrm{I}]:=\mathrm{V}[\mathrm{I}] * \mathrm{WN}[\mathrm{I}] /(\mathrm{BV}[\mathrm{I}] * \mathrm{P}[\mathrm{I}] * \mathrm{DT})-0.5 / \mathrm{SQRT}(\mathrm{KL}[\mathrm{I}] *$

$\mathrm{KL}[\mathrm{I}+1]) * \mathrm{KL}[\mathrm{I}+1] * \mathrm{~N} 0 * \mathrm{KL}[\mathrm{I}] / \mathrm{P}[\mathrm{I}] *((\mathrm{P}[\mathrm{I}+1]-\mathrm{P}[\mathrm{I}]) /$

$\mathrm{DZ}[\mathrm{I}]-1)-\mathrm{SQRT}(\mathrm{KL}[\mathrm{I}] * \mathrm{KL}[\mathrm{I}+1]) / \mathrm{DZ}[\mathrm{I}]$;

IF P[I+1]>=AE[I+1] THEN CDL[I]:=SQRT(KL[I]*KL[I+1])/DZ[I]

ELSE

$\mathrm{CDL}[\mathrm{I}]:=0.5 / \mathrm{SQRT}(\mathrm{KL}[\mathrm{I}] * \mathrm{KL}[\mathrm{I}+1]) * \mathrm{KL}[\mathrm{I}] *(2+3 / \mathrm{BV}[\mathrm{I}+1]) * \mathrm{KL}[\mathrm{I}+1] /$

$\mathrm{P}[\mathrm{I}+1] *((\mathrm{P}[\mathrm{I}+1]-\mathrm{P}[\mathrm{I}]) / \mathrm{DZ}[\mathrm{I}]-1)+\mathrm{SQRT}(\mathrm{KL}[\mathrm{I}] * \mathrm{KL}[\mathrm{I}+1]) /$

$\mathrm{DZ}[\mathrm{I}]$;

END;

IF H[SN-1]<H[SN] THEN BDV:=-EP/(1-H[SN-1])*H[I]*GR*MW/(R*(T+T0))

ELSE BDV: $=0$;

BDV:=BDV-DV[I]/DZ[I]*H[I]*1E3*GR*CVP/WD*SQR(MW/(R*(T+T0)));

END; $\{$ NODE $=0\}$

\{ Node other than surface \}

1:BEGIN

IF ARITH THEN BEGIN

$\mathrm{JL}[\mathrm{I}]:=-(\mathrm{WT} * \mathrm{KL}[\mathrm{I}]+(1-\mathrm{WT}) * \mathrm{KL}[\mathrm{I}+1]) *((\mathrm{P}[\mathrm{I}+1]-\mathrm{P}[\mathrm{I}]) / \mathrm{DZ}[\mathrm{I}]-1)$;

IF P[I-1] $>=$ AE[1-1] THEN ADL[I]:=(WT*KL[I-1]+(1-WT)*KL[I])/

$\mathrm{DZ}[\mathrm{I}-1]$

ELSE

ADL[I]:=WT*KL[I-1]*(2+3/BV[I-1])/P[I-1]*((P[I]-P[I-1])/

DZ[I-1]-1)+WT*KL[I-1]/DZ[I-1]+(1-WT)*KL[I]/DZ[I-1];

IF P[I]>=AE[I] THEN BDL[I]:=-(WT*KL[I-1]+(1-WT)*KL[I])/DZ[I-1] -

ELSE

$(\mathrm{WT} * \mathrm{KL}[\mathrm{I}]+(1-\mathrm{WT}) * \mathrm{KL}[\mathrm{I}+1]) / \mathrm{DZ}[\mathrm{I}]$

$\mathrm{BDL}[\mathrm{I}]:=-\mathrm{WT} * \mathrm{KL}[\mathrm{I}-1] / \mathrm{DZ}[\mathrm{I}-1]+(1-\mathrm{WT}) * \mathrm{~N} 0 * \mathrm{KL}[\mathrm{I}] / \mathrm{P}[\mathrm{I}] *((\mathrm{P}[\mathrm{I}]-\mathrm{P}[\mathrm{I}-1]) /$

$\mathrm{DZ}[\mathrm{I}-1]-1)-(1-\mathrm{WT}) * \mathrm{KL}[\mathrm{I}] / \mathrm{DZ}[\mathrm{I}-1]$

$+\mathrm{V}[\mathrm{I}] * \mathrm{WN}[\mathrm{I}] /(\mathrm{BV}[\mathrm{I}] * \mathrm{P}[\mathrm{I}] * \mathrm{DT})-\mathrm{WT} * \mathrm{~N} 0 *$

$\mathrm{KL}[\mathrm{I}] / \mathrm{P}[\mathrm{I}] *((\mathrm{P}[\mathrm{I}+1]-\mathrm{P}[\mathrm{I}]) / \mathrm{DZ}[\mathrm{I}]-1)-\mathrm{WT} * \mathrm{KL}[\mathrm{I}] / \mathrm{DZ}[\mathrm{I}]-$

$(1-\mathrm{WT})^{*} \mathrm{KL}[\mathrm{I}+1] / \mathrm{DZ}[\mathrm{I}]$

IF P[I+1]>=AE[I+1] THEN CDL[I]:=(WT*KL[I]+(1-WT)*KL[I+1])/DZ[I]

ELSE

$\mathrm{CDL}[\mathrm{I}]:=\mathrm{WT} * \mathrm{KL}[\mathrm{I}] / \mathrm{DZ}[\mathrm{I}]-(1-\mathrm{WT}) *(2+3 / \mathrm{BV}[\mathrm{I}+1]) * \mathrm{KL}[\mathrm{I}+1] / \mathrm{P}[\mathrm{I}+1]$

$*((\mathrm{P}[\mathrm{I}+1]-\mathrm{P}[\mathrm{I}]) / \mathrm{DZ}[\mathrm{I}]-1)+(1-\mathrm{WT}) * \mathrm{KL}[\mathrm{I}+1] / \mathrm{DZ}[\mathrm{I}]$;

END

ELSE BEGIN

$\mathrm{JL}[\mathrm{I}]:=-\mathrm{SQRT}(\mathrm{KL}[\mathrm{I}] * \mathrm{KL}[\mathrm{I}+1]) *((\mathrm{P}[\mathrm{I}+1]-\mathrm{P}[\mathrm{I}]) / \mathrm{DZ}[\mathrm{I}]-1)$;

IF P[I-1]>=AE[I-1] THEN ADL[I]:=SQRT(KL[I-1]*KL[I])/DZ[I-1]

ELSE

$\mathrm{ADL}[\mathrm{I}]:=0.5 / \mathrm{SQRT}\left(\mathrm{KL}[\mathrm{I}-1]^{*} \mathrm{KL}[\mathrm{I}]\right) *(2+3 / \mathrm{BV}[\mathrm{I}-1]) / \mathrm{P}[\mathrm{I}-1]^{*}$

$\mathrm{KL}[\mathrm{I}-1] * \mathrm{KL}[\mathrm{I}] *((\mathrm{P}[\mathrm{I}]-\mathrm{P}[\mathrm{I}-1]) / \mathrm{DZ}[\mathrm{I}-1]-1)+$

SQRT(KL[I-1]*KL[I])/DZ[I-1];

IF P[I] $>=$ AE[I] THEN BDL[I]:=-SQRT(KL[I-1]*KL[I])/DZ[I-1] -

$\mathrm{SQRT}(\mathrm{KL}[\mathrm{I}] * \mathrm{KL}[\mathrm{I}+1]) / \mathrm{DZ}[\mathrm{I}]$

ELSE

$\mathrm{BDL}[\mathrm{I}]:=-0.5 / \mathrm{SQRT}(\mathrm{KL}[\mathrm{I}-1] * \mathrm{KL}[\mathrm{I}]) * \mathrm{KL}[\mathrm{I}-1] * \mathrm{~N} 0 * \mathrm{KL}[\mathrm{I}] / \mathrm{P}[\mathrm{I}] *$

$((\mathrm{P}[\mathrm{I}]-\mathrm{P}[\mathrm{I}-1]) / \mathrm{DZ}[\mathrm{I}-1]-1)-\mathrm{SQRT}\left(\mathrm{KL}[\mathrm{I}-1]^{*} \mathrm{KL}[\mathrm{I}]\right) / \mathrm{DZ}[\mathrm{I}-1]$

$+\mathrm{V}[\mathrm{I}] * \mathrm{WN}[\mathrm{I}] /(\mathrm{BV}[\mathrm{I}] * \mathrm{P}[\mathrm{I}] * \mathrm{DT})-$

$0.5 / \mathrm{SQRT}(\mathrm{KL}[\mathrm{I}] * \mathrm{KL}[\mathrm{I}+1]) * \mathrm{KL}[\mathrm{I}+1] * \mathrm{~N} 0 * \mathrm{KL}[\mathrm{I}] / \mathrm{P}[\mathrm{I}] *$

$((\mathrm{P}[\mathrm{I}+1]-\mathrm{P}[\mathrm{I}]) / \mathrm{DZ}[\mathrm{I}]-1)-\mathrm{SQRT}(\mathrm{KL}[\mathrm{I}] * \mathrm{KL}[\mathrm{I}+1]) / \mathrm{DZ}[\mathrm{I}]$; 


\section{APPENDIX 2. Source Code for the Soil Water-Balance Model--Continued}

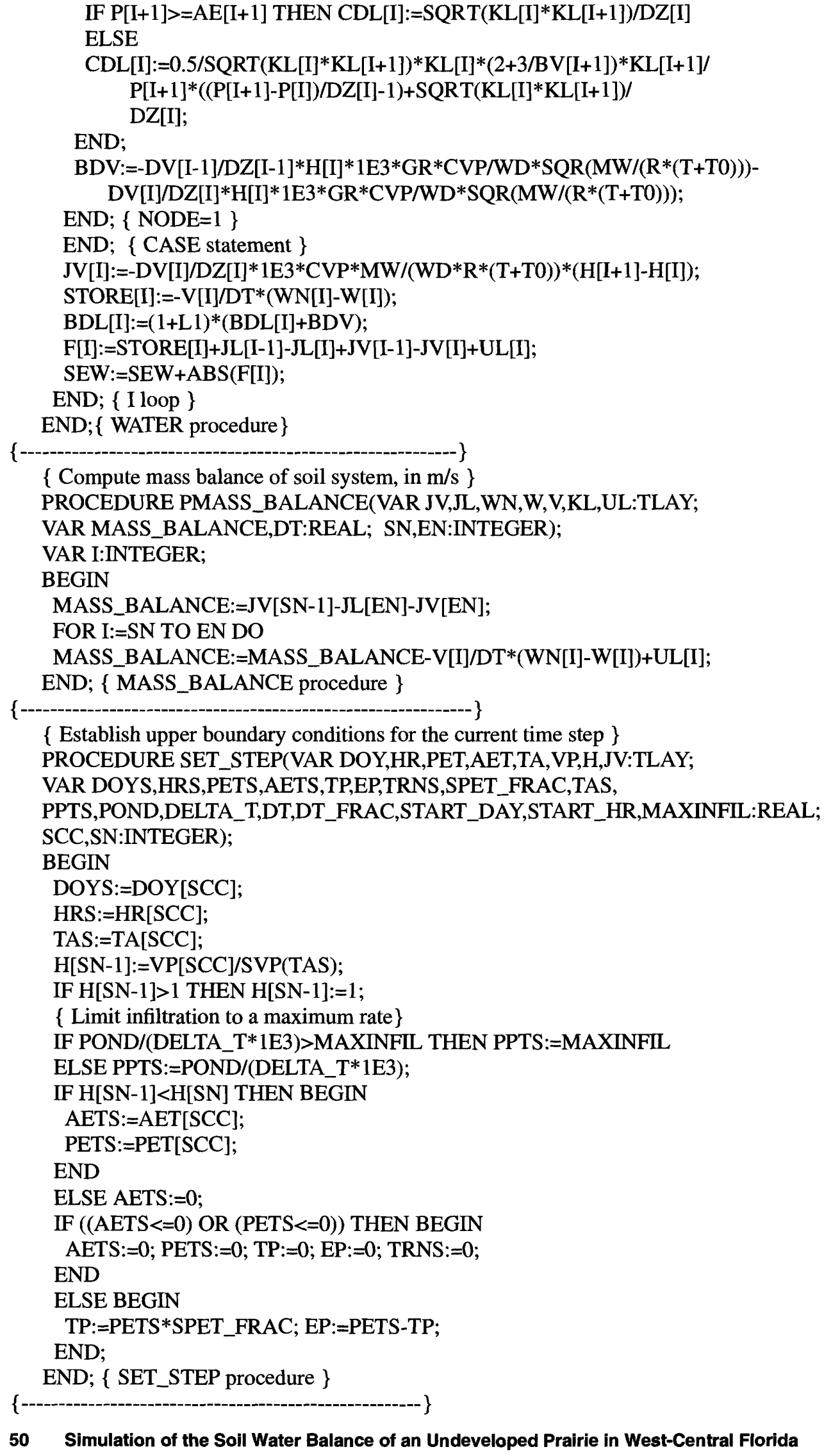




\section{APPENDIX 2. Source Code for the Soil Water-Balance Model--Continued}

PROCEDURE ZERO_ARRAYS(VAR A,B,C,D,E,F,G,H,I,J:TLAY);

VAR K:INTEGER;

BEGIN

FOR K:=CSNP TO CENP DO A[K]:=0;

$\mathrm{B}:=\mathrm{A} ; \mathrm{C}:=\mathrm{A} ; \mathrm{D}:=\mathrm{A} ; \mathrm{E}:=\mathrm{A} ; \mathrm{F}:=\mathrm{A} ; \mathrm{G}:=\mathrm{A} ; \mathrm{H}:=\mathrm{A} ; \mathrm{I}:=\mathrm{A} ; \mathrm{J}:=\mathrm{A}$;

END;

$\{---\cdots+----\cdot\}$

PROCEDURE ZERO_SCALARS_REAL(VAR A,B,C,D,E,F,G,H,I,J:REAL);

BEGIN

$A:=0 ; B:=0 ; C:=0 ; D:=0 ; E:=0 ; F:=0 ; G:=0 ; H:=0 ; \mathrm{I}:=0 ; J:=0$; END;

$\{-------------------------------\}$

PROCEDURE ZERO_SCALARS_INTEGER(VAR A,B,C,D,E,F,G,H,I,J:INTEGER);

BEGIN

$A:=0 ; B:=0 ; C:=0 ; D:=0 ; E:=0 ; F:=0 ; G:=0 ; H:=0 ; I:=0 ; J:=0$;

END;

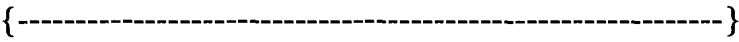

PROCEDURE MOVE_STEP(SOURCE,DEST:INTEGER; VAR DOY,HR,AVL,TA,VP,

PPT:TLAY);

BEGIN

DOY[DEST]:=DOY[SOURCE]; HR[DEST]:=HR[SOURCE]; AVL[DEST]:=AVL[SOURCE];

TA[DEST]:=TA[SOURCE]; VP[DEST]:=VP[SOURCE]; PPT[DEST]:=PPT[SOURCE];

END;

$\{$ -

\{ Establish lower boundary condition above the water table \}

PROCEDURE SET_WTD(VAR Z,P,H,W,WN,AE,BD:TLAY; WTD:REAL; VAR EN:INTEGER);

VAR I:INTEGER;

BEGIN

$\mathrm{I}:=0$; WHILE Z[I] $<$ WTD DO BEGIN I:=I+1; END;

$\mathrm{EN}:=\mathrm{I}-1$

$P[I]:=0$;

$\mathrm{WN}[\mathrm{I}]:=1-\mathrm{BD}[\mathrm{I}] / \mathrm{PD}$

$\mathrm{W}[\mathrm{I}]:=\mathrm{WN}[\mathrm{I}]$

$\mathrm{H}[\mathrm{I}]:=1$;

END; $\{$ SET_WTD procedure $\}$

$\{-----------\}$

\{ Read in initial conditions and properties of the soil-plant system \}

PROCEDURE INITIAL(VAR SETUP_FILE,STEP_FILE,OUTFILE:TEXT; VAR NODE,Z,

DZ,V,AE,BV,KS,BD,L,W,H,P,WN,DOY,HR,AVL,TA,VP,PPT,NPROF_D,

NPROF_H:TLAY; VAR SPET_FRAC,ALPHA_M,ALPHA_L,START_DOY,START_HR, STOP_DOY,STOP_HR,WTD,WT,MAXINFIL:REAL; VAR NPROF,PLEVEL,SN,EN,SCC,

SC:INTEGER; VAR DFLUX,ARITH,B_FLAG,E_FLAG,CRASH:BOOLEAN);

VAR D,WS:REAL;

I:INTEGER;

DIR_STEP,NAME_STEP,DIR_OUT,NAME_OUT:TS;

\{ Trims blank spaces from a string variable \}

PROCEDURE TRIM(VAR S:TS);

BEGIN

WHILE S[1] =' ' DO DELETE(S,1,1);

WHILE S[LENGTH(S)]=' ' DO DELETE(S,1,LENGTH(S));

END; 


\section{APPENDIX 2. Source Code for the Soil Water-Balance Model--Continued}

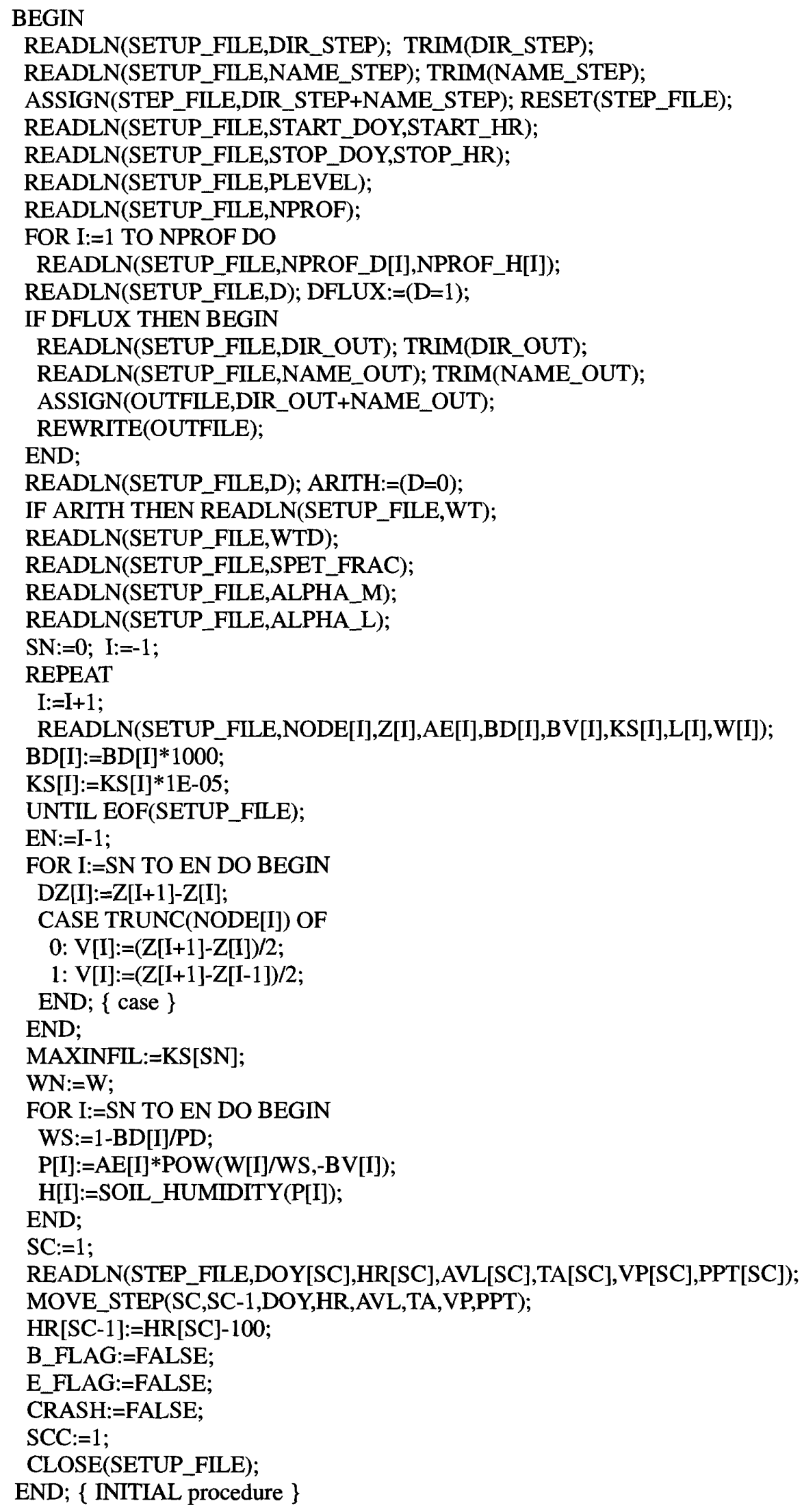




\section{APPENDIX 2. Source Code for the Soil Water-Balance Model--Continued}

$\{---1$ (Red

\{ Read variables to update boundary conditions \}

PROCEDURE READ_DAY(VAR STEP_FILE:TEXT; VAR DOY,HR,AVL,TA,VP,

PPT,WN,P,H,AE,BV,BD:TLAY; VAR SC,SCC,EN:INTEGER;

VAR NEW_DAY,E_FLAG:BOOLEAN);

BEGIN

NEW_DAY:=FALSE;

MOVE_STEP(SC-1,0,DOY,HR,AVL,TA,VP,PPT);

MOVE_STEP(SC,1,DOY,HR,AVL,TA,VP,PPT);

$S C:=2$;

WHILE((NOT EOF(STEP_FILE)) AND (NOT NEW_DAY)) DO BEGIN

READLN(STEP_FILE,DOY[SC],HR[SC],AVL[SC],TA[SC],VP[SC],PPT[SC]);

IF NOT FREQ(DOY[SC],DOY[1]) THEN BEGIN

IF HR[SC] $=0$ THEN BEGIN DOY[SC]:=DOY[1]; HR[SC]:=2400; END

ELSE NEW_DAY:=TRUE;

END;

$\mathrm{SC}:=\mathrm{SC}+1$

END; $\{$ EOF(INFILE) or NEW_DAY $\}$

$\{\mathrm{SC}$ marks first time step of previous day \}

$\mathrm{SC}:=\mathrm{SC}-1$

\{ First time step of the current day is always in row 1 \}

$\mathrm{SCC}:=1$;

END; $\{$ READ_DAY procedure $\}$

$\{--\{$ -

\{Prints profile of water content and pressure potential \}

PROCEDURE PROFILE(VAR DOY,HR:REAL; VAR Z,WN,P,NPROF_D,NPROF_H:TLAY;

NPROF,SN,EN:INTEGER);

VAR I:INTEGER;

FN,A:TS;

PROF:TEXT;

BEGIN

$\mathrm{I}:=0$;

REPEAT

$\mathrm{I}:=\mathrm{I}+1$;

UNTIL(((DOY=NPROF_D[I]) AND (HR=NPROF_H[I])) OR (I>NPROF));

IF I $<=$ NPROF THEN BEGIN

STR(DOY:3:0,FN);

IF FN[1]=' ' THEN FN[1]:='0';

IF FN[2]=' ' THEN FN[2]:='0';

STR(HR:4:0,A);

IF A[1] =' ' THEN A[1]:='0';

$\mathrm{FN}:=\mathrm{P}^{\prime}+\mathrm{FN}+\mathrm{A}+{ }^{\prime} . \mathrm{DAT}$;

ASSIGN(PROF,FN); REWRITE(PROF);

FOR I:=SN TO EN+1 DO

WRITELN(PROF,Z[I]:6:3,' ',WN[I]:6:3,' ',P[I]:6:2);

CLOSE(PROF);

END;

END; $\{$ PROFILE $\}$ 


\section{APPENDIX 2. Source Code for the Soil Water-Balance Model--Continued}

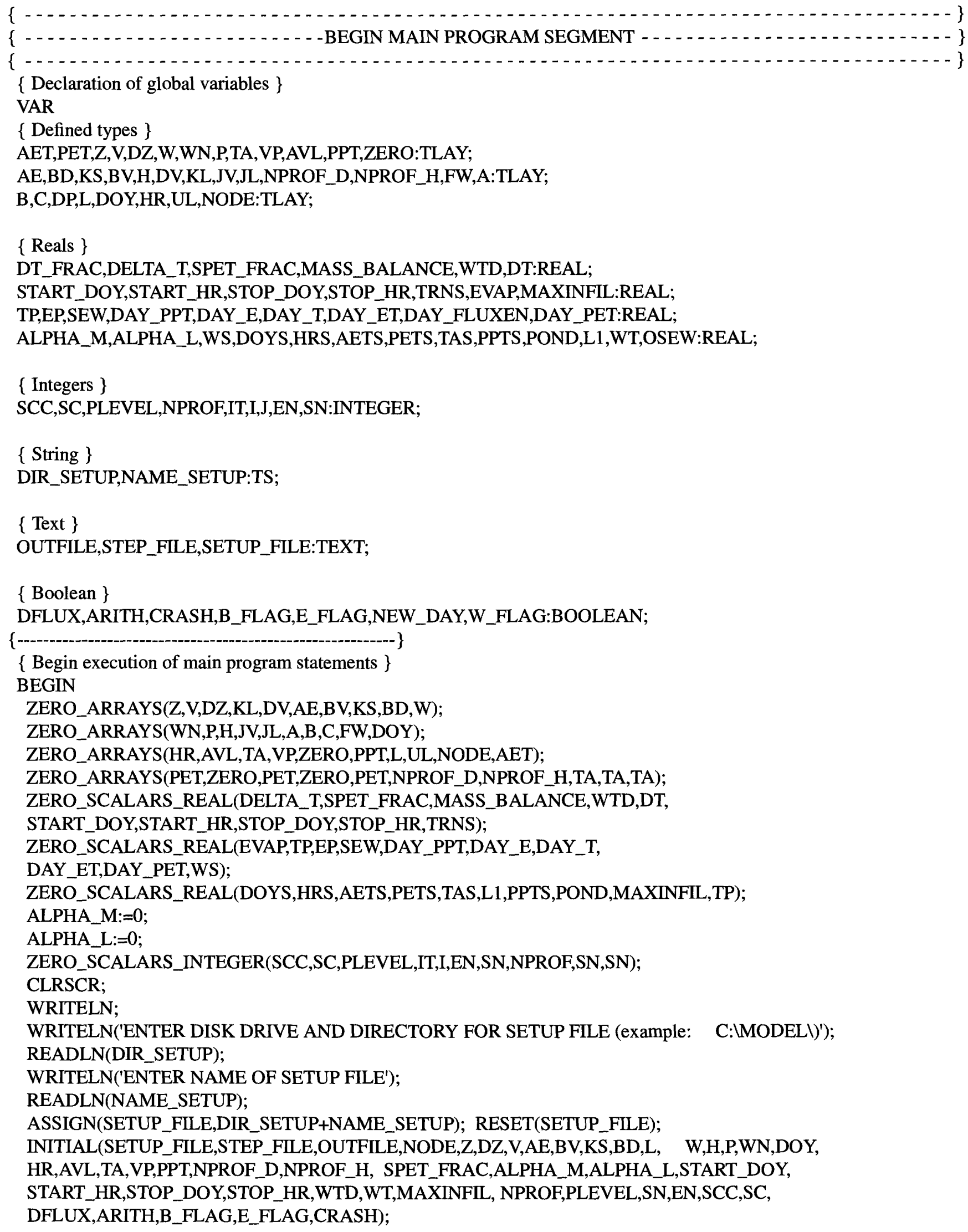




\section{APPENDIX 2. Source Code for the Soil Water-Balance Model--Continued}

SET_WTD(Z,P,H,W,WN,AE,BD,WTD,EN);

REPEAT \{ Until E_FLAG or CRASH \}

ZERO_SCALARS_REAL(DAY_E,DAY_T,DAY_ET,DAY_PET,DAY_PPT,DAY_FLUXEN,DAY_E,

DAY_E,DAY_E,DAY_E);

READ_DAY(STEP_FILE,DOY,HR,AVL,TA,VP,PPT,WN,P,H,AE,BV,BD,

SC,SCC,EN, NEW_DAY,E_FLAG);

FOR I: $=0$ TO SC-1 DO

PAET(PET[I],AET[I],AVL[I],TA[I],ALPHA_M,ALPHA_L);

\{ Execute time steps for the current day \}

WHILE ((SCC $<$ SC) AND (NOT CRASH)) DO BEGIN

IF FTIMER(DOY[SCC],HR[SCC],START_DOY,START_HR)>=0 THEN B_FLAG:=TRUE;

IF FTIMER(DOY[SCC],HR[SCC],START_DOY,START_HR)>

FTIMER(STOP_DOY,STOP_HR,START_DOY,START_HR) THEN E_FLAG:=TRUE;

IF ((B_FLAG) AND NOT (E_FLAG)) THEN BEGIN

DELTA_T:=(FTIMER(DOY[SCC],HR[SCC],START_DOY,START_HR)-

FTIMER(DOY[SCC-1],HR[SCC-1],START_DOY,START_HR))*3600;

DT:=DELTA_T;

DT_FRAC: $=0$;

POND:=POND+PPT $[S C C]$;

OSEW: $=0 ; \mathrm{L} 1:=0.2$;

REPEAT \{ Until time step is complete or CRASH \}

W_FLAG:=FALSE; IT: $=0$;

SET_STEP(DOY,HR,PET,AET,TA,VP,H,JV, DOYS,HRS,PETS,

AETS,TP,EP,TRNS,SPET_FRAC,TAS,PPTS,POND,DELTA_T,DT,

DT_FRAC,START_DOY,START_HR,MAXINFIL, SCC,SN);

REPEAT \{ Until W_FLAG or SEW $<$ MA \}

HYD_PARAM(P,WN,KL,DV,AE,BV,KS,BD,SN,EN);

TRNS:=AETS+JV[SN-1];

IF TRNS $<0$ THEN TRNS: $=0$;

IF TRNS>0 THEN PUPTAKE(KL,V,L,UL,P,WN,AE,BV,TRNS,SN,EN)

ELSE UL:=ZERO;

UL[0]:=UL[0]+PPTS;

WATER(FW,A,B,C,P,WN,W,H,KL,DV,AE,BV,BD,NODE,DZ,V,JL,JV,

UL,EP,TP,SEW,DT,L1,WT,SN,EN,ARITH);

THOMAS(DP,A,B,C,FW,EN,SN);

FOR I:= EN DOWNTO SN DO BEGIN

$\mathrm{P}[\mathrm{I}]:=\mathrm{P}[\mathrm{I}]-\mathrm{DP}[\mathrm{I}]$;

IF $P[I]>Z[I]$ THEN $P[I]:=(P[I]+D P[I]) / 2$;

IF $\mathrm{P}[\mathrm{I}]>=\mathrm{AE}[\mathrm{I}]$ THEN WN[I]:=1-BD[I]/PD

ELSE

$\mathrm{WN}[\mathrm{I}]:=(1-\mathrm{BD}[\mathrm{I}] / \mathrm{PD}) * \mathrm{POW}(\mathrm{AE}[\mathrm{I}] / \mathrm{P}[\mathrm{I}], 1 / \mathrm{BV}[\mathrm{I}])$;

IF P[I] $>=$ AE[I] THEN H[I]:=1 ELSE H[I]:=SOIL_HUMIDITY(P[I]);

END;

IF ((IT>20) AND (SEW>MA)) THEN W_FLAG:=TRUE;

IF SEW >1E3 THEN W_FLAG:=TRUE;

IT: $=$ IT +1 ;

IF PLEVEL $>1$ THEN WRITE(' ',SEW:8);

IF ABS(SEW)>ABS(OSEW) THEN L1:=L1*4 ELSE L1:=L1/1.5;

OSEW:=SEW;

IF L1 >1E03 THEN L1: $=0.2$;

UNTIL ((W_FLAG) OR (SEW $<$ MA));

IF PLEVEL $>1$ THEN WRITELN; 


\section{APPENDIX 2. Source Code for the Soil Water-Balance Model--Continued}

IF W_FLAG THEN BEGIN \{WATER FAILED\}

DT:=DT/2;

IF DT<MDT_FRAC*DELTA_T THEN CRASH:=TRUE;

END

ELSE BEGIN

POND:=POND-PPTS*DT*1E3;

IF POND $<0$ THEN POND: $=0$;

DAY_E:=DAY_E-JV[SN-1]*DT*1E3;

DAY_T:=DAY_T+TRNS $*$ DT $* 1 E 3$;

DAY_PET:=DAY_PET+PETS*DT*1E3;

DAY_PPT:=DAY_PPT+PPTS*DT*1E3;

DAY_FLUXEN:=DAY_FLUXEN+(JL[EN]+JV[EN])*DT*1E3;

$\{$ Convert to $\mathrm{mm} / \mathrm{h}$ or $\mathrm{mm} / \mathrm{d}$ \}

EVAP:=-JV[SN-1]*8.64*1E7;

TRNS:=TRNS*8.64*1E7;

PETS:=PETS*8.64*1E7;

PPTS:=PPTS*3.6*1E6;

PMASS_BALANCE(JV,JL,WN,W,V,KL,UL,MASS_BALANCE,DT,SN,EN);

IF $(($ DT $<$ DELTA_T) AND (PLEVEL $>1))$ THEN WRITELN('DOY: ',

DOYS:3:0,' HR: ',HRS:4:0,' SUB-TIME STEP: ',DT:6:0,

' MASS BAL.: ',MASS_BALANCE:8);

FOR I:=SN TO EN DO W[I] :=WN[I];

DT_FRAC:=DT_FRAC+DT/DELTA_T;

IF IT $<10$ THEN DT:=DT*2;

IF DT $>(1-D T$ FRAC)*DELTA_T THEN DT:=(1-DT_FRAC)*DELTA_T;

IT: $=0$;

END;

UNTIL((DT_FRAC>=1.0) OR (CRASH));

IF CRASH THEN BEGIN

WRITELN;

WRITE('******************************* PROGRAM CRASHED');

WRITELN(' $* * * * * * * * * * * * * * * * * * * * * * * * * * * * * * * ')$;

WRITELN('DAY OF YEAR: ',DOYS:3:0,' HOUR: ',HRS:4:0);

WRITELN('MASS BAL: ',SEW:8,' MAX. TOLERANCE: ',MA:8);

WRITELN('SUB-TIME STEP: ',DT:6:1,' MIN. TOLERANCE: ',

MDT_FRAC*DELTA_T:6:1);

WRITE('****************************************************1) ;

WRITELN('*********************************1);

END

ELSE BEGIN

IF PLEVEL $>1$ THEN PRINT(DOYS,HRS,PPTS,EVAP,TRNS,PETS,SEW, MASS_BALANCE, Z,H,WN,P,JL,JV,UL, SN,EN);

IF NPROF $>0$ THEN PROFILE(DOYS,HRS, Z,WN,P,NPROF_D,

NPROF_H, NPROF,SN,EN);

END;

END; $\{$ If time step is in selected time interval $\}$

SCC: $=$ SCC +1 ;

END; $\{$ While SCC $<$ SC and NOT CRASH $\}$ 


\section{APPENDIX 2. Source Code for the Soil Water-Balance Model--Continued}

IF EOF(STEP_FILE) THEN E_FLAG:=TRUE;

IF B_FLAG THEN BEGIN

DAY_ET:=DAY_E+DAY_T;

IF ((PLEVEL $>0)$ AND (NOT CRASH)) THEN BEGIN

WRITELN('DAY: ',DOY[1]:3:0,' EVAP: ',DAY_E:3:1,

' TRANS: ',DAY_T:3:1,' ET: ',DAY_ET:3:1);

WRITELN(' PET: ',DAY_PET:3:1,' PRECIP: ',DAY_PPT:4:1,

' DRAINAGE: ',DAY_FLUXEN:4:1);

END;

IF ((NOT CRASH) AND (DFLUX)) THEN

WRITELN(OUTFILE,DOY[1]:4:0,' ',DAY_E:5:2,' ',DAY_T:5:2,

' ',DAY_ET:5:2,' ',DAY_PET:5:2,' ',DAY_PPT:5:2,' ',

DAY_FLUXEN:5:2);

END;

UNTIL ((E_FLAG) OR (CRASH));

CLOSE(STEP_FILE);

CLOSE(OUTFILE);

WRITELN; WRITELN('SIMULATION COMPLETE. PRESS "RETURN"'); READLN;

END. 
